NUREG/CR-1489

UCRL-52746

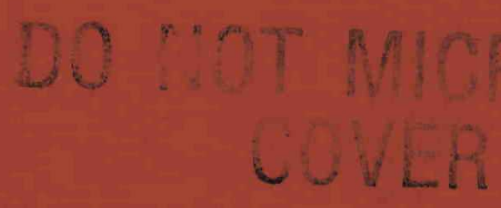

Best Estimate Method vs Evaluation Method:

A Comparison of Two

Techniques in Evaluating

Seismic Analysis and Design

S. E. Bumpus, J. J. Johnson, P. D. Smith

느 Lawrence Livermore National Laboratory

Prepared for

U.S. Nuclear Regulatory

Commission 


\section{NOTICE}

This report was prepared as an account of work sponsored by an agency of the United States Government. Neither the United States Government nor any agency thereof, or any of their employees, makes any warranty, expressed or implied, or assumes any legal liability or responsibility for any third party's use, or the results of such use, of any information, apparatus product or process disclosed in this report, or represents that its use by such third party would not infringe privately owned rights.

This work was supported by the United States Nuclear Regulatory Commission under a Memorandum of Understanding with the United States Department of Energy.

Available from

GPO Sales Program

Division of Technical Information and Document Control

U.S. Nuclear Regulatory Commission

Washington, D.C. 20555

and

National Technical Information Service

Springfield, Virginia 22161 


\section{DISCLAIMER}

This report was prepared as an account of work sponsored by an agency of the United States Government. Neither the United States Government nor any agency Thereof, nor any of their employees, makes any warranty, express or implied, or assumes any legal liability or responsibility for the accuracy, completeness, or usefulness of any information, apparatus, product, or process disclosed, or represents that its use would not infringe privately owned rights. Reference herein to any specific commercial product, process, or service by trade name, trademark, manufacturer, or otherwise does not necessarily constitute or imply its endorsement, recommendation, or favoring by the United States Government or any agency thereof. The views and opinions of authors expressed herein do not necessarily state or reflect those of the United States Government or any agency thereof. 


\section{DISCLAIMER}

Portions of this document may be illegible in electronic image products. Images are produced from the best available original document. 


\title{
Best Estimate Method vs Evaluation Method: A Comparison of Two Techniques in Evaluating Seismic Analysis and Design
}

Manuscript Completed: May 1980

Date Published:

Prepared by:

S. E. Bumpus, J. J. Johnson, P. D. Smith

\author{
Lawrence Livermore National Laboratory \\ 7000 East Avenue \\ Livermore, CA 94550
}

\section{Prepared for}

Division of Reactor Safety Research

U.S. Nuclear Regulatory Commission

Washington, D.C. 20555

NRC FIN NO. A-0130

\section{DISCLAIMER}

\footnotetext{
This report was prepared as an account of work sponsored by an agency of the United States Government. Neither the United States Government nor any agency thereof, nor any of their employees, makes any warranty, express or implied, or assumes any legal liability or responsibility for the accuracy, completeness, or usefulness of any information, apparatus, product, or process disclosed, or represents that its use would not infringe privately owned rights. Reference herein to any specific commercial product, process, or service by trade name, trademark, manufacturer, or otherwise does not necessarily constitute or imply its endorsement, recommendation, or favoring by the United States Government or any agency thereof. The views and opinions of authors expressed herein do not necessarily state or reflect those of the United States Government or any agency thereof.
} 
$\bullet$

:

-

.

• 


\section{FOREWORD}

Under contract with the Division of Reactor Safety Research of the U.S. Nuclear Regulatory Commission (NRC), Lawrence Livermore National Laboratory (LLNL) is currently studying the seismic contribution to reactor risk. This document reports on the initial efforts that have been made on a calculational concept named the Best Estimate Method vs the Evaluation Method (BE-EM). The authors acknowledge the code development contributions made by Shirley Rompel in this study. The NRC FIN number is A-0130. 
$\checkmark$ 
CONTENTS

$\underline{\text { PAGE }}$

Foreword.

Abstract.

Summary

1. Introduction.

1.1 Background

1.2 Purpose and scope.

1.3 Analysis Overview. . . . . . . . . . . . . . . 4

2. The Best Estimate Method and Evaluation Method (BE-EM) Analysis . 9

2.1 General • • • • • • • • • • • • • • • • • . 9

2.2 Structural Model . . . . . . . . . . . . . . . 9

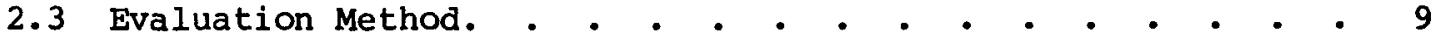

2.3.1 Excitation. . • . . • . • • . • . . . . 11

2.3.1.1 Time Histories . . . . . . . . . . 11

2.3.1.2 Three-Dimensional Response . . . . . . 12

2.3.2 Structural Variability. . . . . . . . . . . 13

2.3.3 Analysis Process. . . . . . . . . . . . . 13

2.4 Best Estimate . • . • • . • . • • • • • • . . 13

2.4.1 Excitation. • • • • • • • • • • • • . . 16

2.4 .2 Structural Variability. • . . . . . . . . . 16

2.4 .3 Analysis Process. • . • • . • . • • . . . 22

2.5 Computer Analysis. • • • • • • • • • • • • • . 28

3. Results. • • • • • • • • • • • • • • • • • • 29

3.1 General . • . • • • • • • • • • • • • • • . 29

$3.2 \mathrm{BE}$ and $\mathrm{EM}$ Response • • • • • • • • • • • • • . 29

3.3 BE-EM Response Comparisons. • • • • • • • • • • 31

3.4 Comparison of Coupled and Uncoupled Response. . . . . . 32

4. Conclusions and Recommendations. - . • . . . . . . . 59

References . . . . . . . . . . . . . . . . . . . . 61

Appendix A: LUSTE Output Descriptions. • . . • . . • . . . A-l

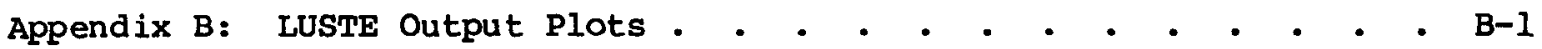


-

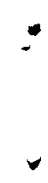

s

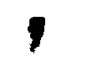

$\bullet$ 


\section{LIST OF FIGURES}

PAGE

1. Key elements of a seismic analysis and design calculational procedure for nuclear power plants . . . . . . 2

2. Structural model of a main steam valve house and quench spray area (MSVH and QSA). . . . . . . . . . . . . . 10

3. Typical peak-broadened response spectrum. • . • . • . . . 14

4. Flow diagram for the EM calculations . . . . . . . . . 15

5. Cumulative Distribution Function (CDF) on frequency modifier based on engineering judgment . . . . . . . . 20

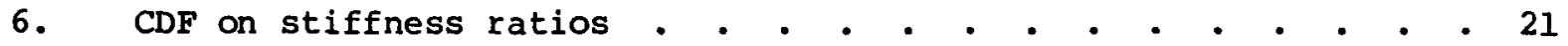

7. Expected CDF on frequency modifier. • • • • • • • • • 23

8. Flow diagram for the BE calculations . . . . . . . . . . 24

9. Mathematical model for main steam valve house and quench spray area $($ key $=1$, node $=6$, direction $=1$ ) . . . . . . . 34

10. Mathematical model for main steam valve house and quench spray area $($ key $=1$, node $=6$, direction $=2) \cdot . . . . . \quad$. 35

11. Mathematical model for main steam valve house and quench spray area $($ key $=3$, node $=6$, direction $=1) . . . . . . \quad$. 36

12. Mathematical model for main steam valve house and quench spray area $($ key $=3$, node $=6$, direction $=2) \cdot . . . \quad \cdot \quad$. 37

13. Mathematical model for main steam valve house and quench spray area $($ key $=8$, node $=6$, direction $=1) \cdot . . . \quad . \quad$. 38

14. Mathematical model for main steam valve house and quench spray area $($ key $=8$, node $=6$, direction $=2) \cdot . . . \quad . \quad . \quad 39$

15. Mathematical model for main steam valve house and quench spray area $($ key $=10$, node $=6$, direction $=1) . . . . . .40$

16. Mathematical model for main steam valve house and quench spray area $($ key $=10$, node $=6$, direction $=2) . . . .4 .41$ 
17. Mathematical model for main steam valve house and quench spray area $($ key $=12$, node $=6$, direction $=1) . . .$. . . . 42

18. Mathematical model for main steam valve house and quench spray area $($ key $=12$, node $=6$, direction $=2) . . . . . . .43$

19. Mathematical model for main steam valve house and quench spray area $($ key $=17$, node $=6$, direction $=1) . . .$. . . . 44

20. Mathematical model for main steam valve house and quench spray area $($ key $=17$, node $=6$, direction $=2) . . . . . .45$

21. Mathematical model for main steam valve house and quench spray area $($ key $=19$, node $=6$, direction $=1) . . .$. . . . 46

22. Mathematical model for main steam valve house and quench spray area $(k e y=19$, node $=6$, direction $=2$ ). . . . . . . 47

23. Mathematical model for main steam valve house and quench spray area $($ key $=21$, node $=6$, direction $=1) . . . . . . \quad$. 48

24. Mathematical model for main steam valve house and quench spray area $(k e y=21$, node $=6$, direction $=2) . . . . . . \quad$. 49

25. Mathematical model for main steam valve house and quench spray area $($ key $=22$, node $=6$, direction $=1) . . . . . . \quad 50$

26. Mathematical model for main steam valve house and quench spray area $($ key $=22$, node $=6$, direction $=2$ ). . . . . . . 51

27. Mathematical model for main steam valve house and quench spray area $($ key $=24$, node $=6$, direction $=1) . . . . . \quad$. . 52

28. Mathematical model for main steam valve house and quench spray area $($ key $=24$, node $=6$, direction $=2) . . . . . . \quad$. 53

29. Mathematical model for main steam valve house and quench spray area (node $=2$, direction = 1) . . . . . . . . . . 54 
LIST OF FIGURES (Continued)

$\underline{\text { PAGE }}$

30. Mathematical model for main steam valve house and quench spray area (node $=2$, direction = 2) . . . . . . . . . 55

31. Mathematical model for main steam valve house and quench spray area (node $=6$, direction $=1$ ) . . . . . . . . . 56

32. Mathematical model for main steam valve house and quench spray area (node $=6$, direction $=2$ ) . . . . . . . . . 57

B-1. Mathematical model for main steam valve house and quench spray area (key $=1$, node $=6$, direction $=1$ ) . . . . . . B-3

$\mathrm{B}-2$. Mathematical model for main steam valve house and quench spray area (key $=\mathrm{L}$, node $=6$, direction $=1$ ) . . . . . . B-4

B-3. Mathematical model for main steam valve house and quench spray area $($ key $=2$, node $=6$, direction $=1) \cdot . . . .$. . B-5

B-4. Mathematical model for main steam valve house and quench spray area (key $=2$, node $=6$, direction $=1$ ) . . . . . . B-6

B-5. Mathematical model for main steam valve house and quench spray area (key $=2$, node $=6$, direction $=1$ ) . . . . . . B-7

B-6. Mathematical model for main steam valve house and quench spray area (key $=3$, node $=6$, direction $=1$ ) . . . . . . B-8

B-7. Mathematical model for main steam valve house and quench spray area $($ key $=4$, node $=6$, direction $=1$ ) . . . . . . . B-9

B-8. Mathematical model for main steam valve house and quench spray area $(k e y=5$, node $=6$, direction $=1) . . . . .$. B-10

B-9. Mathematical model for main steam valve house and quench spray area $($ key $=6$, node $=6$, direction $=1$ ) . . . . . . B-1l

B-10. Mathematical model for main steam valve house and quench spray area (key $=7$, node $=6$, direction $=1$ ) . . . . . . B-12

B-11. Mathematical model for main steam valve house and quench spray area (key $=8$, node $=6$, direction $=1$ ) . . . . . . B-13 
LIST OF FIGURES (Continued)

PAGE

B-12. Mathematical model for main steam valve house and quench spray area (key $=9$, node $=6$, direction $=1$ ) . . . . . .. B-14

B-13. Mathematical model for main steam valve house and quench spray area $(k e y=10$, node $=6$, direction $=1) . . . . . . \quad . \quad$ B-15

B-14. Mathematical model for main steam valve house and quench spray area (key $=11$, node $=6$, direction $=1$ ). . . . . . . B-16

B-15. Mathematical model for main steam valve house and quench spray area $($ key $=11$, node $=6$, direction $=1$ ). . . . . . . B-17

B-16. Mathematical model for main steam valve house and quench spray area $($ key $=11$, node $=6$, direction $=1) . . . . . . \quad . \quad$ B-18

B-17. Mathematical model for main steam valve house and quench spray area (key = 12, node = 6, direction = 1). . . . . . . B-19

B-18. Mathematical model for main steam valve house and quench spray area (key $=13$, node $=6$, direction = 1). . . . . . . B-20

B-19. Mathematical model for main steam valve house and quench spray area (key $=14$, node $=6$, direction $=1$ ). . . . . . . B-21

B-20. Mathematical model for main steam valve house and quench spray area $($ key $=15$, node $=6$, direction $=1$ ) $. . . \quad . \quad . \quad \cdot$ B-22

B-21. Mathematical model for main steam valve house and quench spray area $($ key $=16$, node $=6$, direction $=1$ ). $. . . . . \quad . \quad$ B-23

B-22. Mathematical model for main steam valve house and quench spray area $($ key $=17$, node $=6$, direction $=1$ ). $. . . \quad . \quad . \quad$ B-24

B-23. Mathematical model for main steam valve house and quench spray area (key $=18$, node $=6$, direction $=1$ ). $. . . \quad . \quad . \quad$ B-25

B-24. Mathematical model for main steam valve house and quench spray area $\langle$ key $=19$, node $=6$, direction $=1$ ). . . . . . . B-26

B-25. Mathematical model for main steam valve house and quench spray area $($ key $=20$, node $=6$, direction $=1) . . . . \quad . \quad \cdot$ B-27 
B-26. Mathematical model for main steam valve house and quench

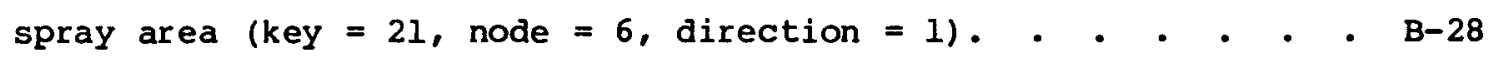

B-27. Mathematical model for main steam valve house and quench spray area $(k e y=22$, node $=6$, direction $=1) . . . . \quad$.. B-29

B-28. Mathematical model for main steam valve house and quench spray area (key $=23$, node $=6$, direction $=1$ ). . . . . . B-30

B-29. Mathematical model for main steam valve house and quench spray area (key $=24$, node $=6$, direction $=1) . . . . . . \quad \mathrm{B}-31$

B-30. Mathematical model for main steam valve house and quench spray area (key $=25$, node $=6$, direction $=1$ ). . . . . . B-32

B-31. Mathematical model for main steam valve house and quench spray area (key $=26$, node $=6$, direction $=1$ ). . . . . . B-33

B-32. Mathematical model for main steam valve house and quench spray area $($ key $=26$, node $=6$, direction $=1) . . . .$. . B-34 
•

4 
1. Earthquake records used in structural analyses. . . . . . . 17

2. Values of damping used in BE analysis. • . • • • • • • • • 25

3. Values of frequency modifier used in BE analysis . . • • • . 26

4. Pairs of damping and frequency modifiers used in BE analysis . . 27 
$\bullet$

$:$

$\checkmark$

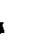

1 


\section{BEST ESTIMATE METHOD VS EVALUATION METHOD:}

A COMPARISON OF TWO TECHNIQUES IN

EVALUATING SEISMIC ANALYSIS AND DESIGN

ABSTRACT

The concept of how two techniques, Best Estimate Method and Evaluation Method, may be applied to the traditional seismic analysis and design of a nuclear power plant is introduced. Only the four links of the seismic analysis and design methodology chain (SMC)--seismic input, soil-structure interaction, major structural response, and subsystem response--are considered. The objective is to evaluate the compounding of conservatisms in the seismic analysis and design of nuclear power plants, to provide guidance for judgments in the SMC, and to concentrate the evaluation on that part of the seismic analysis and design which is familiar to the engineering community. An example applies the effects of three-dimensional excitations on a model of a nuclear power plant structure. The example demonstrates how conservatisms accrue by coupling two links in the SMC and comparing those results to the effects of one link alone. The utility of employing the Best Estimate Method vs the Evaluation Method is also demonstrated. 
The primary purposes of this report are to introduce the concept of Best Estimate Method vs Evaluation Method (BE-EM) as it applies to the seismic analysis and design of nuclear power plants, to demonstrate BE-EM with an illustrative example coupling two links in the Seismic Methodology Chain (SMC), and to demonstrate the effects of three-dimensional excitations. The term BE-EM was introduced to represent the comparison of any two seismic analysis methodologies. BE-EM is limited to a systematic evaluation of the SMC only; i.e., seismic input, soil-structure interaction, major structural response, and subsystem response, whereas the Seismic Safety Margins Research Program (SSMRP) treats the SMC along with the failure of systems and components and their functional interdependence. The example considered in this study links two phases of the SMC--seismic input and structural response. All of the results demonstrate three-dimensional effects. The Best Estimate Method (BE) and Evaluation Method (EM) analysis considered two links in the SMC. The EM procedure was composed of synthetic time histories generated to meet the design criteria of R.G. 1.60, the square-root-of-the-sum-of-the-squares (SRSS) rule of combination for response due to three components of motion, and broadening of in-structure response spectra to account for uncertainties in the dynamic characteristics of structures. Corresponding elements in the BE procedure were recorded time histories--three components with recorded phasing, and probability distributions on structural dynamic characteristics which were sampled repetitively to incorporate structural uncertainties directly. Response was in the form of in-structure response spectra.

Two quantities were used in the comparison of $\mathrm{BE}$ and $\mathrm{EM}$ response. Factors of Comparison (FOC) were computed as the quotient of the mean $F M$ response spectra and the mean (or the mean-plus-one-standard-deviation) BE response spectra. In addition, Probabilities of Exceedance (POE) were computed representing the probability of a $\mathrm{BE}$ response exceeding the corresponding EM response. Both FOC and POE vary over the frequency range 
of interest. The results demonstrated the apparent conservatism of the EM design criteria subject to the assumptions of the study.

The results of the present investigation were compared with a previous study which considered only the seismic input phase. The comparison demonstrated a compounding of effects through coupling two links in the SMC as compared to computing one link alone. 


\section{INTRODUCTION}

\subsection{BACKGROUND}

Performing the seismic analysis of a nuclear power plant and designing that plant to resist earthquakes requires a significant multidisciplinary effort. ${ }^{l}$ This effort includes contributions from geologists, seismologists, and engineers specializing in structural, mechanical, and electrical design and in soils. For some time there has been a strong motivation to reexamine the traditional process of seismic analysis and design of nuclear power plants in an overall system context. This motivation comes principally from the widely held belief that a compounding of conservatisms occurs in the current process. That is, at each stage of the current process, conservatisms are introduced to account for uncertainties, and these conservatisms compound from one stage to the next. However, in each stage only minimal compensations are made for the compounding of conservatisms because they are not quantified. The result may be an overconservative seismic design.

A methodology that will examine the current seismic analysis and design process of nuclear power plants in an overall system context is being developed in the Seismic Safety Margins Research Program (SSMRP) at Lawrence Livermore National Laboratory (LLNL). ${ }^{2}$ Figure 1 depicts the seismic analysis and design methodology chain (SMC) and its relationship to the SSMRP systems model. The traditional SMC is shown separated from the SSMRP systems analysis by a segmented line to emphasize that the overall seismic analysis and design problem is treated in two parts calculationally in the SSMRP. The systems analysis (under the dashed line) represents reactor systems using an event tree/fault tree methodology, and it also employs an overall computational procedure to compute the probability of failure of structures, components, and systems, the probability of radioactive releases, and variations in these probabilities due to uncertainties in the SMC. (The specially developed SEISIM code is used for these computations.) clearly, examining the nuclear power plant system in total, including the functional requirements of safety systems and their interdependence, is the most complete 


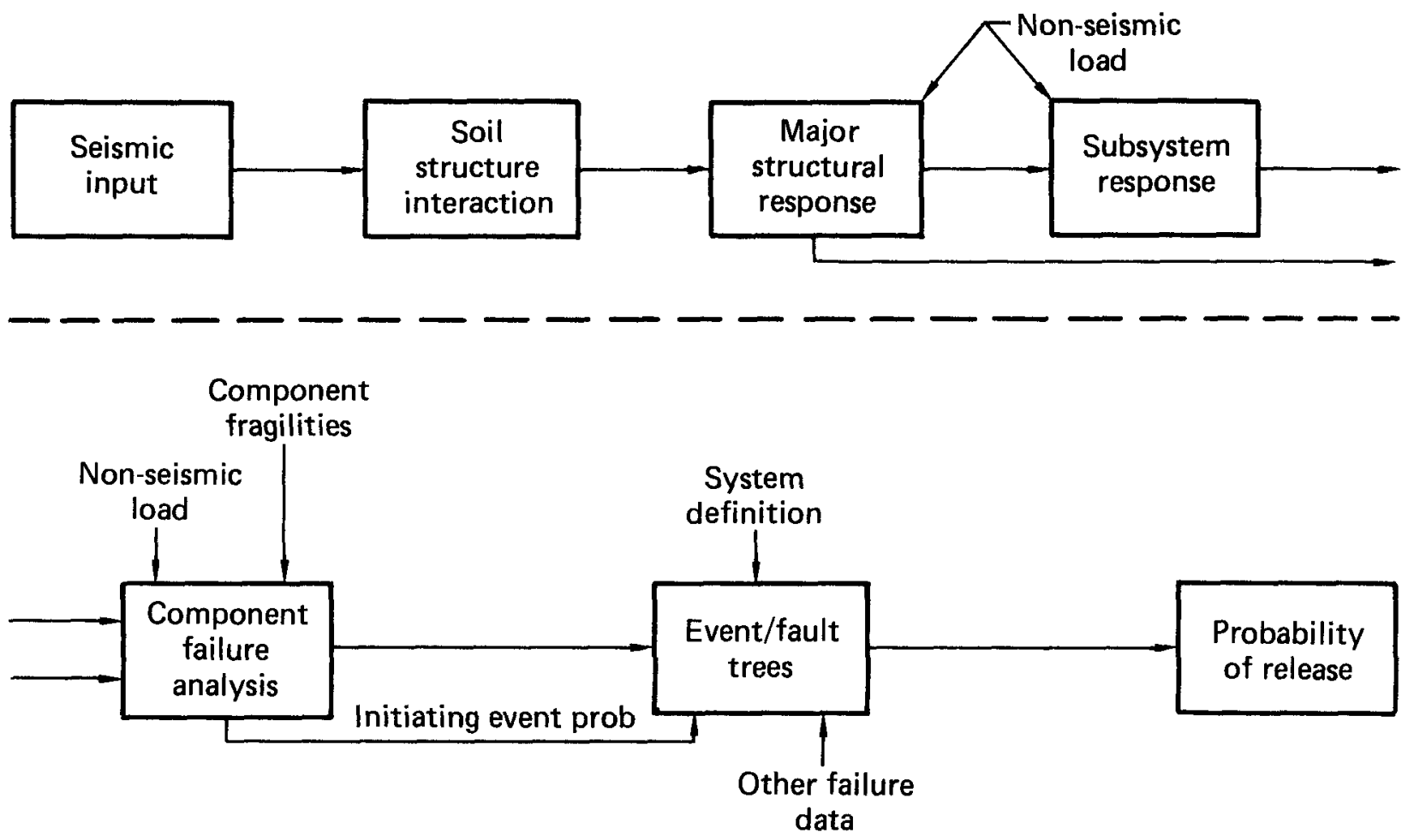

FIG. 1. Key elements of a seismic analysis and design calculational procedure for nuclear power plants. In evaluating possible compounding of conservatisms in such a procedure the Seismic Safety Margins Research Program (SSMRP) calculates values in the entire system, from seismic input to probability of release. The Best Estimate Method vs Evaluation Method procedure, however, reduces the problem by coupling the four traditional elements of seismic analysis and design (boxes above the dashed line) and analyzing them independent of the probabilities of failure and radioactive release. 
manner of treating the problem--and this is the SSMRP approach. However, it is possible to consider only the four elements of the SMC (seismic input, soil-structure interaction, major structural response, and subsystem response) in a coupled or "system" fashion independent of the calculation of probabilities of failure or radioactive release. The quantities of interest then become response parameters and their statistics; for example, in-structure response spectra, displacements, velocities, accelerations, forces, rather than probabilities of failure or radioactive release. The concept for such a simplification is introduced in this report.

\subsection{PURPOSE AND SCOPE}

We simplify in this report the systematic evaluation of the seismic analysis and design of a nuclear power plant to encompass only the four links of the SMC: seismic input, soil-structure interaction, major structural response, and subsystem response. The term Best Estimate Method vs Evaluation Method (BE-EM) is introduced to identify this simplification. The objective of BE-EM is to develop a basis for the comparison of any two seismic analysis procedures. One comparison would be between a Best Estimate Method (BE) and an Evaluation Method (EM); hence, the term BE-EM. However, comparison possibilities are not limited to BE-EM--any two seismic analysis methodologies may be compared. Examples include any combination of best estimate, standard review plan (SRP), design methodologies of older plants, proposed new techniques, erroneous methods of analysis, and so forth. There are two key points to be emphasized in the BE-EM concept. The methodology comparison should include as many links of the SMC as possible and appropriate. For example, in the BE-EM concept, it could be misleading to compare a soilstructure interaction result such as base-mat response instead of a design parameter including structural and subsystem response. Second, the basis of comparison will, in most cases, be statistical; that is, mean vs mean, mean vs mean-plus-one-standard-deviation, mean vs point estimate, etc. When calculating a Best Estimate response, this will always be the case since Best Estimate by definition includes a measure of uncertainty. The Evaluation Method may or may not be statistical. 
The term BE-EM is not new. A similar concept was applied to postulated loss-of-coolant accidents (LOCA).$^{3}$ Thermal conditions resulting from a LOCA as predicted by a "best estimate" or realistic model were compared with those predicted by an "evaluation model." The comparison provided a measure of the margin between best estimate and design.

The objectives, then, of the present study are:

1. To introduce and apply the BE-EM concept to the seismic analysis and design of nuclear facilities.

2. To demonstrate BE-EM through an illustrative example showing the coupling effects between two links in the SMC.

3. To indicate the sensitivity of response to three components of input motion.

\subsection{ANALYSIS OVERVIEW}

The present investigation is an extension and coupling of two previous studies, ${ }^{4,5}$ which will be briefly reviewed.

Reference 4 addressed the topic of synthetic time histories and their combination vs recorded ground motions. A suite of synthetic time histories was sought and obtained from firms active in the nuclear power industry. ${ }^{6}$ These time histories had been generated to match the design ground response spectra of the U.S. Nuclear Regulatory Commission's Regulatory Guide $1.60^{7}$ (R.G. 1.60). The recorded ground motions were from the original data base used to develop R.G. 1.60. Three structural models were analyzed for the synthetic time histories and the recorded ground motions. The responses, in the form of in-structure response spectra, were compared. The mean of the responses due to the synthetic motions was compared to the mean-plus-onestandard-deviation (MSD) of the responses due to the recorded motions. This reflects the assumption that the design criteria of R.G. 1.60 were based on a goal of the MSD. In the notation of this report, the use of recorded ground motions would be considered the Best Estimate Method and the use of synthetic time histories the Evaluation Method. 
Reference 5 addressed the practice of enveloping and broadening in-structure response spectra to account for uncertainties. Calculations of two types were performed on a relatively simple structural model using only one-dimensional excitations. The excitations used were the suite of synthetic time histories discussed above and two cases of analyses were considered:

Case 1: A dynamic analysis was performed for each of the synthetic time histories. Structural frequencies and damping were held constant at their nominal values for each analysis. Each resulting in-structure response spectrum was broadened by \pm 158 . The mean spectra were computed for comparison purposes.

Case 2: Dynamic analyses were performed with the excitation randomly selected from the suite of synthetic time histories. The frequency and damping of the structural model were also randomly selected from hypothesized distributions. These distributions were obtained from the open literature and represent dispersion about the nominal values used in Case 1 . In-structure response spectra were generated. The MSD spectra were computed for comparison.

Again, in the notation of this report, Case 1 would be considered the Evaluation Method and Case 2 the Best Estimate. The present investigation is an extension and coupling of the two studies just described. The structural model analyzed here is the same as the model of Ref. 4. This model has a large degree of asymmetry; that is, it has coupling of responses in all degrees of freedom.

Key elements of the Best Estimate Method are:

1. Excitations are the three components of recorded ground motion applied simultaneously and with their recorded phasing.

2. Variability in stiffness and damping are incorporated in the analysis by random sampling from distributions.

3. Mean and MSD response specta were generated. The corresponding elements of the Evaluation Method are:

1. Excitations are synthetic time histories applied in each of the horizontal and vertical directions independently, the resulting 
in-structure response spectra being combined by the square-root-of-thesum-of-the-squares rule (SRSS); i.e., the spectral ordinate $S$ at a point in direction 1 is computed by

$$
s_{1}=\left(s_{11}^{2}+s_{12}^{2}+s_{13}^{2}\right)^{1 / 2} \text {, }
$$

where

$$
\begin{array}{ll}
s_{1}= & \text { response spectrum ordinate in direction } 1 \text { due to three } \\
& \text { components of motion }(1,2,3) \text { and } \\
s_{1 j}= & \text { response spectrum ordinate in direction } 1 \text { due to an excitation } \\
& \text { in direction } j(j=1,2,3) .
\end{array}
$$

2. Variability in stiffness and damping is incorporated by peak-broadening of in-structure response spectra. Nominal values of frequency and damping are assumed in each analysis.

3. Mean response spectra are generated.

This study demonstrates the coupling and compounding of effects through two links in the SMC: seismic input and structural response. The results should be interpreted in the context of this coupling and in the suggestion of one way of comparing two alternative methodologies. For a number of reasons, the significance of the quantitative results is limited. All of the ingredients of the analysis were selected to be compatible with the previous studies. ${ }^{4,5}$ The same time histories, structural model, and variability of structural dynamic characteristics were used in the present study as in the previous uncoupled analyses. Hence, the parameter selections and, in particular, their variability do not reflect information available in the interim. For example, the uncertainty in structural damping was represented by a normal distribution with a coefficient of variation of 0.1 . Recent information ${ }^{8}$ indicates that a minimum coefficient of variation of 0.2 for structural damping is more appropriate. In addition, the present investigation considers only seismic input and structural response and thus neglects soil-structure interaction and its associated uncertainties. Hence, in the most useful situation, the quantitative results would only apply to 
structures founded on extremely stiff soils or rock where soil-structure interaction effects can be considered negligible.

Chapter 2 describes the Best Estimate Method and Evaluation Method procedures used herein. Chapter 3 presents results for the Best Estimate Method and Evaluation Method both separately and in comparison. Chapter 4 discusses our conclusions and recommendations. 
dod
$\mathbf{d}$ 


\section{THE BEST ESTIMATE METHOD AND EVALUATION \\ METHOD (BE-EM) ANALYSIS}

\subsection{GENERAL}

The Best Estimate Method and Evaluation Method analysis, in the example presented here, couples two links (seismic input and structural response) in the seismic analysis and design methodology chain (SMC), as described in Sec. 1.3. The key ingredients for the Best Estimate Method and Evaluation Method are described in this chapter. They include the excitations in the form of free-field acceleration time histories, structural model, variations of the structure dynamic characteristics, combination of three-dimensional response, and broadening of in-structure response spectra to account for uncertainties.

\subsection{STRUCTURAL MODEL}

The structural model for the BE-EM analysis is of a main steam valve house and quench spray area (MSVH and QSA) for a pressurized water reactor. It was supplied by the U.S. NRC and is identical to one of the models analyzed in Ref. 4. It is fully three-dimensional with a high degree of asymmetry. Figure 2 shows the model: six nodes with six active degrees of freedom (three translational and three rotational) per node. Modal analys is was performed throughout using the first fourteen modes. The first three frequencies of the structural model were $3.45 \mathrm{~Hz}, 3.97 \mathrm{~Hz}$, and $8.03 \mathrm{~Hz}$. For convenience' sake we discuss the Evaluation Method first.

\subsection{EVALUATION METHOD}

The Evaluation Method (EM) for the present study includes three major i tems :

1. Generation of synthetic time histories that essentially envelope the design ground response spectra of Regulatory Guide 1.60 (R.G. 1.60).

2. Determination of three-dimensional responses due to three directions of excitation.

3. Modification of computed in-structure response spectra to account for uncertainties (broadening). 

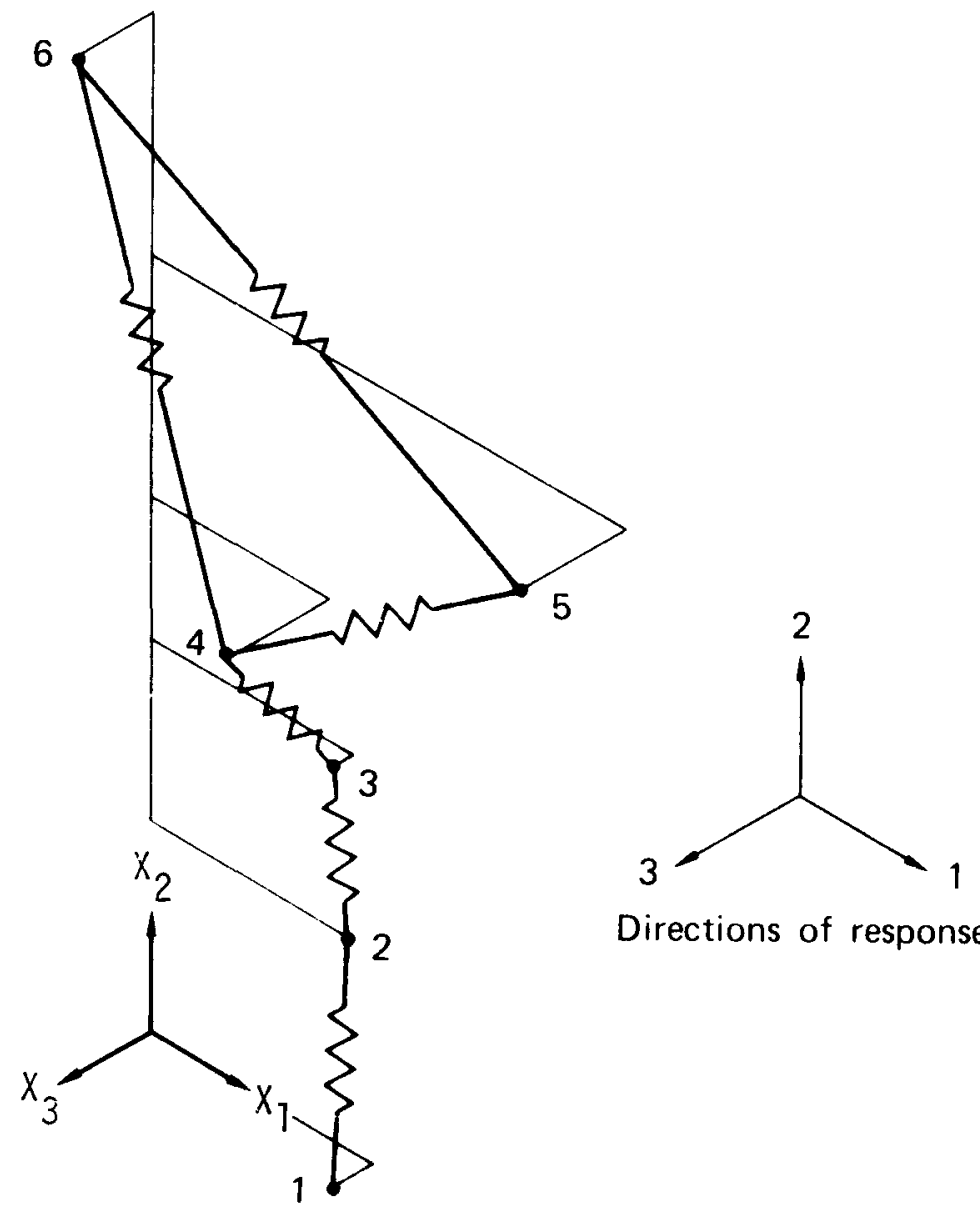

Directions of response

FIG. 2. Structural model of a main steam valve house and quench spray area (MSVH and QSA). I and 3 are the horizontal components and 2 is the vertical. This study analyzes responses at nodes 2 and 6 . 
Each of these items and the resulting combinations are discussed below.

\subsubsection{Excitation}

2.3.1.1 Time Histories. Specification of the seismic input for the analysis and design of nuclear power plants includes three parameters for the earthquake motion: (1) a measure of the size of the earthquake; (2) the frequency content of the motion; and (3) the duration of the strong motion. In this study, the size of the earthquake is measured by the peak acceleration. The frequency content is specified by the design response spectra of R.G. 1.60. Duration of the ground motion was determined by synthetic time histories obtained from industry. 6

The peak acceleration of each of the two horizontal components were taken equal. The corresponding peak acceleration of the vertical component is two-thirds of the peak horizontal as defined by R.G. 1.60. For convenience, the peak horizontal acceleration was assumed to be $1.0 \mathrm{~g}$. Since a linear analys is is performed throughout, the results may be scaled linearly to any other excitation level.

It is helpful to review the process by which R.G. 1.60 response spectra were constructed: (1) A data base of strong-motion earthquake time histories was established; (2) displacement, velocity, and acceleration scaling was performed on the data base time histories; (3) the mean and mean-plus-onestandard-deviation (MSD) response spectra were constructed, frequency point by frequency point; and (4) the resulting MSD response spectra were smoothed and served as the basis for R.G. 1.60. In many cases, the seismic analysis of structures is performed using time histories rather than the design response spectra of R.G. 1.60. One way of performing such an analysis would be to utilize the earthquake data base of R.G. 1.60, performing multiple analyses, and interpreting the results in a statistical manner; e.g., MSD. In the design process, this could be prohibitively expensive. However, for a limited number of comparative cases, this approach is feasible, and, in fact, comprises the Best Estimate model used herein. To circumvent using all the time histories, it is common practice to generate synthetic time histories whose response spectra essentially envelope the corresponding response spectra of R.G. 1.60 . 
The synthetic time histories were obtained from the nuclear industry as reported in Ref. 6. Obviously, this data base does not represent all such histories used in seismic design. However, it is the most complete data base presently available. The goodness of fit of these histories to R.G. 1.60 was not assessed; the entire set, however, met the requirement of essentially enveloping the target spectra. Sixteen horizontal and 12 vertical time histories were obtained. For this study, the assumption was made that each of the 16 horizontal histories could be combined with any other horizontal history and with any of the 12 vertical histories. This assumption led to $16 \times 16 \times 12=3072$ possible combinations. All such combinations were calculated. 9 Further, each such combination of two horizontals and one vertical was assumed equally likely.

The excitations, both Best Estimate Method and Evaluation Method, were applied to the structure in the principal coordinate directions of Fig. 2 . coordinates $x_{1}$ and $x_{3}$ correspond to the horizontal directions and $x_{2}$ to the vertical. Other assumptions and sensitivity studies could have been made; for example, azimuth variation of the motions with respect to the structural coordinate system. However, additional assumptions were beyond the scope of this study.

\subsubsection{Three-Dimensional Response. Nuclear power plants are designed to} resist the three translational components of ground motion. When using synthetic time histories, it is common practice to analyze the structure for each component of ground motion separately and combine the results. The Evaluation Method followed this practice. The combination rule applied is the square-root-of-the-sum-of-the-squares (SRSS). 10 That is, in-structure response spectra were generated at nodal degrees of freedom of interest for each component of motion. The resulting spectra were combined by the SRSS rule: where

$$
s_{1}=\left(s_{11}^{2}+s_{12}^{2}+s_{13}^{2}\right)^{1 / 2}
$$

$$
\begin{array}{ll}
s_{1}= & \text { response spectrum ordinate in direction } 1 \\
& \text { due to three components of motion }(1,2,3) \text { and } \\
s_{1 j}= & \begin{array}{l}
\text { response spectrum ordinate in direction } 1 \\
\text { due to an excitation in direction } j(j=1,2,3) .
\end{array}
\end{array}
$$


The SRSS rule was applied separately at each frequency point. The SRSS rule is based on statistical considerations; namely, that the peak spectral responses at a given frequency due to three independent motions are not expected to occur at the same instant of time.

\subsubsection{Structural Variability}

The in-structure response spectra computed for the Evaluation Method were modified to account for uncertainties in the modeling procedure and in the degree of accuracy of the basic material properties. ${ }^{9}$ The in-structure response spectra were broadened \pm 158 at all frequencies. Figure 3 shows typical broadened and unbroadened response spectra. Note that the broadened spectrum is smoother than the unbroadened spectrum and envelopes it.

\subsubsection{Analysis Process}

The calculational process for the Evaluation Method is depicted in Fig. 4. Repeated time history analyses were performed to encompass all possible combinations of horizontal and vertical synthetic time histories; i.e., $16 \times 16 \times 12=3072$ combinations. Nominal values of frequency and damping were used for the structural model. In-structure response spectra were generated at all points and directions of interest. The analysis for each direction of excitation was performed separately and the resulting in-structure response combined by the SRSS rule. The spectra were broadened by \pm 158 to account for uncertainties. After completion of the repeated analyses, the mean response spectra were computed.

\subsection{BEST ESTIMATE}

The Best Estimate method (BE) for the present investigation includes:

1. Recorded ground motion time histories from the data base for R.G. 1.60;

2. Three components of ground motion applied simultaneously and with their recorded time phasing;

3. Variability in the stiffness and damping of the structure incorporated by random sampling on hypothesized distributions. 


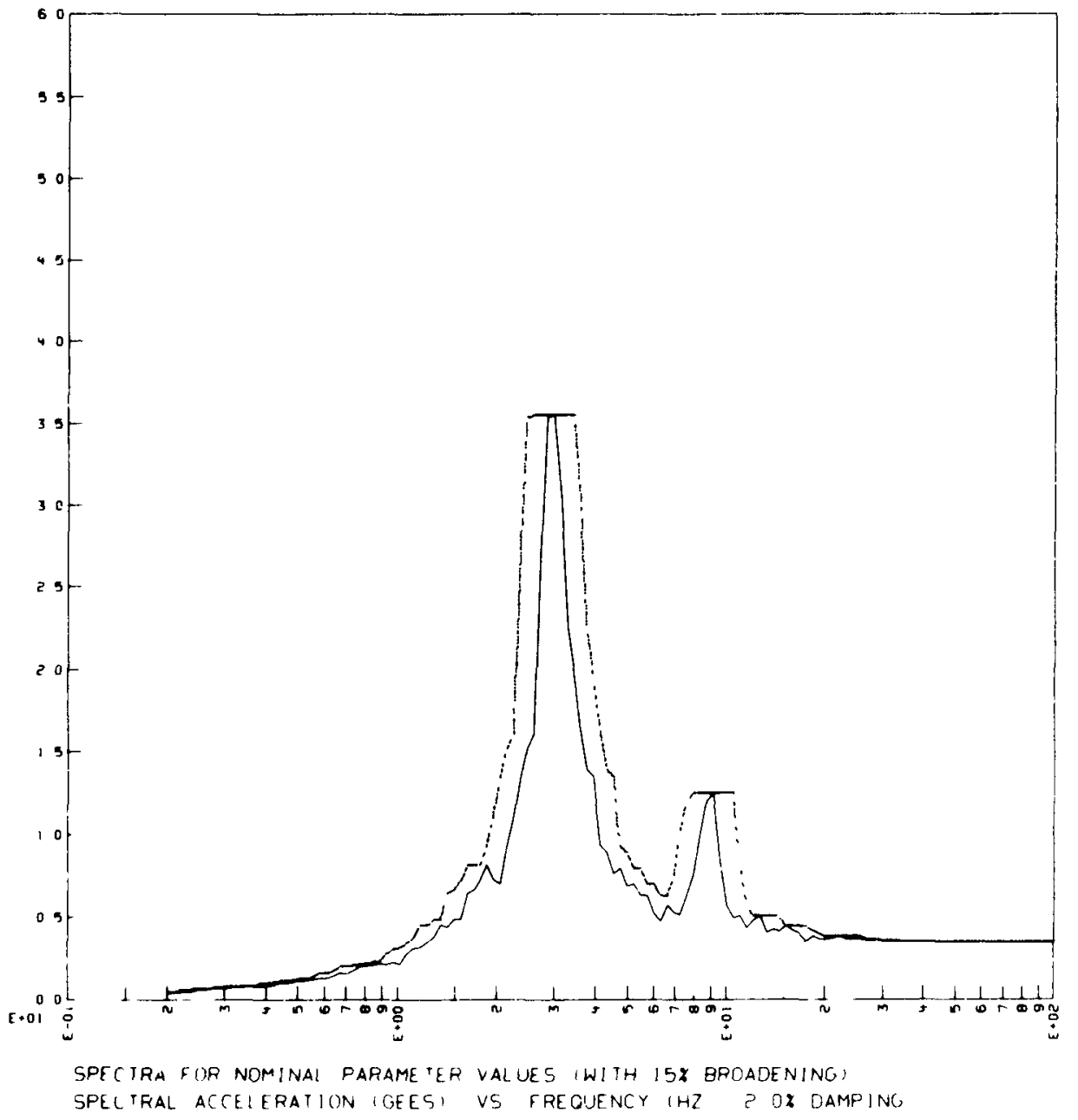

FIG. 3. Typical peak-broadened response spectrum (broken line). 


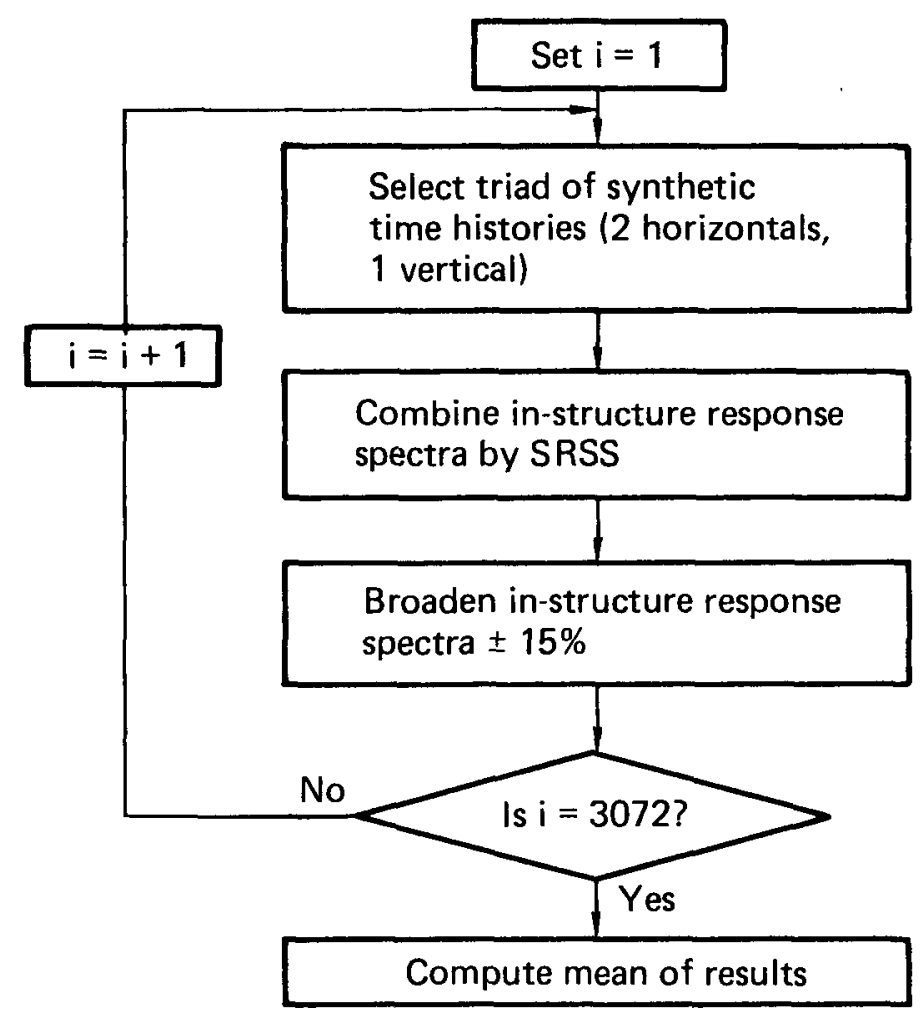

FIG. 4. Flow diagram for the EM calculations. 


\subsubsection{Excitation}

Recorded time histories from the California Institute of Technology (CALTECH) earthquake data base ${ }^{11}$ were used in the analysis. These records are identified in Table 1 and include 23 of the earthquakes used to develop R.G. 1.60 design response spectra. The so-called corrected or Vol. II version of the records was used. In constructing the design response spectra of R.G. 1.60, the recorded motions were scaled with respect to displacement, velocity, and acceleration. The present investigation only scaled the accelerations. The three components of motion were scaled by a common factor such that the horizontal component with the largest recorded peak acceleration was scaled to $1.0 \mathrm{~g}$. The resulting peak accelerations are shown in Table 1.

As a point of interest, Table 1 also shows the change in peak acceleration between uncorrected (Vol. I) and corrected (Vol. II) accelerograms.

Structural response was calculated assuming the three components of recorded motion act simultaneously and with their recorded phasing. Therefore, no additional processing of the in-structure response spectra (corresponding to the SRSS rule of Sec. 2.3.1.2) was necessary.

\subsubsection{Structural Variability}

Variability in the structural model was incorporated into the Best Estimate analysis by defining distributions of frequency and damping, sampling from the distributions, and performing response calculations for the selected parameters. For frequency, two probability density functions were assumed. The first addressed the uncertainty introduced by the process of an engineer developing a structural model from engineering drawings. The second addressed uncertainty in material properties. Both distributions were based on experimental information available in the open literature. 12,13 of the alternative distributions proposed in Ref. 12 which are dependent on the experience of the engineer and complexity of the structure, the distribution representing an experienced engineer modeling a complex structure was assumed. Figures 5 and 6 show the appropriate distributions. It is important to recognize that these two functions were applied sequentially in the 
TABLE 1. Earthquake records used in structural analyses.

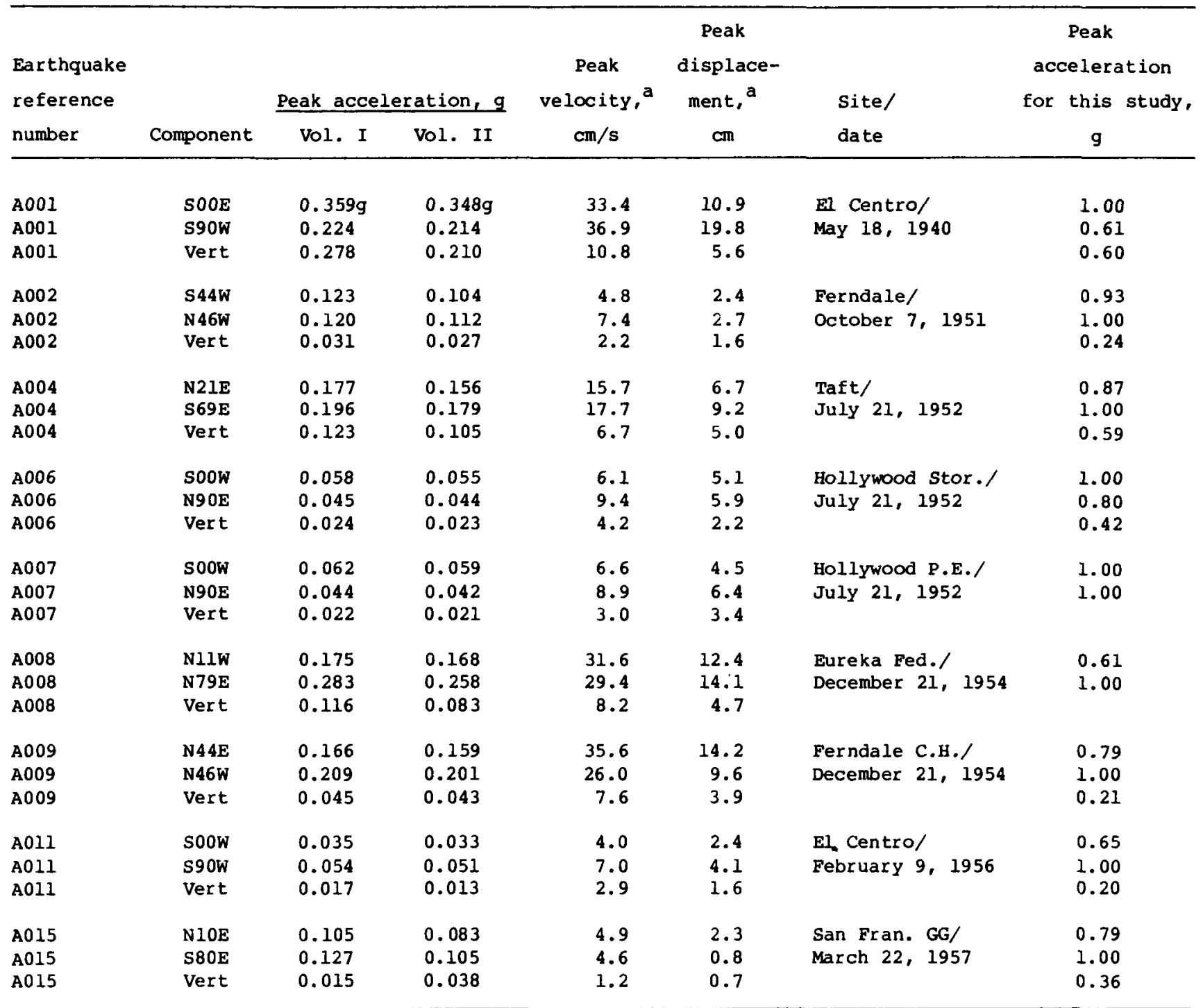

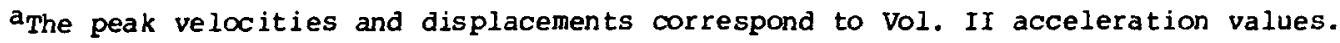


TABLE 1. (continued).

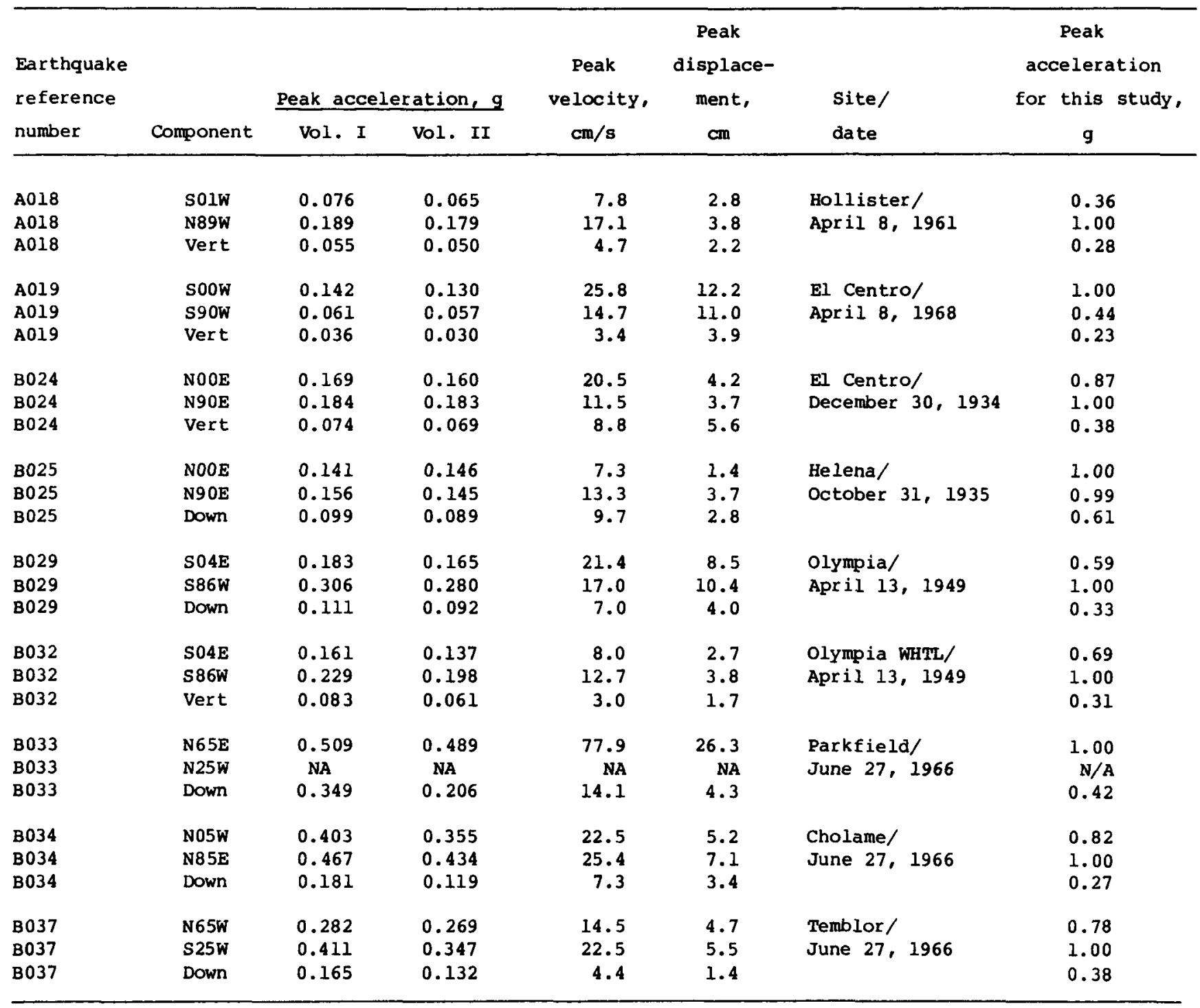


TABLE 1. (continued).

\begin{tabular}{|c|c|c|c|c|c|c|c|}
\hline \multirow{2}{*}{$\begin{array}{l}\text { Earthquake } \\
\text { reference } \\
\text { number }\end{array}$} & \multirow[b]{2}{*}{ Component } & \multicolumn{2}{|c|}{ Peak acceleration, $g$} & \multirow{2}{*}{$\begin{array}{l}\text { Peak } \\
\text { velocity, } \\
\mathrm{cm} / \mathrm{s}\end{array}$} & \multirow{2}{*}{$\begin{array}{c}\text { Peak } \\
\text { displace- } \\
\text { ment, } \\
\text { cm }\end{array}$} & \multirow{2}{*}{$\begin{array}{l}\text { Site/ } \\
\text { date }\end{array}$} & $\begin{array}{l}\text { Peak } \\
\text { celeration }\end{array}$ \\
\hline & & Vol. I & Vol. II & & & & $g$ \\
\hline $\begin{array}{l}C 041 \\
C 041 \\
C 041\end{array}$ & $\begin{array}{l}\text { S16E } \\
\text { S74W } \\
\text { Down }\end{array}$ & $\begin{array}{l}1.242 \\
1.251 \\
0.718\end{array}$ & $\begin{array}{l}1.170 \\
1.075 \\
0.709\end{array}$ & $\begin{array}{r}113.2 \\
57.7 \\
58.3\end{array}$ & $\begin{array}{l}37.7 \\
10.8 \\
19.3\end{array}$ & $\begin{array}{l}\text { Pacoima dam/ } \\
\text { February 9, } 1971\end{array}$ & $\begin{array}{l}1.00 \\
0.92\end{array}$ \\
\hline $\begin{array}{l}C 048 \\
C 048 \\
C 048\end{array}$ & $\begin{array}{l}\text { No0w } \\
\text { S90W } \\
\text { Down }\end{array}$ & $\begin{array}{l}0.258 \\
0.140 \\
0.178\end{array}$ & $\begin{array}{l}0.255 \\
0.134 \\
0.171\end{array}$ & $\begin{array}{l}30.0 \\
23.9 \\
32.0\end{array}$ & $\begin{array}{l}14.9 \\
13.8 \\
14.6\end{array}$ & $\begin{array}{l}8244 \text { Orion, LA/ } \\
\text { February 9, } 1971\end{array}$ & $\begin{array}{l}1.00 \\
0.92 \\
0.61\end{array}$ \\
\hline $\begin{array}{l}\text { D056 } \\
\text { D056 } \\
\text { D056 }\end{array}$ & $\begin{array}{l}\text { N21E } \\
\text { N69W } \\
\text { Down }\end{array}$ & $\begin{array}{l}0.335 \\
0.289 \\
0.180\end{array}$ & $\begin{array}{l}0.315 \\
0.271 \\
0.156\end{array}$ & $\begin{array}{r}16.5 \\
27.2 \\
6.4\end{array}$ & $\begin{array}{l}4.2 \\
9.3 \\
3.5\end{array}$ & $\begin{array}{l}\text { Castaic/ } \\
\text { February 9, } 1971\end{array}$ & $\begin{array}{l}1.00 \\
0.86 \\
0.50\end{array}$ \\
\hline $\begin{array}{l}\text { H } 115 \\
H 115 \\
H 115\end{array}$ & $\begin{array}{l}\text { N11E } \\
\text { N79w } \\
\text { Down }\end{array}$ & $\begin{array}{l}0.225 \\
0.152 \\
0.108\end{array}$ & $\begin{array}{l}0.225 \\
0.149 \\
0.096\end{array}$ & $\begin{array}{r}28.2 \\
23.5 \\
9.4\end{array}$ & $\begin{array}{r}13.4 \\
10.3 \\
4.3\end{array}$ & $\begin{array}{l}15250 \text { Ventura LA/ } \\
\text { February } 9,1971\end{array}$ & $\begin{array}{l}1.00 \\
0.66 \\
0.43\end{array}$ \\
\hline $\begin{array}{l}\text { Ll66 } \\
\text { L166 } \\
\text { Ll66 }\end{array}$ & $\begin{array}{l}\text { NOOE } \\
\text { S9OW } \\
\text { Down }\end{array}$ & $\begin{array}{l}0.181 \\
0.154 \\
0.085\end{array}$ & $\begin{array}{l}0.167 \\
0.150 \\
0.071\end{array}$ & $\begin{array}{r}12.3 \\
15.0 \\
5.0\end{array}$ & $\begin{array}{l}4.9 \\
5.4 \\
2.4\end{array}$ & $\begin{array}{l}3838 \text { Lkshm. LA/ } \\
\text { February } 9,1971\end{array}$ & $\begin{array}{l}1.00 \\
0.90 \\
0.42\end{array}$ \\
\hline $\begin{array}{l}\text { Mean } \\
\text { MSD }\end{array}$ & $\begin{array}{l}\text { Hor izontal } \\
\text { Hor izontal }\end{array}$ & $\begin{array}{l}0.241 \\
0.488\end{array}$ & $\begin{array}{l}0.223 \\
0.445\end{array}$ & & & $\begin{array}{l}\text { Mean of horizontals } \\
\text { with lesser peak } \\
\text { acceleration standard } \\
\text { deviation }\end{array}$ & 0.73 \\
\hline $\begin{array}{l}\text { Mean } \\
\text { MSD }\end{array}$ & $\begin{array}{l}\text { Vertical } \\
\text { Vertical }\end{array}$ & $\begin{array}{l}0.134 \\
0.287\end{array}$ & $\begin{array}{l}0.114 \\
0.256\end{array}$ & & & & $\begin{array}{l}0.16 \\
0.40 \\
0.14\end{array}$ \\
\hline
\end{tabular}




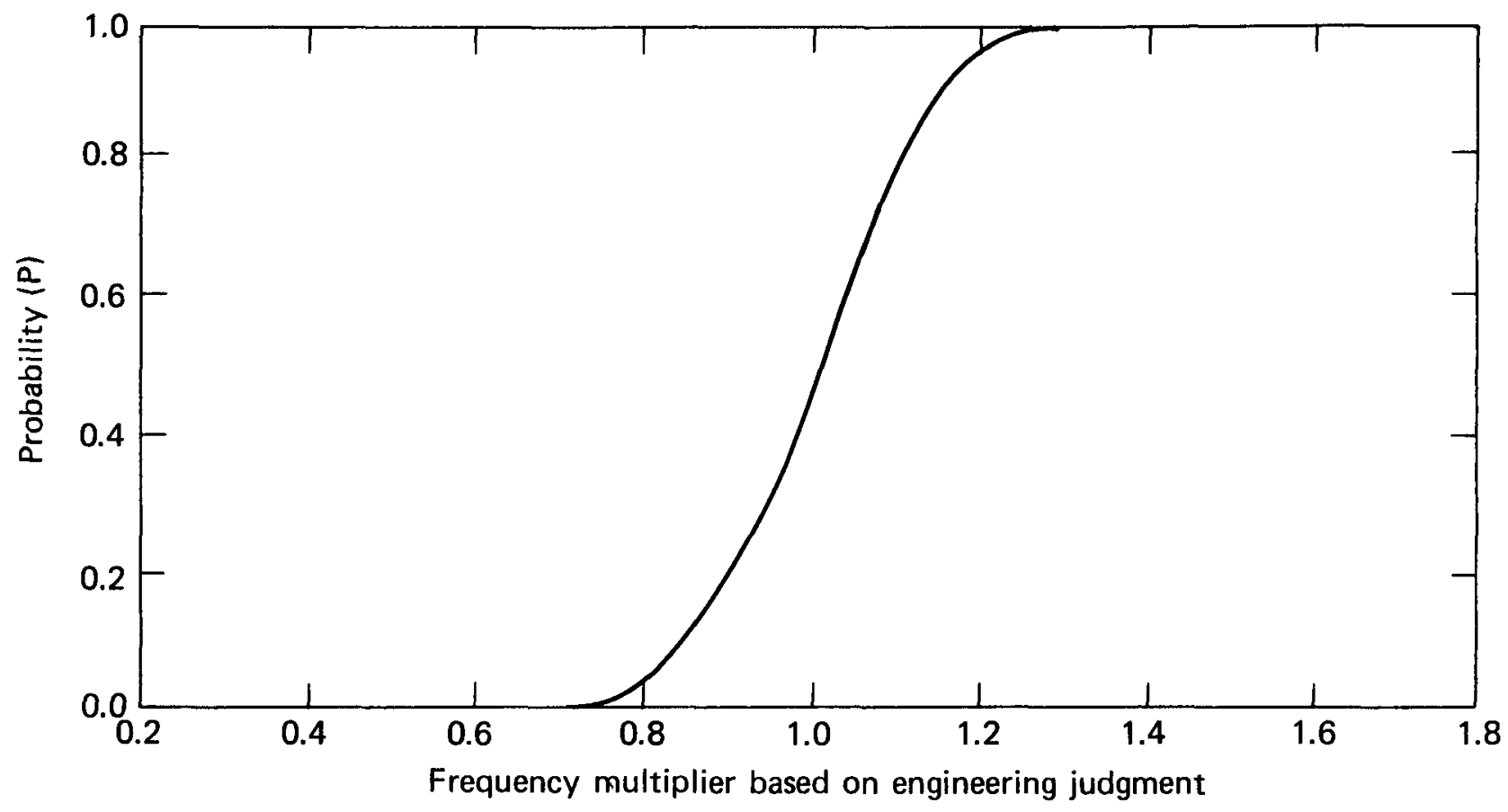

FIG. 5. Cumulative Distribution Function (CDF) on frequency modifier based on engineering judgment. 


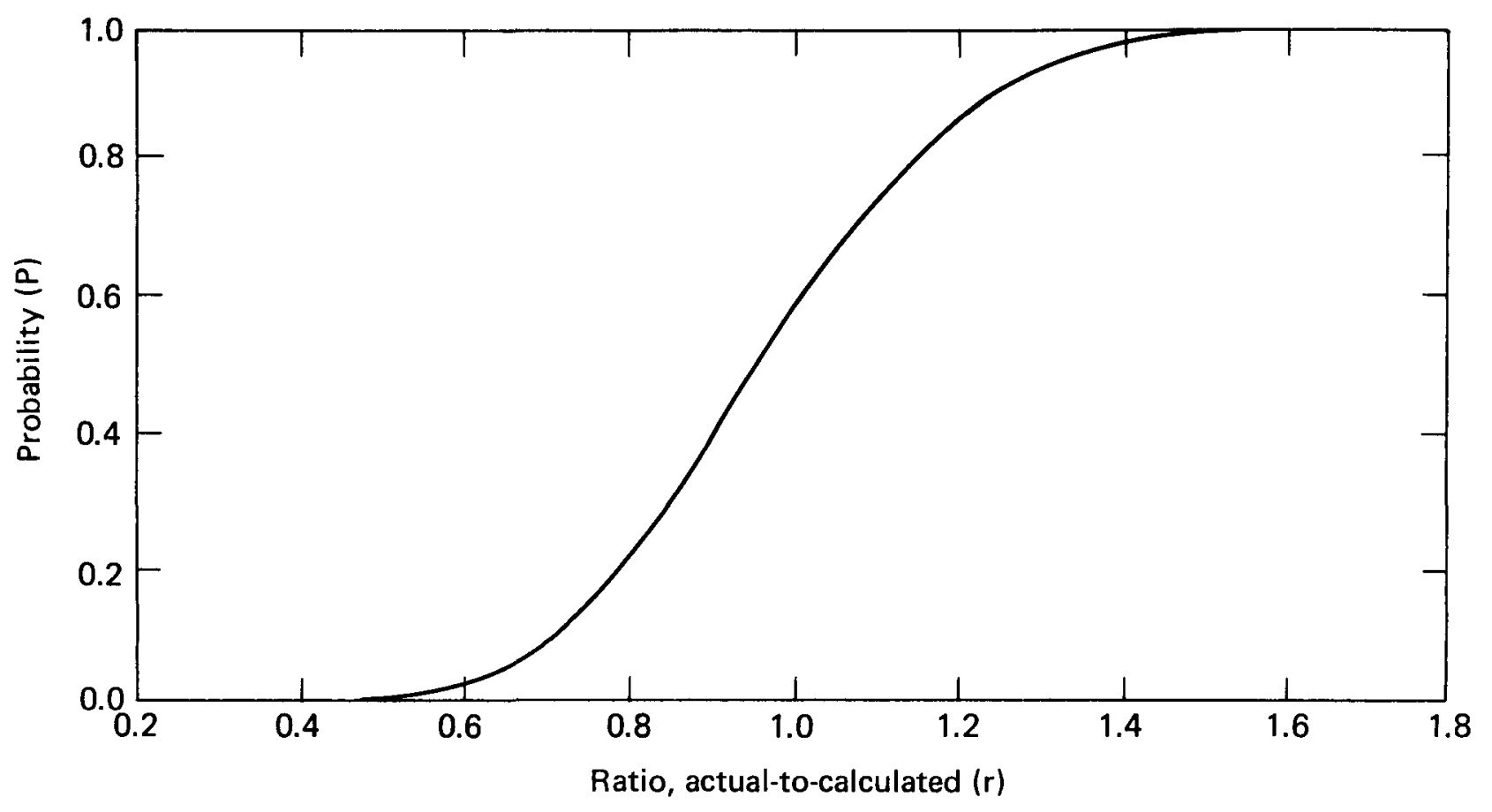

$\begin{array}{cc}\frac{p}{0.01} & \frac{r}{0.5854} \\ 0.05 & 0.6726 \\ 0.10 & 0.7243 \\ 0.15 & 0.7615 \\ 0.25 & 0.8200 \\ 0.35 & 0.8700 \\ 0.45 & 0.9176 \\ 0.50 & 0.9416\end{array}$

$\begin{array}{cc}\frac{p}{0.55} & r \\ 0.65 & 1.0190 \\ 0.75 & 1.0813 \\ 0.85 & 1.1647 \\ 0.90 & 1.2247 \\ 0.95 & 1.3195 \\ 0.99 & 1.5176\end{array}$

FIG. 6. Cumulative Distribution Function (CDF) on stiffness ratios. 
analysis process. Their effects were compounded. Figure 7 shows the resulting function. It was this distribution which served as the basis for a random sampling on frequency.

Variability in the energy dissipation characteristics of the structure was incorporated into the analysis through variations in the values of modal damping. Modal damping was assumed to be normally distributed with a mean value of 0.05 or 58 of critical and a coefficient of variation of 0.1

The distributional shapes of both frequency and damping were selected to be identical to those used in Ref. 5. This permits a direct comparison of the results. However, the parameter selections and their variability do not reflect information available in the interim.

\subsubsection{Analysis Process}

The calculational procedure for the Best Estimate analysis is shown in Fig. 8. As in the Evaluation Method, repeated time history analyses were performed. In-structure response spectra at points of interest were generated. The excitations, however, were the recorded time histories of motion described in Sec. 2.4.1. Twenty-three sets of three components of motion are shown. This data set was expanded to 46 by first analyzing the structural model assuming that horizontal components 1 and 2 align with the model coordinates $x_{1}$ and $x_{3}$, respectively, and then interchanging them to align 1 with $x_{3}$ and 2 with $x_{1}$. Variations in frequency and damping characteristics were incorporated by sampling from the distributions described in Sec. 2.4.2. A stratified sampling method was used to span the parameter space. The distributions on frequency and damping characteristics were divided into 46 equal probability segments, each representing a probability of 1/46. Pairs of frequencies and damping were selected through the use of a random two-column selection of the parameters listed in Tables 2 and 3 . The resulting pairs are listed in Table 4. After completion of the repeated analyses, the mean and MSD response spectra were computed for comparison purposes. 

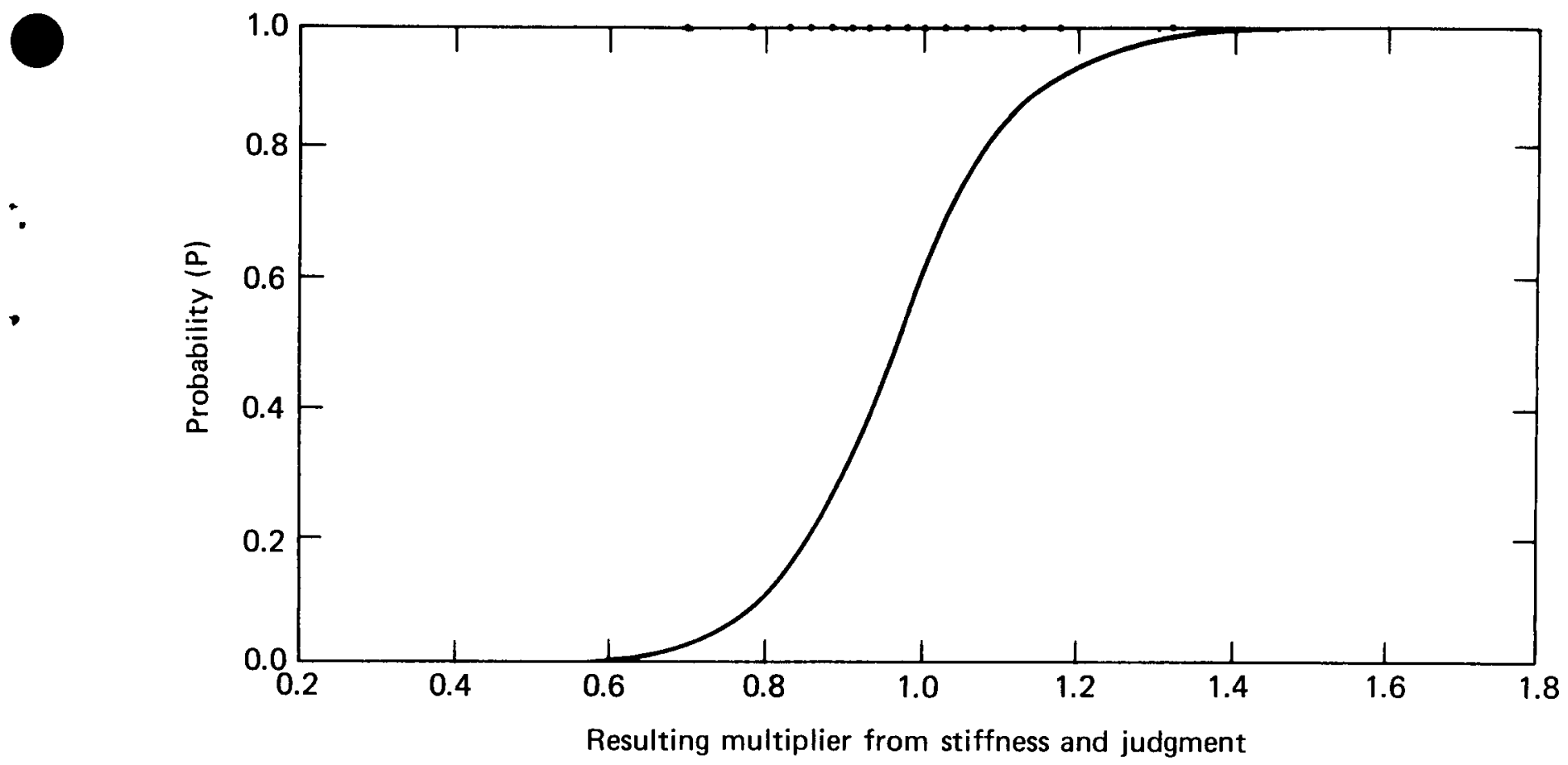

FIG. 7. Expected CDF on frequency modifier. 


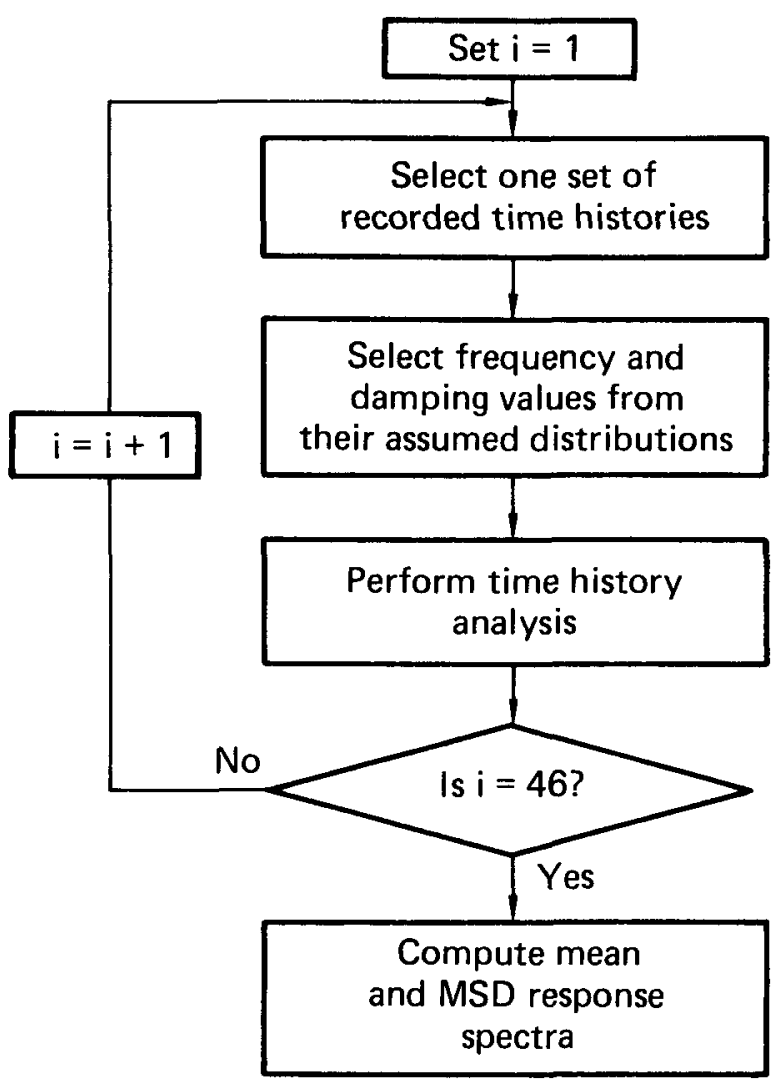

FIG. 8. Flow diagram for the BE calculations. 
TABLE 2. Values of damping used in BE analysis.

\begin{tabular}{rlll}
1. & 0.03805 & 24. & 0.05014 \\
2. & 0.04074 & 25. & 0.05041 \\
3. & 0.04197 & 26. & 0.05068 \\
4. & 0.04283 & 27. & 0.05096 \\
5. & 0.04353 & 28. & 0.05124 \\
6. & 0.04411 & & \\
7. & 0.04463 & 29. & 0.05152 \\
8. & 0.04509 & 30. & 0.05181 \\
9. & 0.04551 & 31. & 0.05210 \\
10. & 0.04591 & 32. & 0.05241 \\
& & 33. & 0.05272 \\
11. & 0.04628 & & \\
12. & 0.04663 & 34. & 0.05304 \\
13. & 0.04697 & 35. & 0.05337 \\
14. & 0.04728 & 36. & 0.05372 \\
15. & 0.04759 & 37. & 0.05409 \\
& & 38. & 0.05449 \\
16. & 0.04790 & & \\
17. & 0.04819 & 39. & 0.05491 \\
18. & 0.04848 & 40. & 0.05537 \\
19. & 0.04876 & 41. & 0.05589 \\
20. & 0.04904 & 42. & 0.05647 \\
& & 43. & 0.05717 \\
21. & 0.04931 & & \\
22. & 2.04959 & 44. & 0.05803 \\
23. & 0.04986 & 45. & 0.05926 \\
\hline & & 46. & 0.06195
\end{tabular}


TABLE 3. Values of frequency modifier used in $\mathrm{BE}$ analysis.

\begin{tabular}{clll}
\hline & & & \\
1. & 0.6975 & 24. & 0.9720 \\
2. & 0.7393 & 25. & 0.9795 \\
3. & 0.7640 & 26. & 0.9870 \\
4. & 0.7827 & 27. & 0.9957 \\
5. & 0.7978 & 28. & 1.0027 \\
6. & 0.8124 & & \\
7. & 0.8234 & 29. & 1.0106 \\
8. & 0.8362 & 30. & 1.0208 \\
9. & 0.8453 & 31. & 1.0292 \\
10. & 0.8577 & 32. & 1.0372 \\
& & 33. & 1.0479 \\
11. & 0.8651 & & \\
12. & 0.8753 & 34. & 1.0562 \\
13. & 0.8846 & 35. & 1.0678 \\
14. & 0.8922 & 36. & 1.0768 \\
15. & 0.8998 & 37. & 1.0891 \\
& & 38. & 1.1017 \\
16. & 0.9083 & & \\
17. & 0.9163 & 39. & 1.1154 \\
18. & 0.9246 & 40. & 1.1306 \\
19. & 0.9321 & 41. & 1.1441 \\
20. & 0.9408 & 42. & 1.1639 \\
& & 43. & 1.1820 \\
21. & 0.9486 & & \\
22. & 0.9562 & 44. & 1.2102 \\
23. & 0.9628 & 45. & 1.2494 \\
\hline & & 46. & 1.3195 \\
\hline
\end{tabular}


TABLE 4. Pairs of damping and frequency modifiers used in BE analys is.

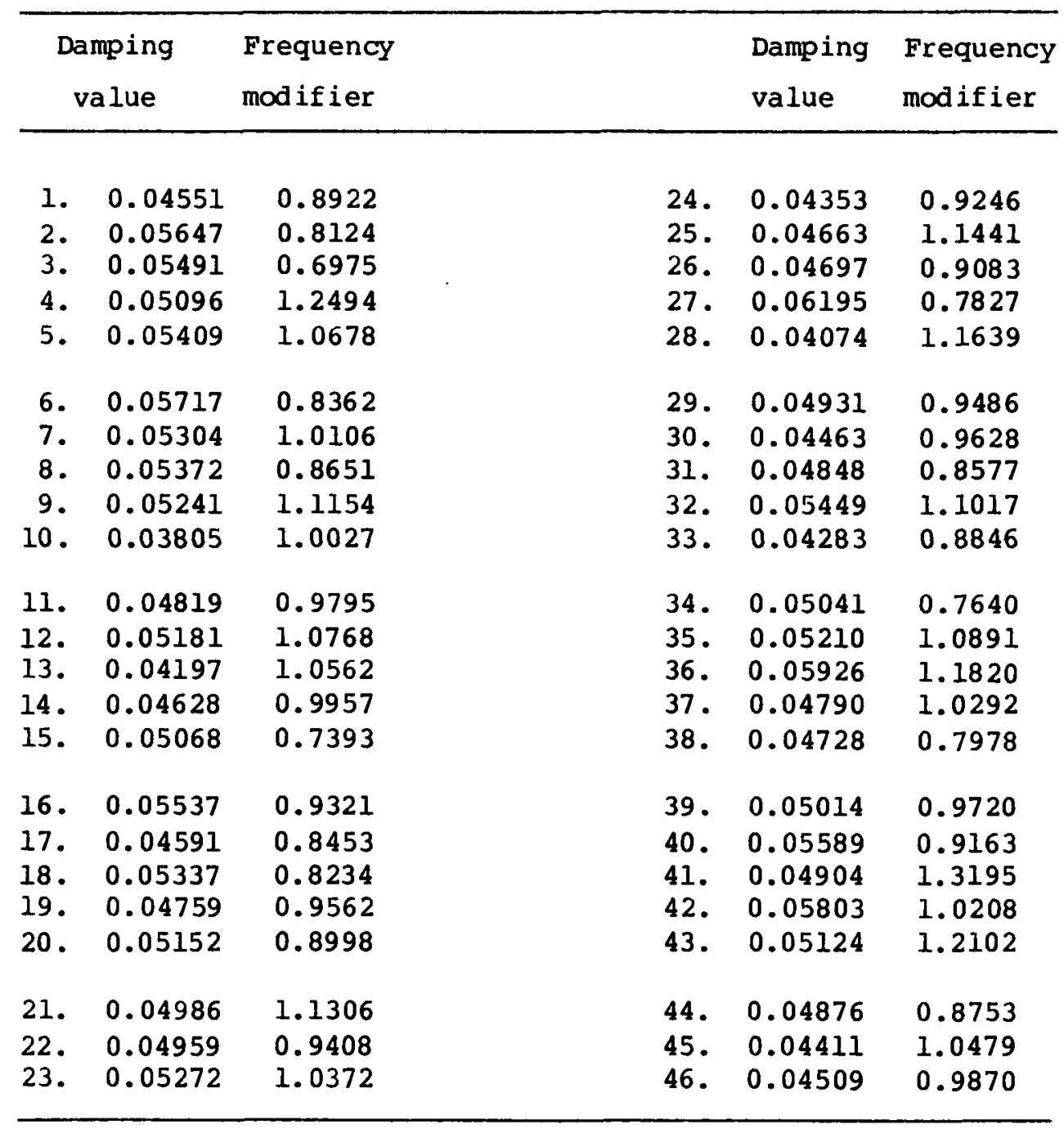




\subsection{COMPUTER ANALYSIS}

The computer program used in the present investigation was an extension of the program LUST developed and used in the studies of Ref. 4. The extended version is denoted LUSTE, an acronym for Limited Understanding of the Statistics of Transients with Extension. A review of several basic elements of LUSTE is appropriate.

LUSTE was assembled using the SAP IV computer program as a basis for the dynamic response calculations and the International Mathematical and Statistical Library of statistical routines. Graphic display capability unique to the Lawrence Livermore Laboratory computer system was incorporated.

LUSTE minimizes the chance for human error in data handling by automating the different stages of the calculations. One execution of LUSTE completes the analysis.

The large amount of data is output in graphical form. Twenty-seven different types of computer plots are available as described in Appendix $A$ and displayed in Appendix B.

Response spectra were computed at 111 frequency points between 0.2 and $33 \mathrm{~Hz}$ and one additional value at $100 \mathrm{~Hz}$. Excluding the value at $100 \mathrm{~Hz}$, frequency points were selected according to the rule $\mathrm{f}_{\mathrm{i}+1}=1.048 \mathrm{f}_{\mathrm{i}}$ with $\mathrm{f}_{1}=0.2 \mathrm{~Hz}$. This yields $\mathrm{f}_{i+3}=1.15 \mathrm{f}_{i}$ and permits an automated scheme for broadening of response spectra. Note that adjacent frequency points were less than 58 apart. Automation of this type of calculation was essential. 


\section{RESULTS}

\subsection{GENERAL}

The analysis procedures for the Best Estimate (BE) and Evaluation Method (EM) calculations were described in Sections 2.4 .3 and 2.3 .3 , respectively. The calculations were performed with the computer program LUSTE (Sec. 2.5). The principal dynamic response quantities of interest in this investigation are in-structure response spectra--individual, mean, and mean-plus-one-standard-deviation (MSD) spectra. The majority of the output from LUSTE is in plot form due to the large amount of data generated. Appendix A describes the types of plots produced. Appendix B contains an example of each plot.

Response spectra were generated at node points 2 and 6 of the structural model (Fig. 2). Node point 6 lies at the top of the structure and typically has the largest response. Node point 2 lies at an intermediate elevation. Response spectra were generated in two horizontal directions and the vertical direction. Results are shown herein for one horizontal direction (denoted direction 1) and the vertical direction (denoted direction 2). for node point 6. The response in the other horizontal direction is similar to the first and not shown. The response at node point 2 is similar to node point 6 . The principal results for the individual Best Estimate and Evaluation Method analyses are contained in Section 3.2. Comparisons of the BE-EM type are discussed in Section 3.3.

\subsection{BE AND EM RESPONSE}

Figures 9 through 14 show results from the Evaluation Method analysis. Figures 9 and 10 contain in-structure response spectra at node point 6 , direction 1 and direction 2, respectively. Forty-four curves are plotted corresponding to the response due to each of the 44 synthetic time histories. As discussed in section 2.3.3, each of the 16 horizontal time histories was applied independently in the two horizontal directions and each of the 12 vertical time histories were applied in the vertical direction to yield 44 responses $(16+16+12=44)$. Therefore, Figs. 9 and 10 contain the basic 
data for the Evaluation Method. These raw spectra were combined by the SRSS rule and then broadened which resulted in 3072 spectral values for each frequency point. All possible combinations were considered $(16 \times 16 \times 12=$ 3072). Figures 11 and 12 display the results of the process. The means and the extremes of the combined spectra are shown. Five curves are plotted in each figure and described here in order of increasing magnitude. The lowest curve (dotted) is a compilation of the minimum spectral values before combination, i.e., Fig. 11 (Fig. 12) shows the minimum values from Fig. 9 (Fig. 10). The next highest curve shows the minimum spectral values from the 3072 combined spectra. The middle curve (distinguished by the $\mathbf{N}$ over print) is the mean of the 3072 combined spectra. At each spectral frequency, the mean was calculated as the simple arithmetic average of the 3072 spectra values. The two remaining higher curves display the maximum spectral values: the dotted curve shows the maxima for the raw data (Figs. 9 and 10); and the solid curve the maxima for the combined spectra. Figures 13 and 14 repeat the plot of the mean response spectra of the smoothed, broadened, and SRSS combined spectra. The corresponding 958 confidence intervals, assuming a normal distribution, are shown by the dotted curves. Due to the large number of combined spectra comprising the data base, the typical confidence intervals about the estimate of the mean are quite narrow. While the classical statistical meaning and interpretation of such narrow confidence bands is clear, their usefulness for engineering purposes is not.

Figures 15 through 22 show results from the Best Estimate analysis. Figures 15 and 16 contain in-structure response spectra at node point 6 , direction 1 and direction 2, respectively. Forty-six curves are plotted, corresponding to the response due to the 46 sets of recorded time histories (Sec. 2.4). The scatter of data in the figures is due to variability in time histories and structural dynamic characteristics (frequency and damping). Figures 15 and 16 contain the basic data for the Best Estimate analysis and are analogous to Figs. 9 and 10. Figures 17 and 18 display the MSD (curve with $\mathbf{N}$ over print) response spectra and the extremes (minima and maxima). Figures 19 and 20 show the means of the 46 spectra and the corresponding 958 confidence intervals, assuming a normal distribution for node point 6 , 
direction 1 and direction 2, respectively. The mean curves of Figs. 19 and 20 represent the Best Estimate of the in-structure response spectra due to three-dimensional real earthquakes. Figs. 21 and 22 repeat the plot of the MSD response spectra shown in Figs. 17 and 18 and include 958 confidence intervals.

\subsection{BE-EM RESPONSE COMPARISONS}

The comparison of the Best Estimate and Evaluation Method response is performed by the computation of two quantities: Factor of Comparison (FOC) and the Probability of Exceedance (POE). The Factor of Comparison for instructure response spectra is the quotient of the BE and EM computed spectra, frequency point by frequency point. The Probability of Exceedance is the probbility a $\mathrm{BE}$ response spectral ordinate exceeds the corresponding EM ordinate. The POE was computed by comparing each of the 3072 combined spectra with the first of the 46 spectra from the BE analysis and counting the number of times the latter exceeded the former to yield $n_{1}$. The process was repeated for the remaining 45 spectra to yield $n$, where $n=n_{1}+\cdots+n_{46}$. The POE was calculated as $\mathrm{n} /(46 \times 3072)$. The calculation was performed separately for each frequency value.

It is convenient to identify three frequency ranges of the FOC and POE for discussion purposes. A low-frequency range, $0.2 \mathrm{~Hz}$ to about $1.3 \mathrm{~Hz}$, in the past, has been called the "time history" section to emphasize that the differences in this range are primarily due to the time histories themselves. The middle-frequency range, $1.3 \mathrm{~Hz}$ to about $15 \mathrm{~Hz}$, is associated with amplified structural response. The high-frequency range, above $15 \mathrm{~Hz}$, represents differences in the peak accelerations or the Zero Period Amplitude (ZPA). Of principal interest are the latter two frequency ranges; i.e., middle and high. These ranges profoundly influence the design of structures and equipment.

Two sets of FOCs were generated and are shown in Figs. 23, 24, 27, and 28. Figures 23 (direction 1) and 24 (direction 2) show the FOC computed as the quotient of the mean of the EM response spectra and the MSD of the BE response spectra. This comparison reflects the policy used during the 
development of the design response spectra of R.G. 1.60 ; i.e., the resulting design spectra were based on the MSD of the spectra generated from recorded time histories. In addition, the comparison implies this policy is appropriate for a subsequent link, in the SMC. Figure 23 shows the FOC for horizontal response at the top of the structure. In the low-frequency range, the minimum FOC is approximately 1.1. The FOC in the mid-frequency range varies from 1.4 to 3.5. In the high-frequency range, the FOC is approximately 1.8 or greater. Hence, the design objective in the frequency range of most interest has been exceeded on the average by a factor of 2 provided the assumptions made herein apply. These assumptions include the definition of the $\mathrm{BE}$ and $\mathrm{EM}$ procedures and the extension of the MSD policy to multiple links in the SMC. Figure 24 shows similar results for the vertical response.

Figures 25 (direction 1 ) and 26 (direction 2) show the POEs corresponding to the results of Figures 23 and 24 respectively. The POEs have large variations over the frequency range. In the mid-frequency range, no pOEs are greater than 0.1 .

Figures 27 (direction 1) and 28 (direction 2) show the FOC computed as the quotient of the means of the $E M$ and $B E$ response spectra. Such a comparison reflects an alternative design objective and is given here for illustrative purposes. The FOCs are obviously higher throughout the frequency range.

\subsection{COMPARISON OF COUPLED AND UNCOUPLED RESPONSE}

To demonstrate the coupling effects between two links in the SMC, the results of Ref. 4 are compared with the present case. As summarized in Sec. 1.3, the study of Ref. 4 encompassed only the seismic input phase of the SMC; i.e., synthetic vs real time histories. Figures 29 through 32 show a comparison of FOCs as computed for seismic input alone (Ref. 4) and seismic input plus structural uncertainty. The comparison is based on Focs computed from means of the BE and EM response. Node points 2 and 6 for horizontal and vertical degrees of freedom are shown. As expected, this comparison shows a general trend of increasing FOCs as additional links in the SMC are considered (the results of this study suggest greater Focs than in Ref. 4). Generally, 
there is an average factor of about 1.2 due to this compounding effect. This represents a "compounding of conservatism" as hypothesized. Note that minimums occur at frequencies near the limit of the broadened peaks. This could indicate that the broadening rule used ( \pm 158) may not be accomplishing the desired result. However, further investigation including additional parameter studies would be necessary before a definitive conclusion can be made. 
MATHEMATICAL MODEL FOR MAIN STEAM VALVE HOUSE \& QUENCH SPRAY AREA

KEY $=1$ NODE $=6 \quad$ DIRECTION $=1 \quad$ DT $=0.0100$ SEC $\quad$ CODE $=02 / 15 / 80 R$ STRUCTURAL DAMPING IN ALL MODES 5.0\% AVERAGE DVFV SCALEV $=0.66667$

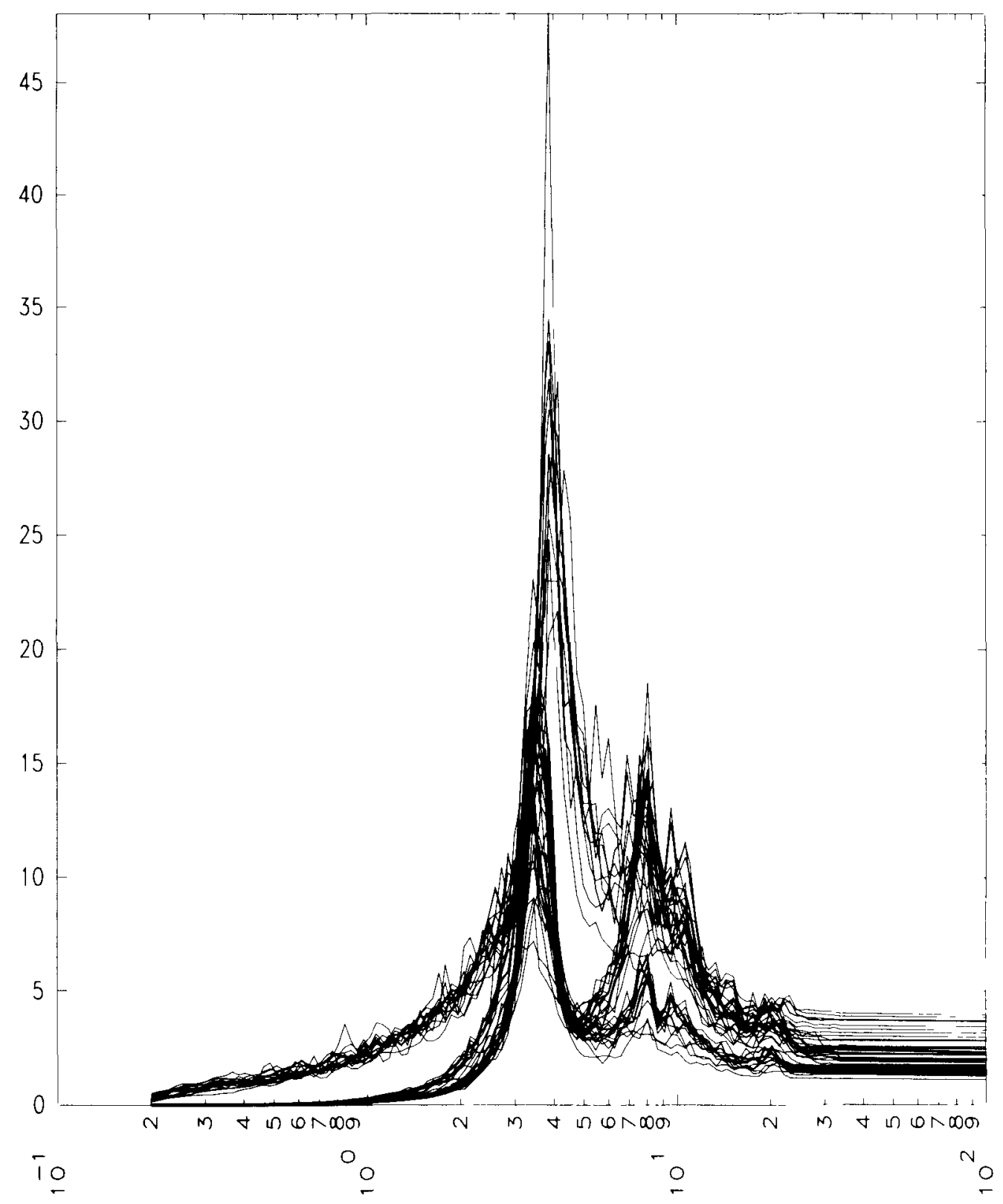

R.G. 1.60 EQ ACCELERATION SPECTRA (GEES) VS FREQUENCY (HZ) $2.0 \%$ DAMPING

FIG. 9. Mathematical model for main steam valve house and quench spray area $($ key $=1$, node $=6$, direction $=1)$. 
MATHEMATICAL MODEL FOR MAIN STEAM VALVE HOUSE \& QUENCH SPRAY AREA

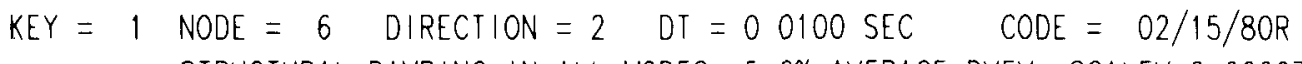
STRUCTURAL DAMPING IN ALL MODES 5 0\% AVERAGE DVFV SCALEV=0 66667

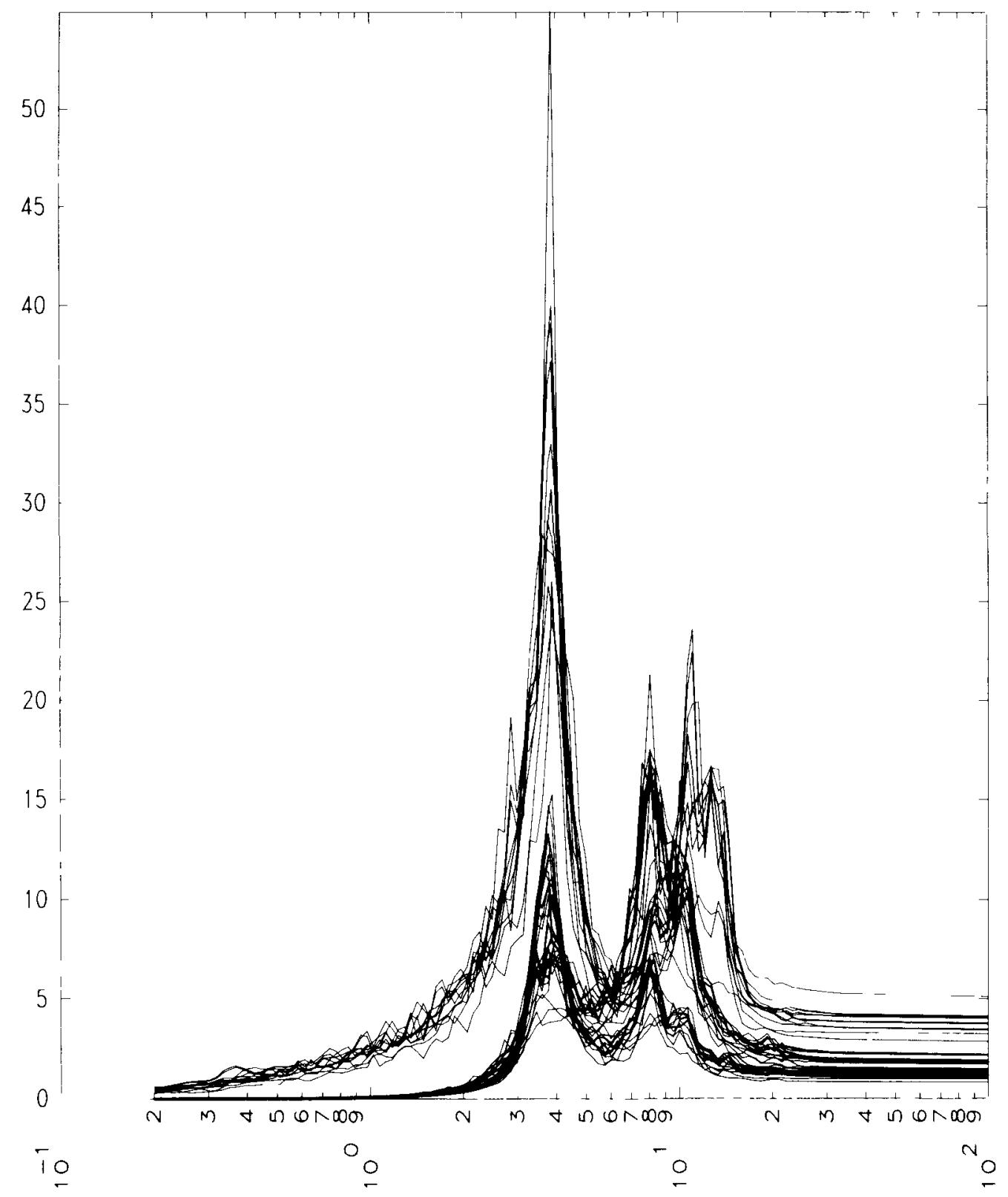

RG 160 EQ ACCELERATION SPECTRA (GEES) VS FREQUENCY (HZ) $20 \%$ DAMPING

FIG. 10. Mathematical model for main steam valve house and quench spray area $($ key $=1$, node $=6$, direction $=2$ ). 
MATHEMUTICAL MODEL FOR MAIN STEAM VALVE HOUSE \& QUENCH SPRAY AREA

KEY $=3$ NODE $=6 \quad$ DIRECTION $=1 \quad$ DT $=0.0100 \mathrm{SEC} \quad$ CODE $=02 / 15 / 80 \mathrm{R}$ STRUCTURAL DAMPING IN ALL MODES 5.0\% AVERAGE DVFV BROADENED $15 \%$

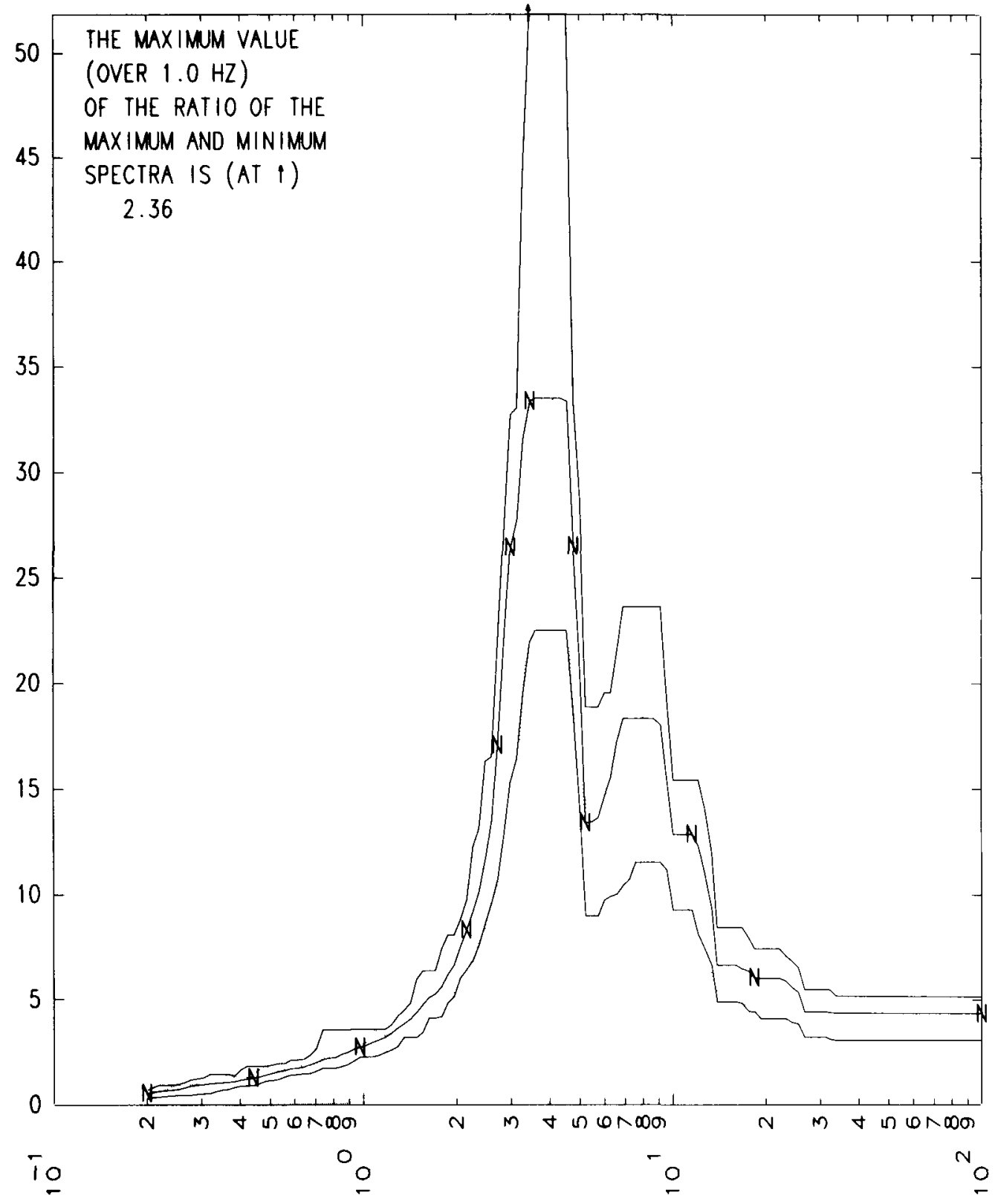

MAX. MEAN + MIN. ACC. SPECTRA (RG EQ,GEES) VS FREQUENCY (HZ) $2.0 \%$ DAMP

FIG. 11. Mathematical model for main steam valve house and quench spray area $($ key $=3$, node $=6$, direction $=1)$. 
MATHEMATICAL MODEL FOR MAIN STEAM VALVE HOUSE \& QUENCH SPRAY AREA

KEY $=3 \quad$ NODE $=6 \quad$ DIRECTION $=2 \quad$ DT $=0.0100$ SEC $\quad$ CODE $=02 / 15 / 80 \mathrm{R}$ STRUCTURAL DAMPING IN ALL MODES 5.0\% AVERAGE DVFV BROADENED $15 \%$

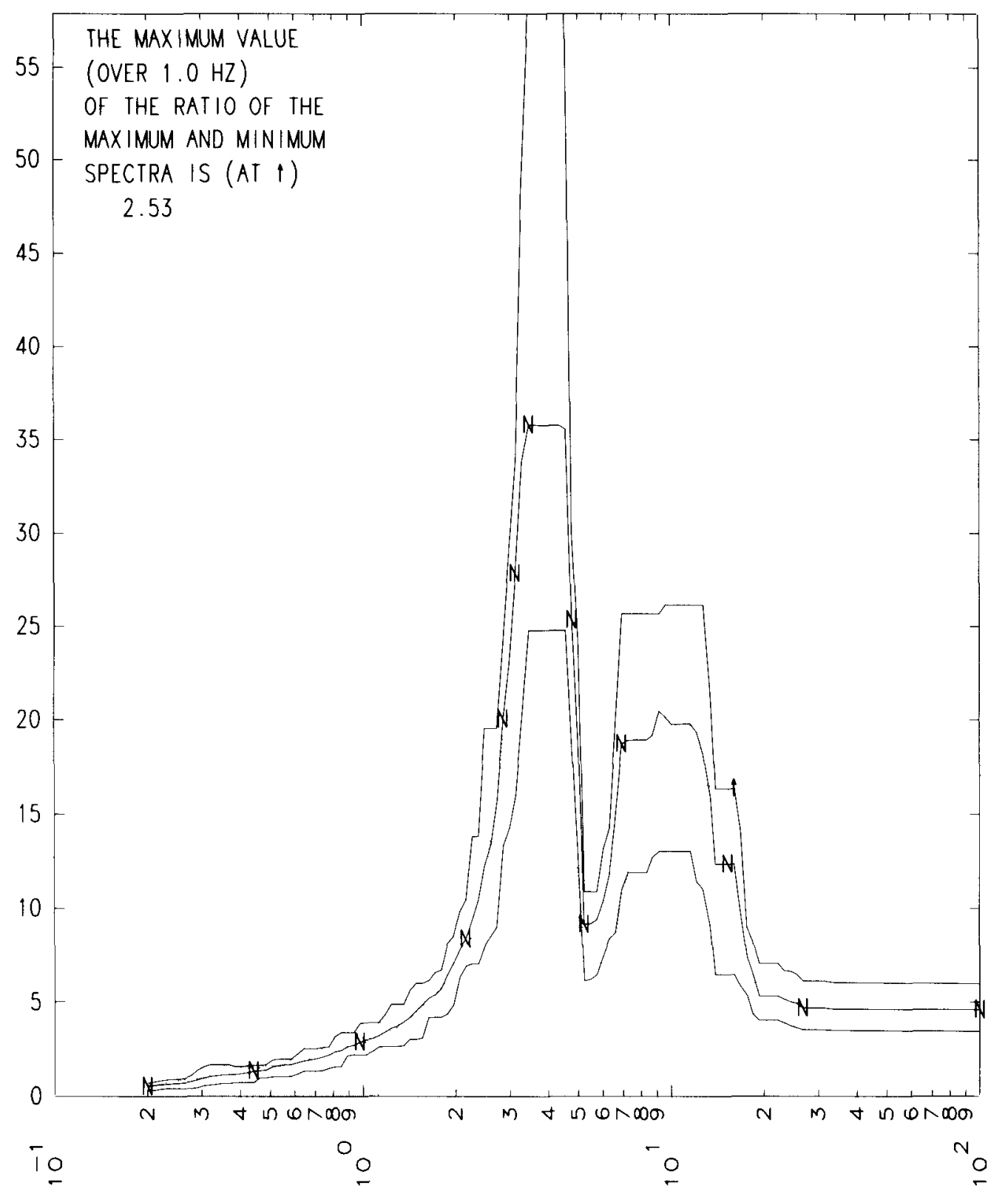

MAX. MEAN + MIN. ACC. SPECTRA (RG EQ,GEES) VS FREQUENCY (HZ) $2.0 \%$ DAMP

FIG. 12. Mathematical model for main steam valve house and quench spray area $($ key $=3$, node $=6$, direction $=2)$. 
MATHEMATICAL MODEL FOR MAIN STEAM VALVE HOUSE \& QUENCH SPRAY AREA

KEY $=8$ NODE $=6 \quad$ DIRECTION $=1 \quad$ DT $=0.0100$ SEC $\quad$ CODE $=02 / 15 / 80 R$ STRUCTURAL DAMPING IN ALL MODES 5.0\% AVERAGE DVFV BROADENED $15 \%$

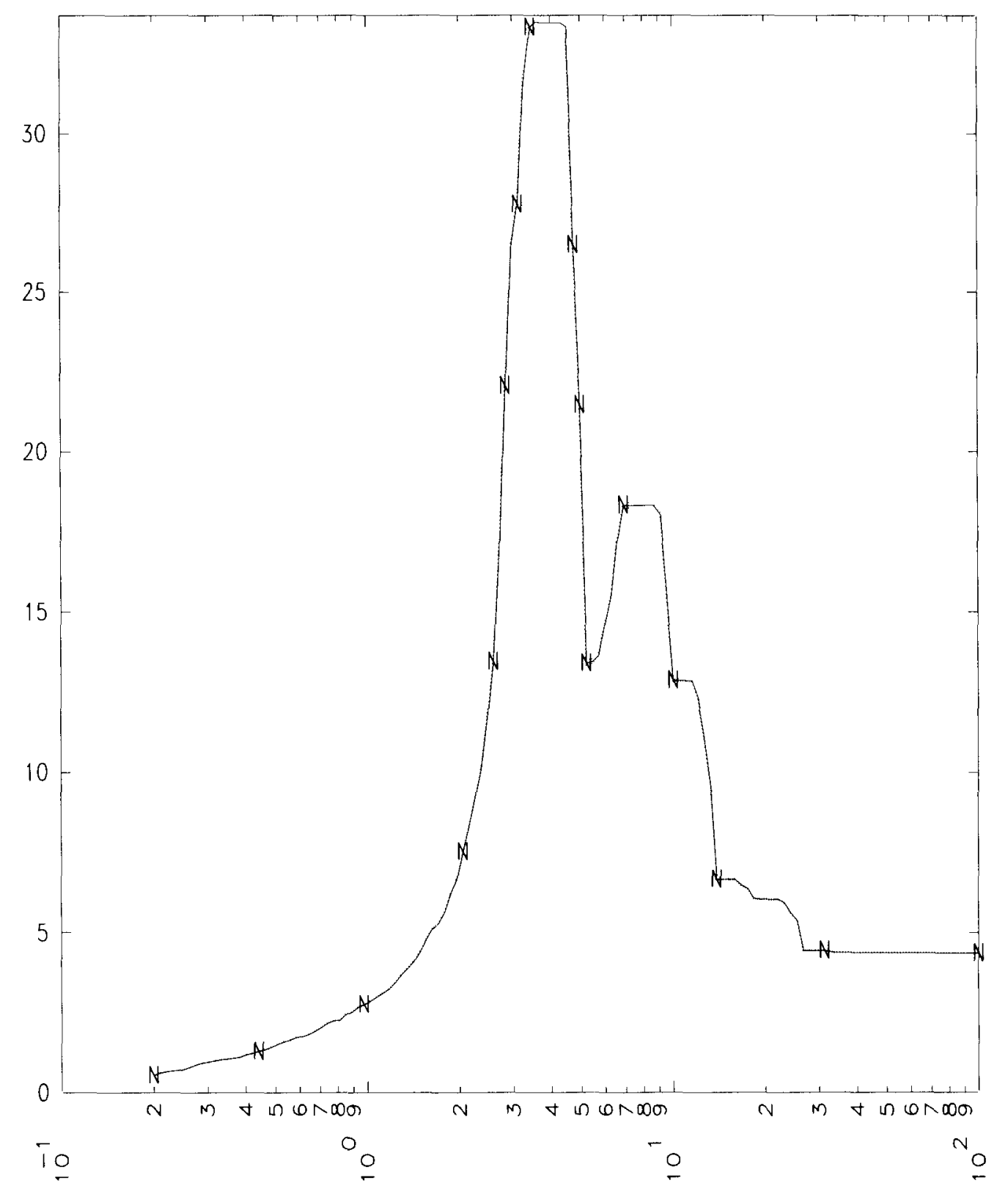

MEAN AND 95\% CONF. LIMIT SPECTRA (RG EQ,GEES) VS FREQ. (HZ) $2.0 \%$ DAMP

FIG. 13. Mathematical model for main steam valve house and quench spray area $($ key $=8$, node $=6$, direction $=1)$. 
MATHEMATICAL MODEL FOR MAIN STEAM VALVE HOUSE \& QUENCH SPRAY AREA

$K E Y=8 \quad$ NODE $=6 \quad$ DIRECTION $=2 \quad$ DT $=0.0100$ SEC $\quad$ CODE $=02 / 15 / 80 R$ STRUCTURAL DAMPING IN ALL MODES 5.0\% AVERAGE DVFV BROADENED $15 \%$

$\because$

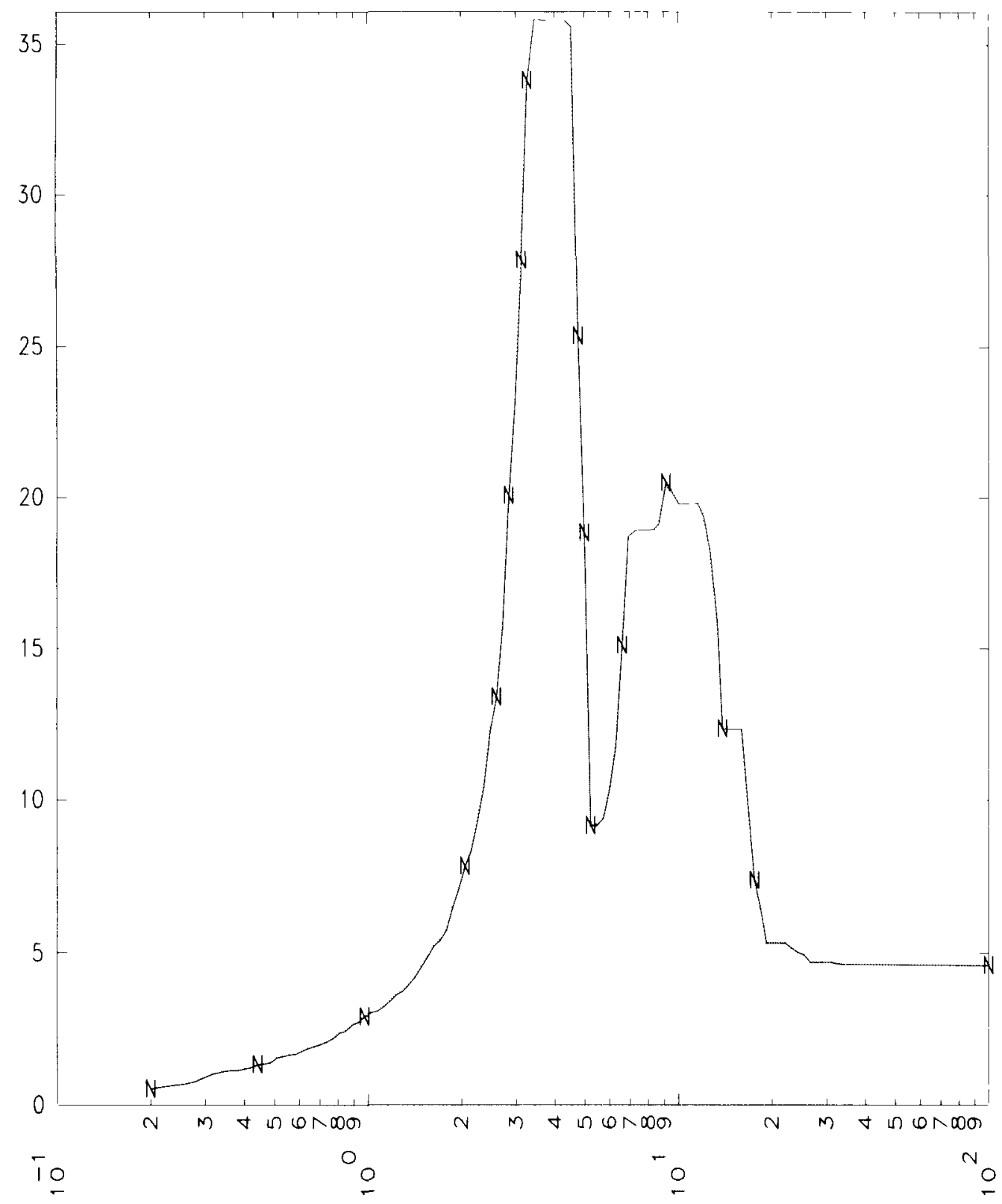

MEAN AND 95\% CONF. LIMIT SPECTRA (RG EQ, GEES) VS FREQ. (HZ) $2.0 \%$ DAMP

FIG. 14. Mathematical model for main steam valve house and quench spray area $($ key $=8$, node $=6$, direction $=2)$. 
MATHEMATICAL MODEL FOR MAIN STEAM VALVE HOUSE \& QUENCH SPRAY AREA

KEY $=10 \quad$ NODE $=6 \quad$ DIRECTION $=1 \quad$ DT $=0.0100 \mathrm{SEC} \quad$ CODE $=02 / 15 / 80 \mathrm{R}$ STRUCTURAL DAMPING IN ALL MODES 5.0\% AVERAGE DVFV

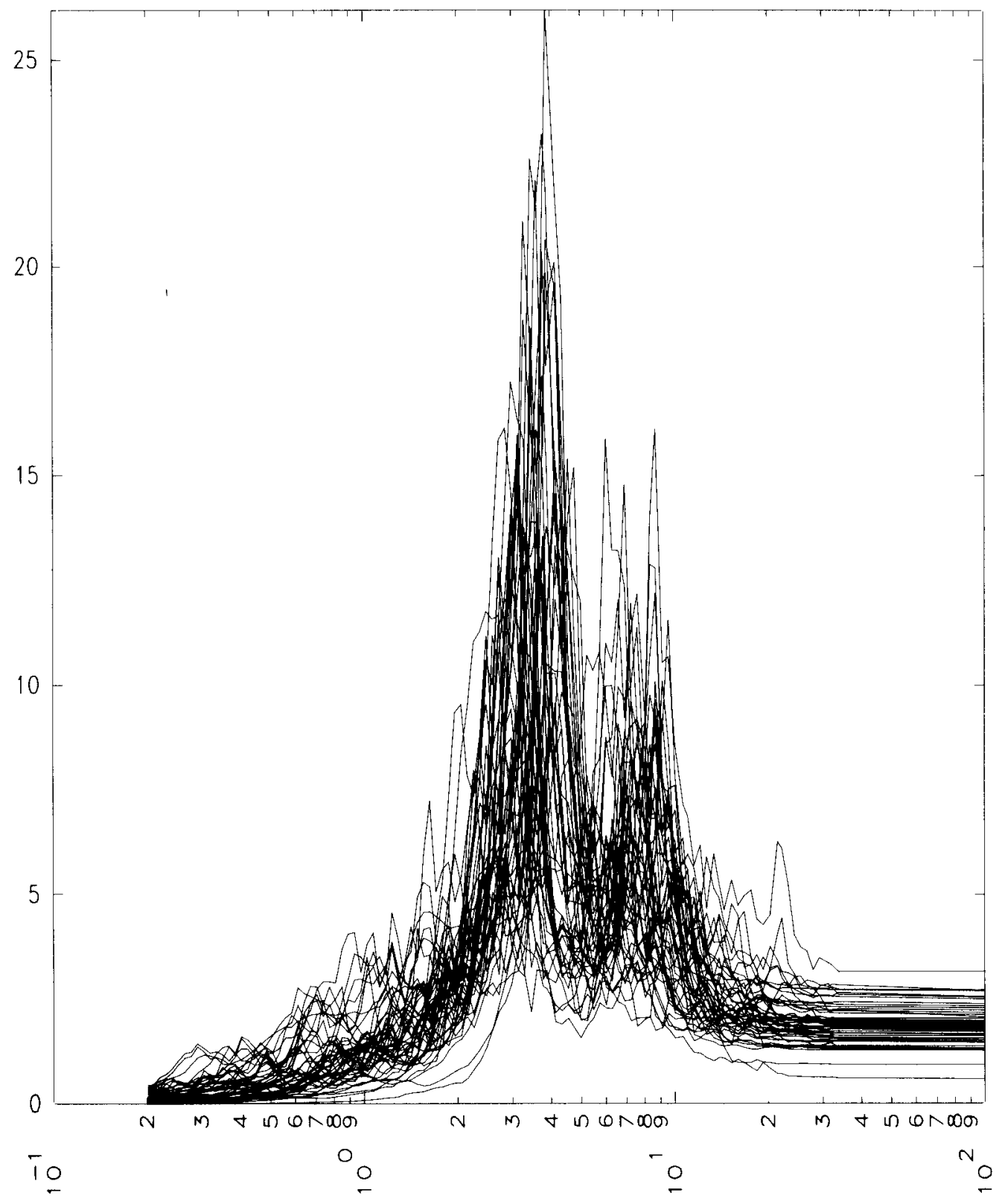

REAL EQ ACCELERATION SPECTRA (GEES) VS FREQUENCY (HZ) $2.0 \%$ DAMPING

FIG. 15. Mathematical model for main steam valve house and quench spray area $($ key $=10$, node $=6$, direction $=1)$. 
MATHEMATICAL MODEL FOR MAIN STEAM VALVE HOUSE \& QUENCH SPRAY AREA

KEY $=10 \quad$ NODE $=6 \quad$ DIRECTION $=2 \quad$ DT $=00100 \mathrm{SEC} \quad$ CODE $=02 / 15 / 80 R$ STRUCTURAL DAMPING IN ALL MODES 5.0\% AVERAGE DVFV

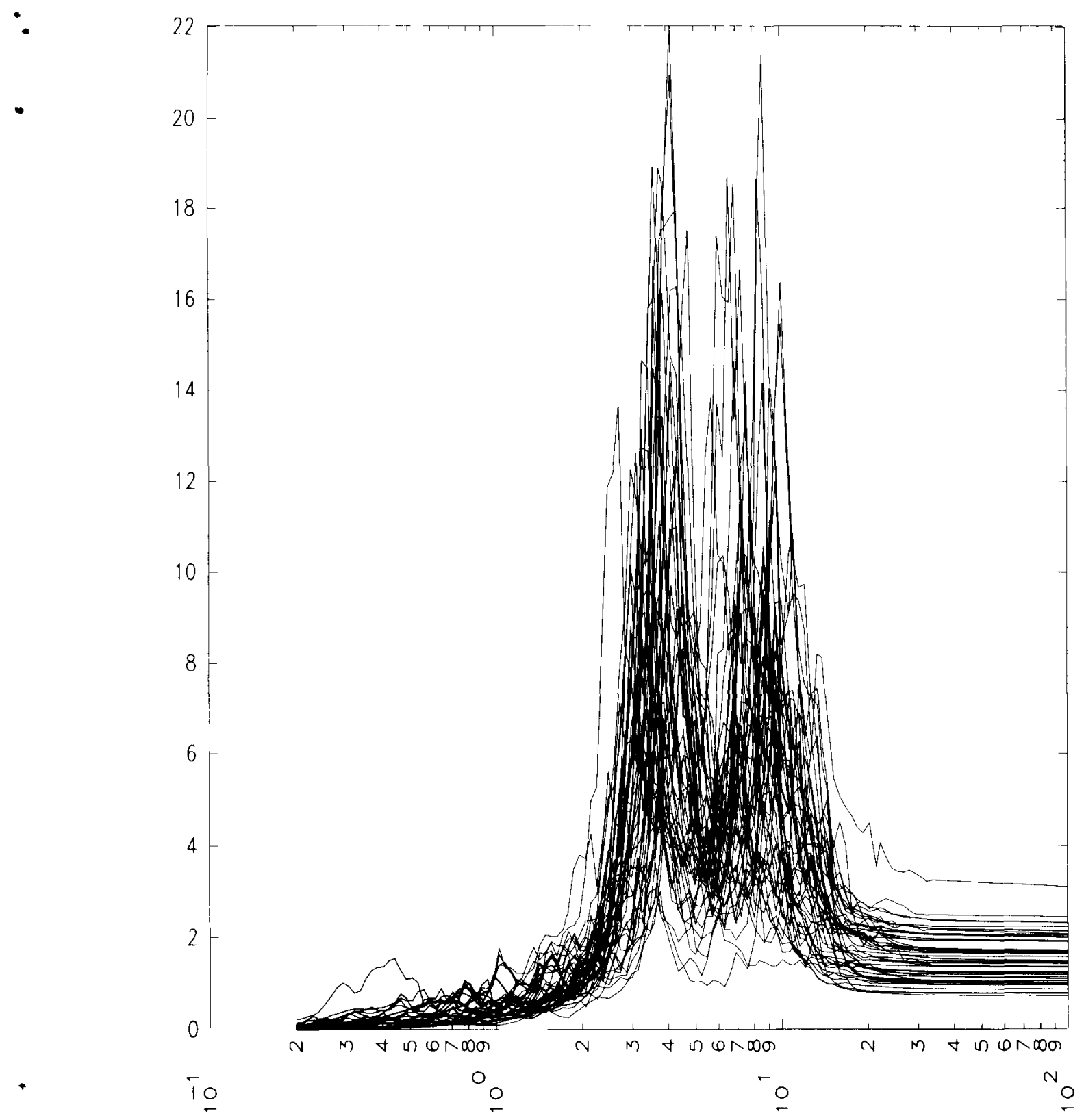

REAL EQ ACCELERATION SPECTRA (GEES) VS FREQUENCY (HZ) $2.0 \%$ DAMPING

FIG. 16. Mathematical model for main steam valve house and quench spray area (key $=10$, node $=6$, direction $=2$ ). 
MATHEMATICAL MODEL FOR MAIN STEAM VALVE HOUSE \& QUENCH SPRAY AREA

KEY $=12 \quad$ NODE $=6 \quad$ DIRECTION $=1 \quad$ DT $=0.0100$ SEC $\quad$ CODE $=02 / 15 / 80 R$ STRUCTURAL DAMPING IN ALL MODES 5.0\% AVERAGE DVFV

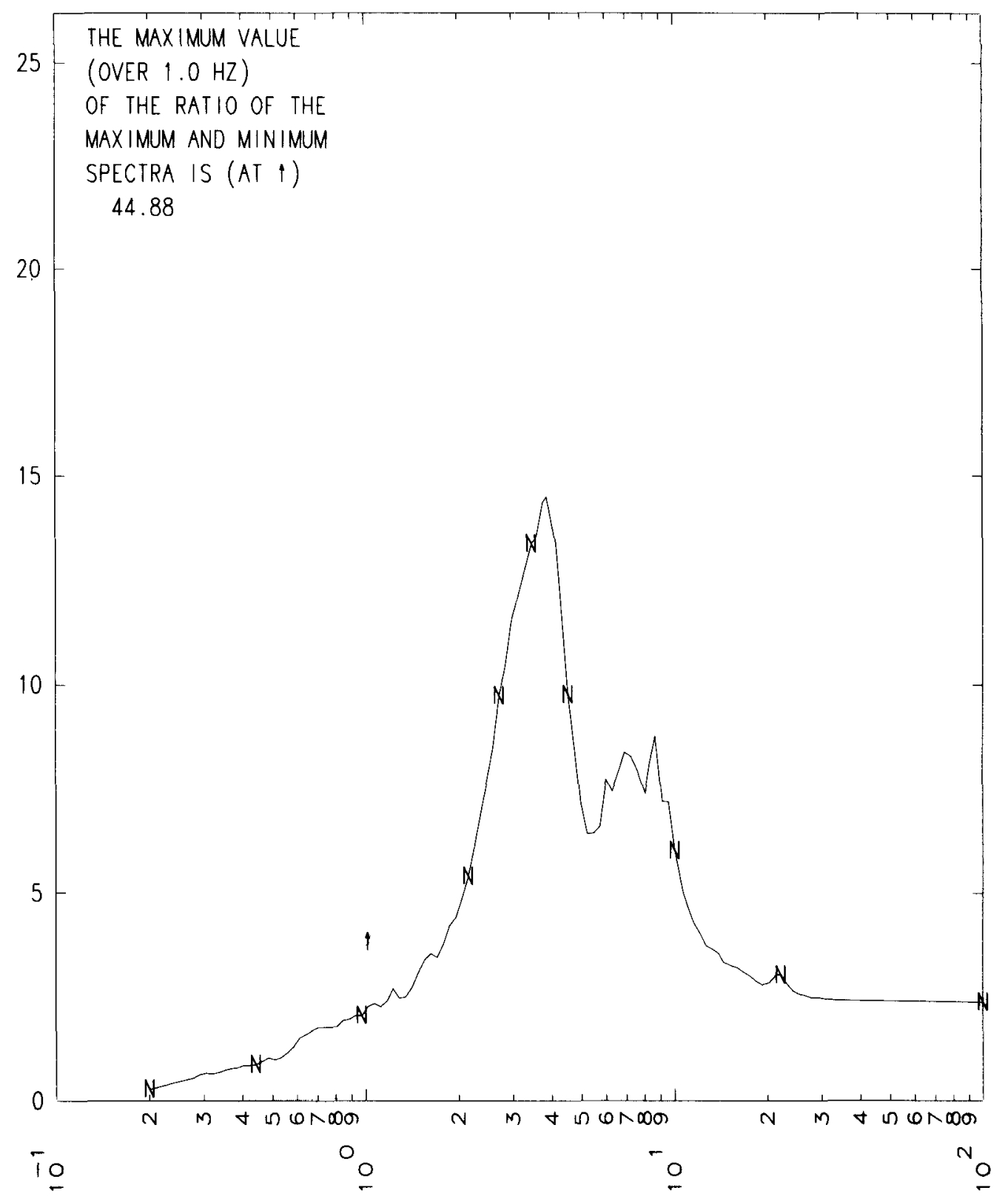

MAX. MSD + MIN. ACC. SPECTRA (REAL EQ,GEES) VS FREQUENCY (HZ) $2.0 \%$ DAMP

FIG. 17. Mathematical model for main steam valve house and quench spray area (key $=12$, node $=6$, direction $=1$ ). 
MATHEMATICAL MODEL FOR MAIN STEAM VALVE HOUSE \& QUENCH SPRAY AREA

KEY $=12 \quad$ NODE $=6 \quad$ DIRECTION $=2 \quad$ DT $=0.0100 \mathrm{SEC} \quad$ CODE $=02 / 15 / 80 \mathrm{R}$ STRUCTURAL DAMPING IN ALL MODES 5.0\% AVERAGE DVFV

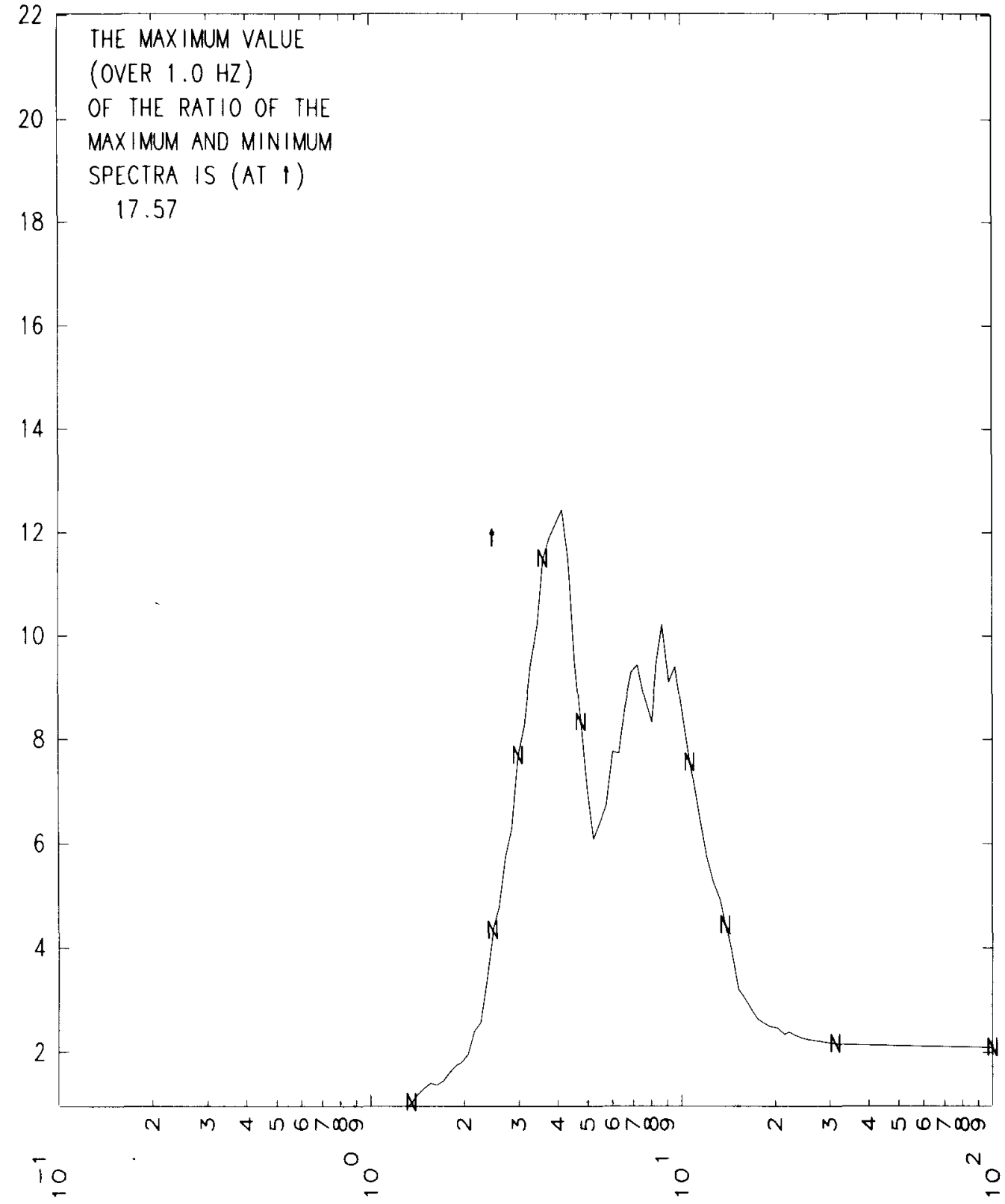

MAX. MSD + MIN. ACC. SPECTRA (REAL EQ, GEES) VS FREQUENCY (HZ) $2.0 \%$ OAMP

FIG. 18. Mathematical model for main steam valve house and quench spray area $($ key $=12$, node $=6$, direction $=2)$. 
MATHEMATICAL MODEL FOR MAIN STEAM VALVE HOUSE \& QUENCH SPRAY AREA

KEY $=17 \quad$ NODE $=6 \quad$ DIRECTION $=1 \quad$ DT $=0.0100 \mathrm{SEC} \quad$ CODE $=02 / 15 / 80 \mathrm{R}$

STRUCTURAL DAMPING IN ALL MODES 5.0\% AVERAGE DVFV

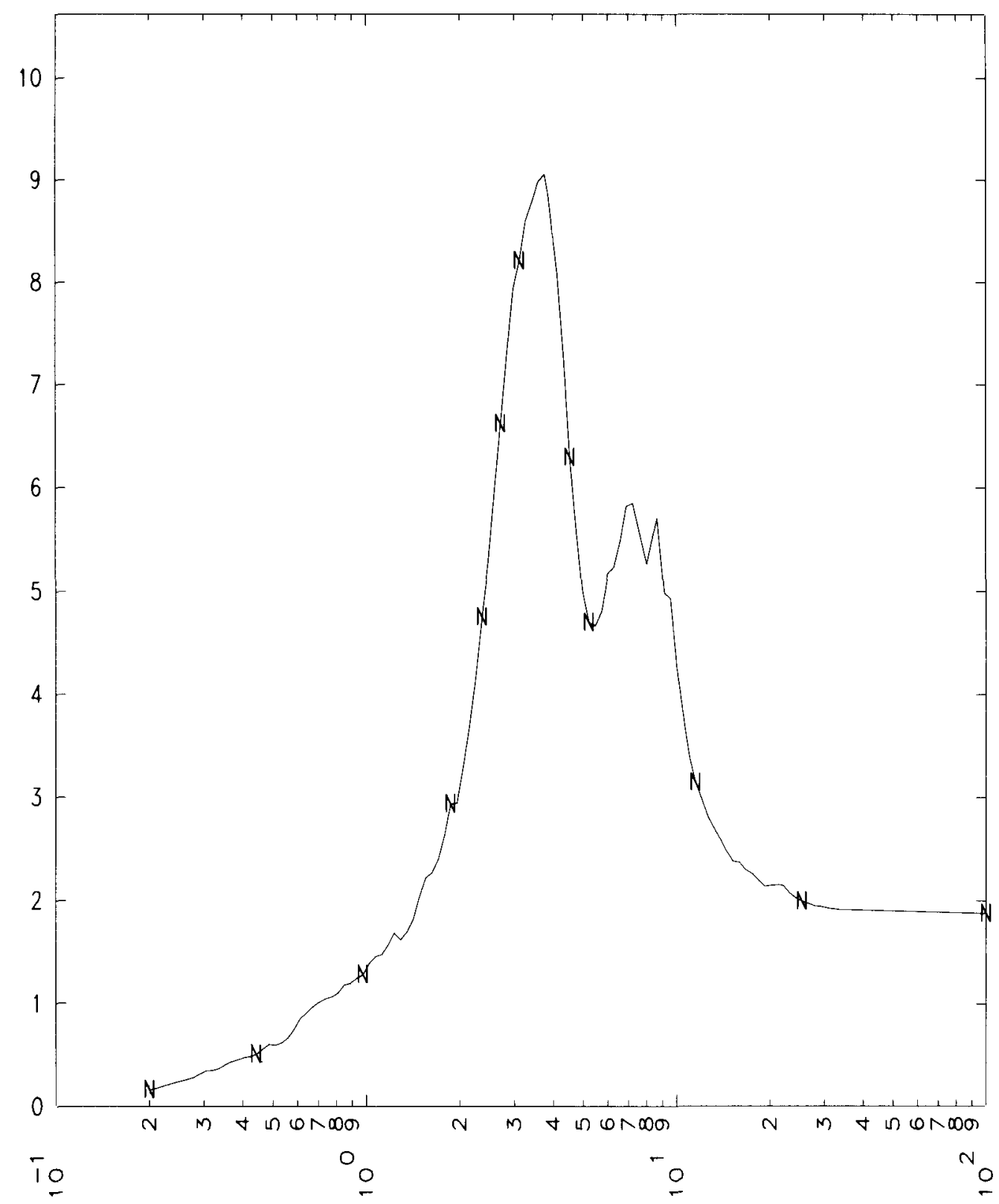

MEAN AND 95\% CONF. LIMIT SPECTRA (REAL EQ,GEES) VS FREQ. (HZ) $2.0 \%$ DAMP

FIG. 19. Mathematical model for main steam valve house and quench spray area $($ key $=17$, node $=6$, direction $=1)$. 
MATHEMATICAL MODEL FOR MAIN STEAM VALVE HOUSE \& QUENCH SPRAY AREA

KEY $=17 \quad$ NODE $=6 \quad$ DIRECTION $=2 \quad$ DT $=0.0100 \mathrm{SEC} \quad$ CODE $=02 / 15 / 80 R$ STRUCTURAL DAMPING IN ALL MODES 5.0\% AVERAGE DVFV

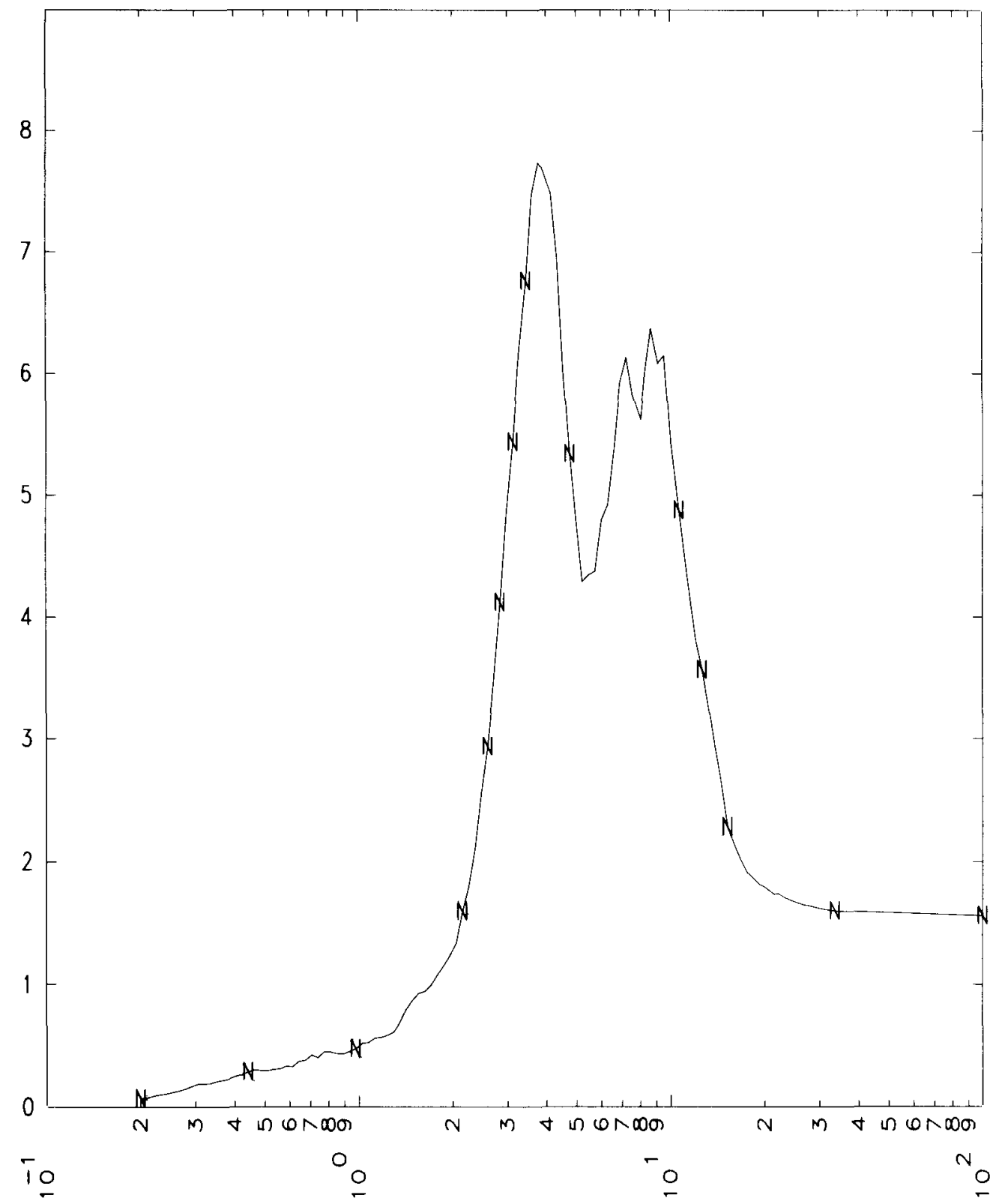

MEAN AND 95\% CONF. LIMIT SPECTRA (REAL EQ,GEES) VS FREQ. (HZ) $2.0 \%$ DAMP

FIG. 20. Mathematical model for main steam valve house and quench spray area $($ key $=17$, node $=6$, direction $=2)$. 
MATHEMATICAL MODEL FOR MAIN STEAM VALVE HOUSE \& QUENCH SPRAY AREA

KEY $=19 \quad \mathrm{NODE}=6 \quad$ DIRECTION $=1 \quad$ DT $=0.0100 \mathrm{SEC} \quad$ CODE $=02 / 15 / 80 \mathrm{R}$ STRUCTURAL DAMPING IN ALL MODES 5.0\% AVERAGE DVFV

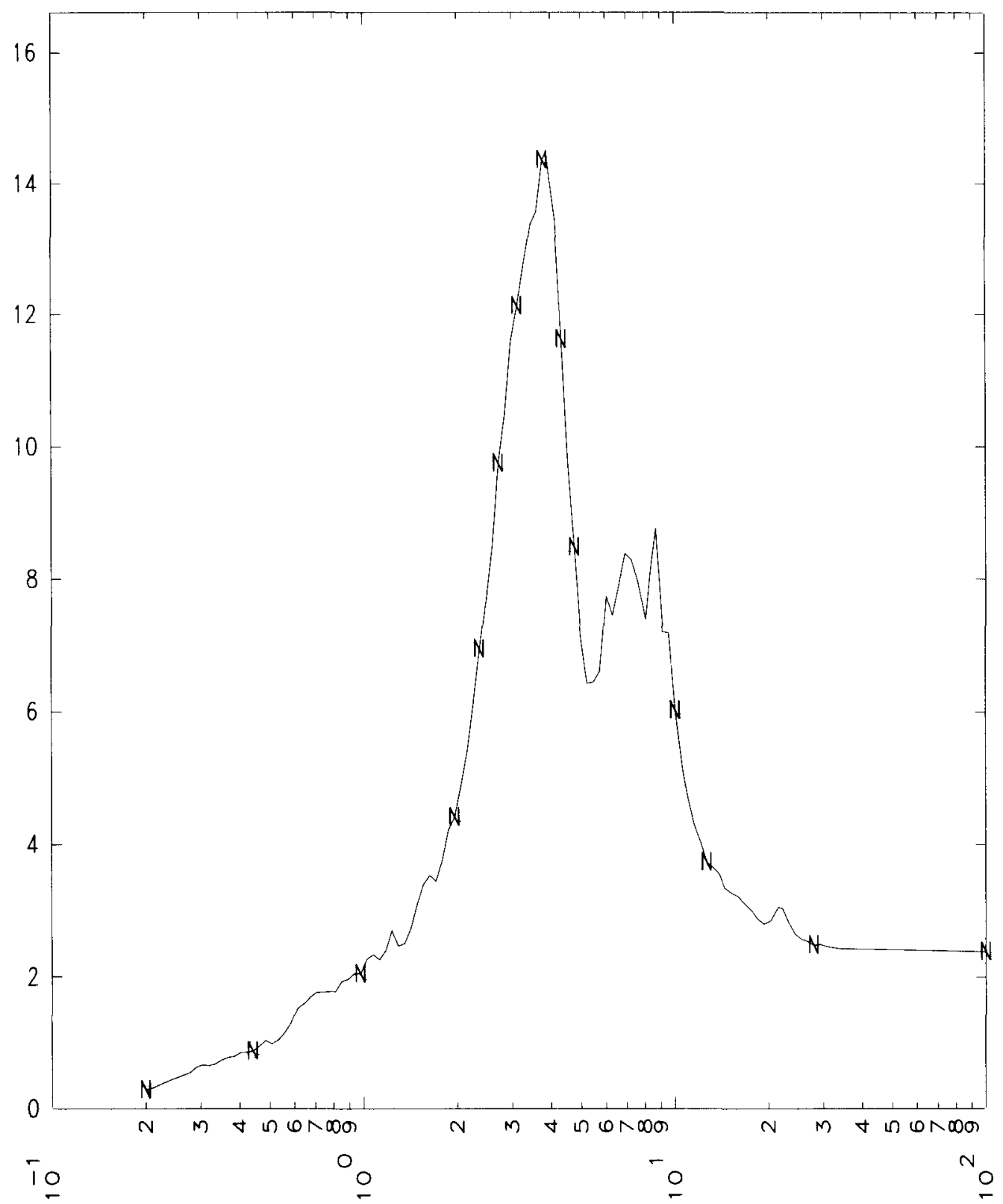

MSD AND 95\% CONF. LIMIT SPECTRA (REAL EQ,GEES) VS FREQ. (HZ) $2.0 \%$ DAMP

FIG. 21. Mathematical model for main steam valve house and quench spray area (key $=19$, node $=6$, direction $=1$ ). 
MATHEMATICAL MODEL FOR MAIN STEAM VALVE HOUSE \& QUENCH SPRAY AREA

KEY $=19 \quad$ NODE $=6 \quad$ DIRECTION $=2 \quad$ DT $=0.0100 \mathrm{SEC} \quad$ CODE $=02 / 15 / 80 \mathrm{R}$ STRUCTURAL DAMPING IN ALL MODES 5.0\% AVERAGE DVFV

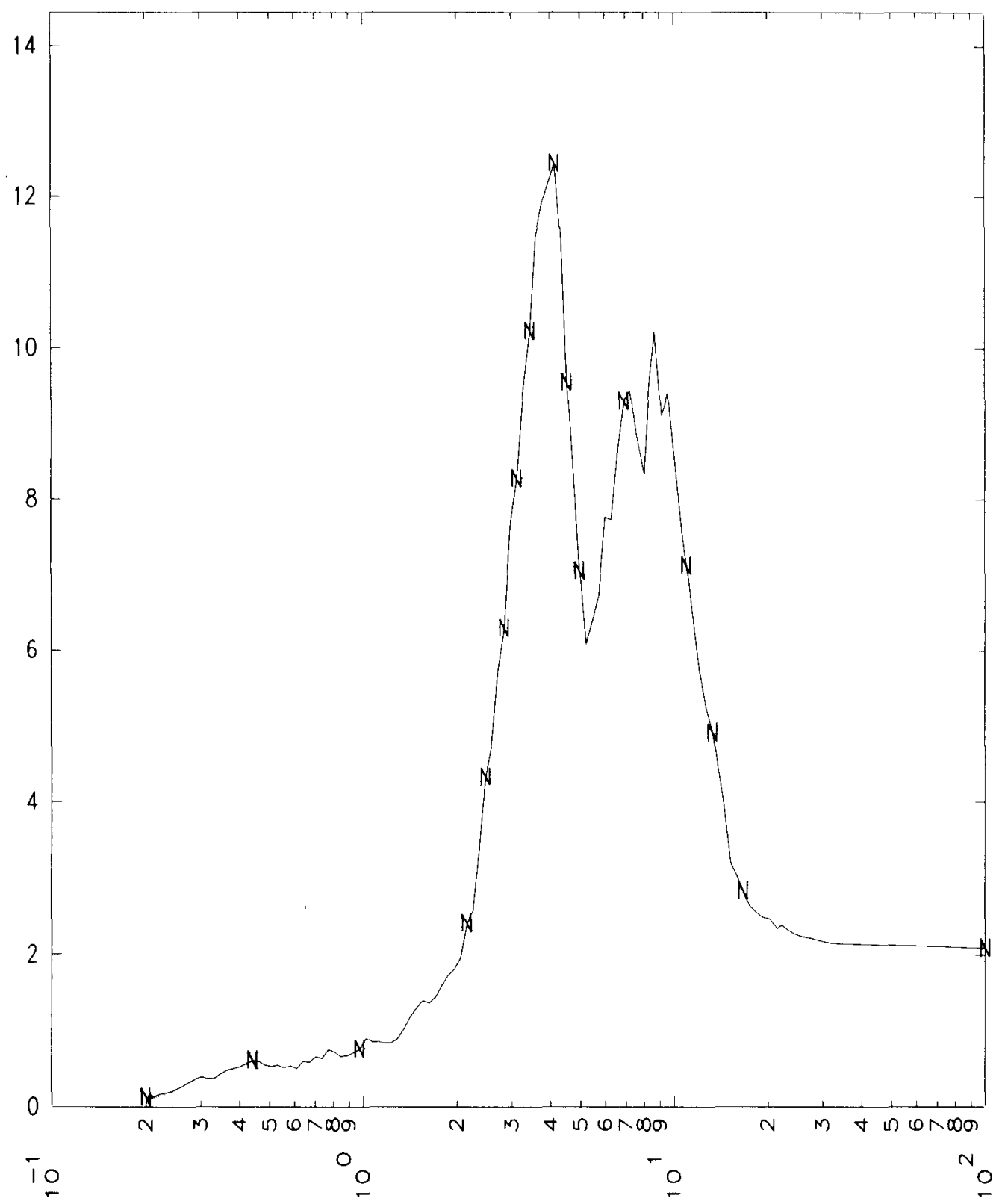

MSD AND 95\% CONF. LIMIT SPECTRA (REAL EQ,GEES) VS FREQ. (HZ) 2.0\% DAMP

FIG. 22. Mathematical model for main steam valve house and quench spray area $($ key $=19$, node $=6$, direction $=2)$. 
MATHEMATICAL MODEL FOR MAIN STEAM VALVE HOUSE \& QUENCH SPRAY AREA

KEY $=21 \quad$ NODE $=6 \quad$ DIRECTIION $=1 \quad$ DT $=00100 \mathrm{SEC} \quad$ CODE $=02 / 15 / 80 \mathrm{R}$

STRUCTURAL DAMPING IN ALL MODES 5 O\% AVERAGE DVFV BROADENED $15 \%$

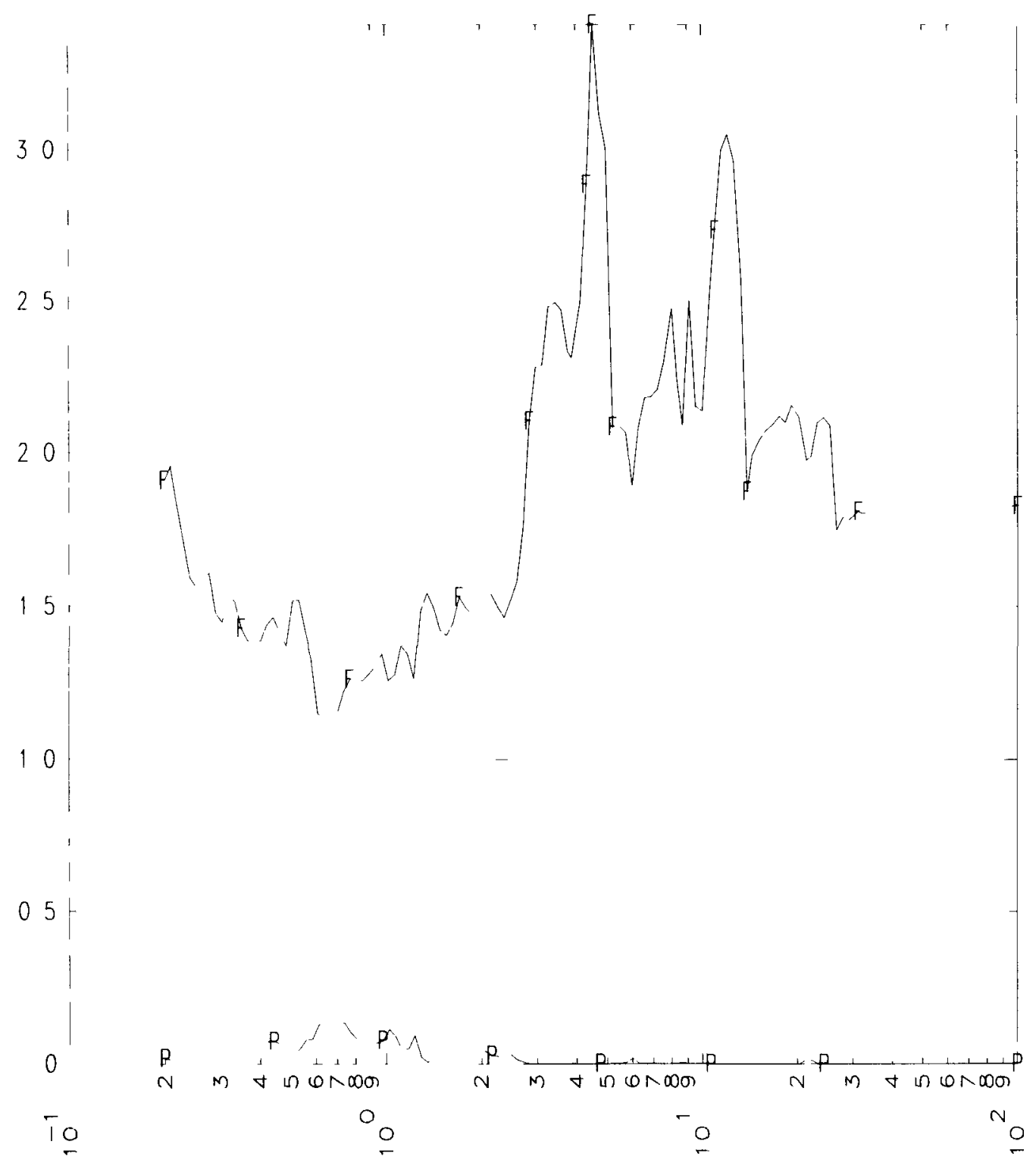

FACTOR OF COMPARISON (F) VS FREQUENCY SUPERIMPOSED ON MEASURE OF

PROBABILITY OF EXCEEDING SRSS SPECTRA FROM R G 1 6O SYNTHETIC TIME HIST

PROBABILITY VS FREQUENCY (HZ) $20 \%$ DAMPING

FIG. 23. Mathematical model for main steam valve nouse and quench spray area $($ key $=21$, node $=6$, direction $=1)$. 
MATHEMATICAL MOOEL FOR MAIN STEAM VALVE HOUSE \& QUENCH SPRAY AREA

KEY $=21 \quad$ NODE $=6 \quad$ DIRECTION $=2 \quad$ DT $=00100 \mathrm{SEC} \quad$ CODE $=02 / 15 / 80 \mathrm{R}$ STRUCTURAL DAMPING IN ALL MODES 5.0\% AVERAGE DVFV BROADENED $15 \%$

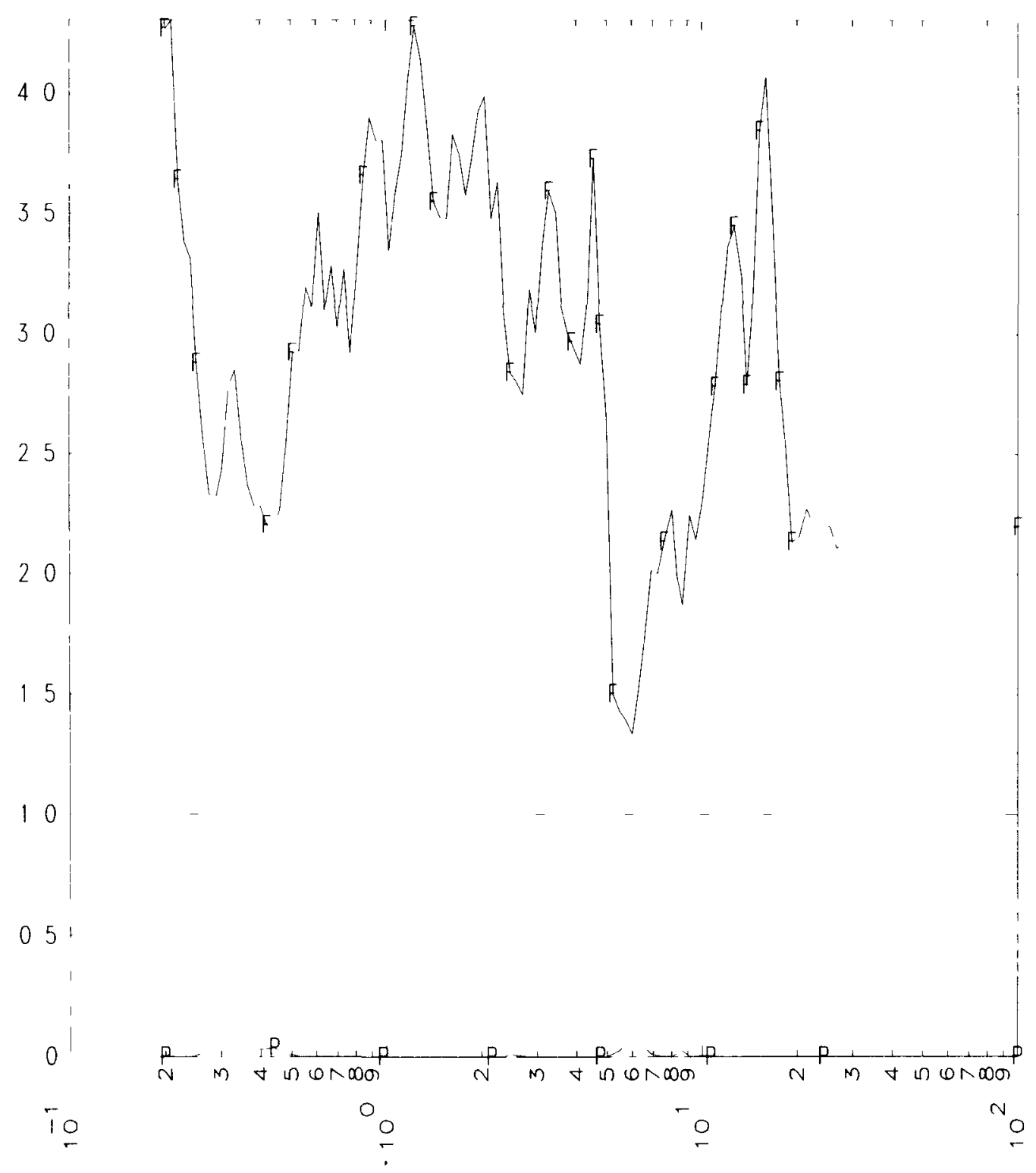

FACTOR OF COMPARISON (F) VS FREQUENCY SUPERIMPOSED ON MEASURE OF PROBABILITY OF EXCEEDING SRSS SPECTRA FROM R.G 1 6O SYNTHETIC TIME HIST. PROBABILITY VS FREQUENCY (HZ) $20 \%$ DAMPING

FIG. 24. Mathematical model for main steam valve house and quench spray area $($ key $=21$, node $=6$, direction $=2)$. 
MATHEMATICAL MODEL FOR MAIN STEAM VALVE HOUSE \& QUENCH SPRAY AREA

KEY $=22 \quad$ NODE $=6 \quad$ DIRECTION $=1 \quad$ DT $=0.0100 \mathrm{SEC} \quad$ CODE $=02 / 15 / 80 \mathrm{R}$ STRUCTURAL DAMPING IN ALL MODES 5.0\% AVERAGE DVFV BROADENED $15 \%$

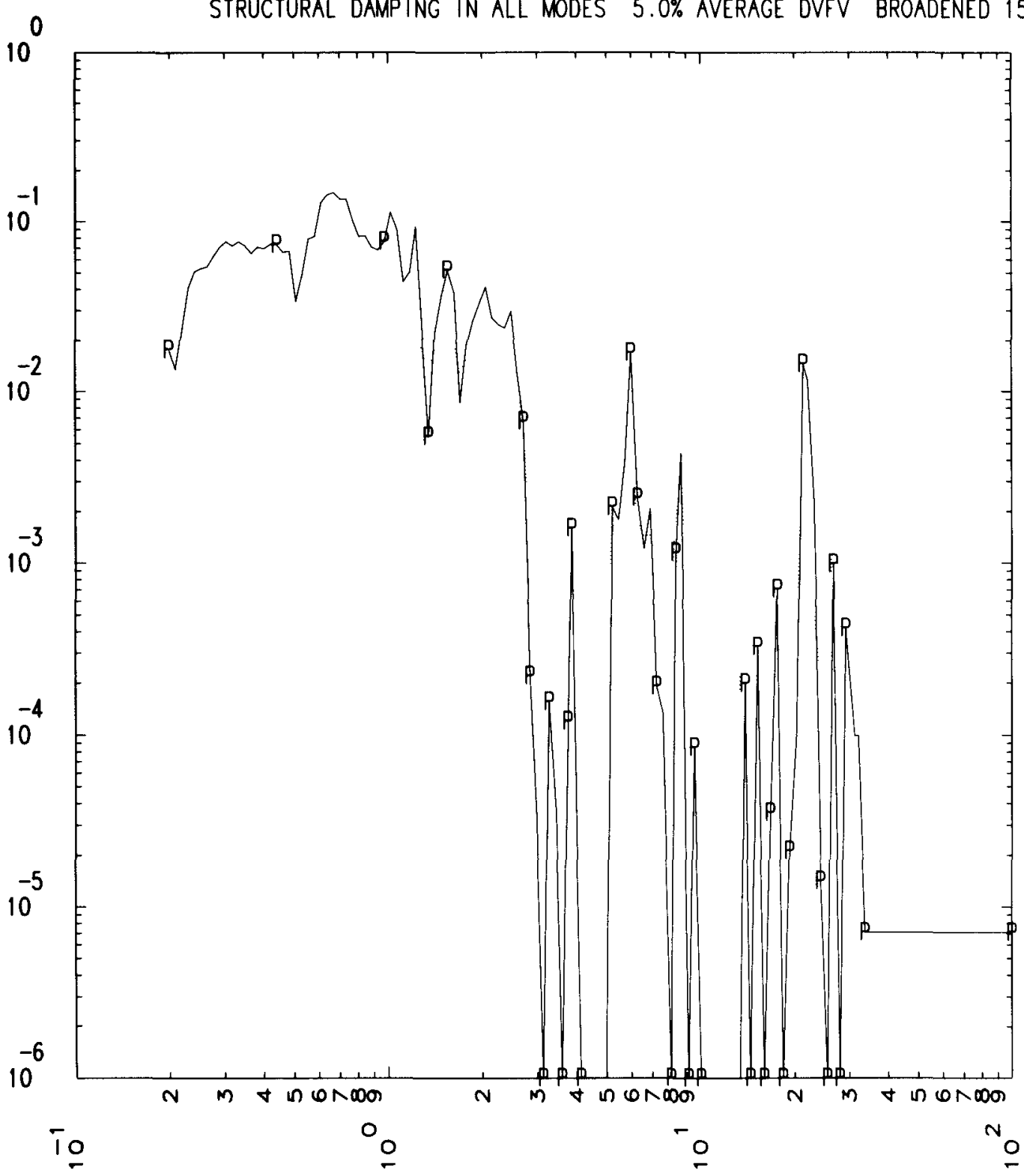

PROBABILITY OF EXCEEDING SRSS SPECTRA FROM R.G. 1.60 SYNTHETIC TIME HIST. PROBABILITY VS FREQUENCY (HZ) $2.0 \%$ DAMPING

FIG. 25. Mathematical model for main steam valve house and quench spray area (key $=22$, node $=6$, direction $=1)$. 
MATHEMATICAL MODEL FOR MAIN STEAM VALVE HOUSE \& QUENCH SPRAY AREA

KEY $=22 \quad$ NODE $=6 \quad$ DIRECTION $=2 \quad$ DT $=0.0100$ SEC $\quad$ CODE $=02 / 15 / 80 R$ STRUCTURAL DAMPING IN ALL MODES 5.0\% AVERAGE DVFV BROADENED $15 \%$

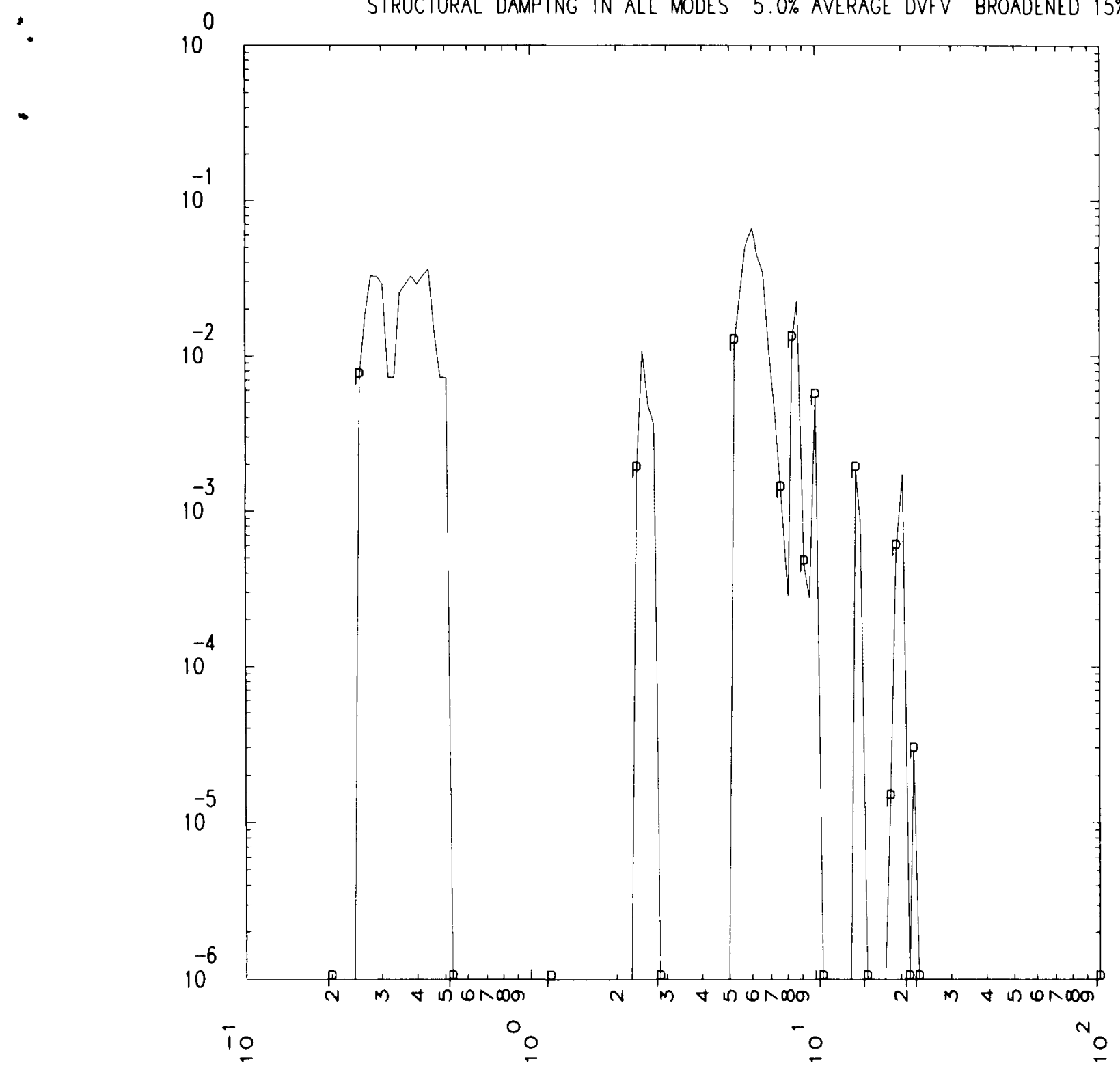

PROBABILITY OF EXCEEDING SRSS SPECTRA FROM R.G. 1.60 SYNTHETIC TIME HIST. PROBABILITY VS FREQUENCY (HZ) $2.0 \%$ DAMPING

FIG. 26. Mathematical model for main steam valve house and quench spray area (key $=22$, node $=6$, direction $=2$ ) . 
MATHEMATICAL MODEL FOR MAIN STEAM VALVE HOUSE \& QUENCH SPRAY AREA

KEY $=24$ NODE $=6 \quad$ DIRECTION $=1 \quad$ DT $=00100 \mathrm{SEC} \quad$ CODE $=02 / 15 / 80 \mathrm{R}$

STRUCTURAL DAMPING IN ALL MODES 5 0\% AVERAGE DVFV BROADENED $15 \%$

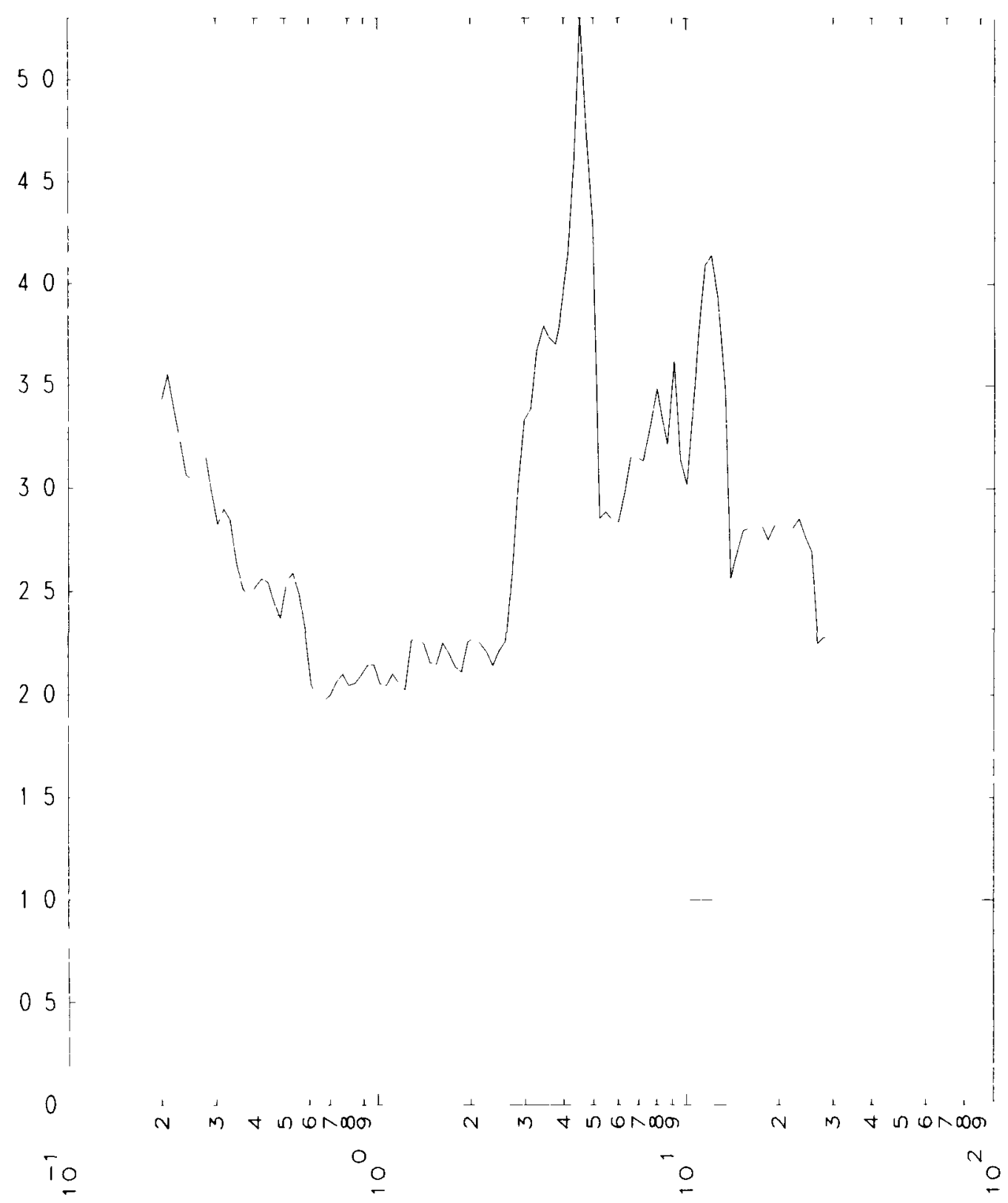

RATIO OF MEAN VALUE OF RG TO MEAN VALUE OF REAL VS FREQ (HZ) $20 \%$ DAMP

FIG. 27. Mathematical model for main steam valve house and quench spray area $($ key $=24$, node $=6$, direction $=1)$. 
MATHEMATICAL MODEL FOR MAIN STEAM VALVE HOUSE \& QUENCH SPRAY AREA

KEY $=24$ NODE $=6 \quad$ DIRECTION $=2 \quad$ DT $=00100 \mathrm{SEC} \quad$ CODE $=02 / 15 / 80 \mathrm{R}$ STRUCTURAL DAMPING IN ALL MODES 5 O\% AVERAGE DVFV BROADENED $15 \%$

$\because$

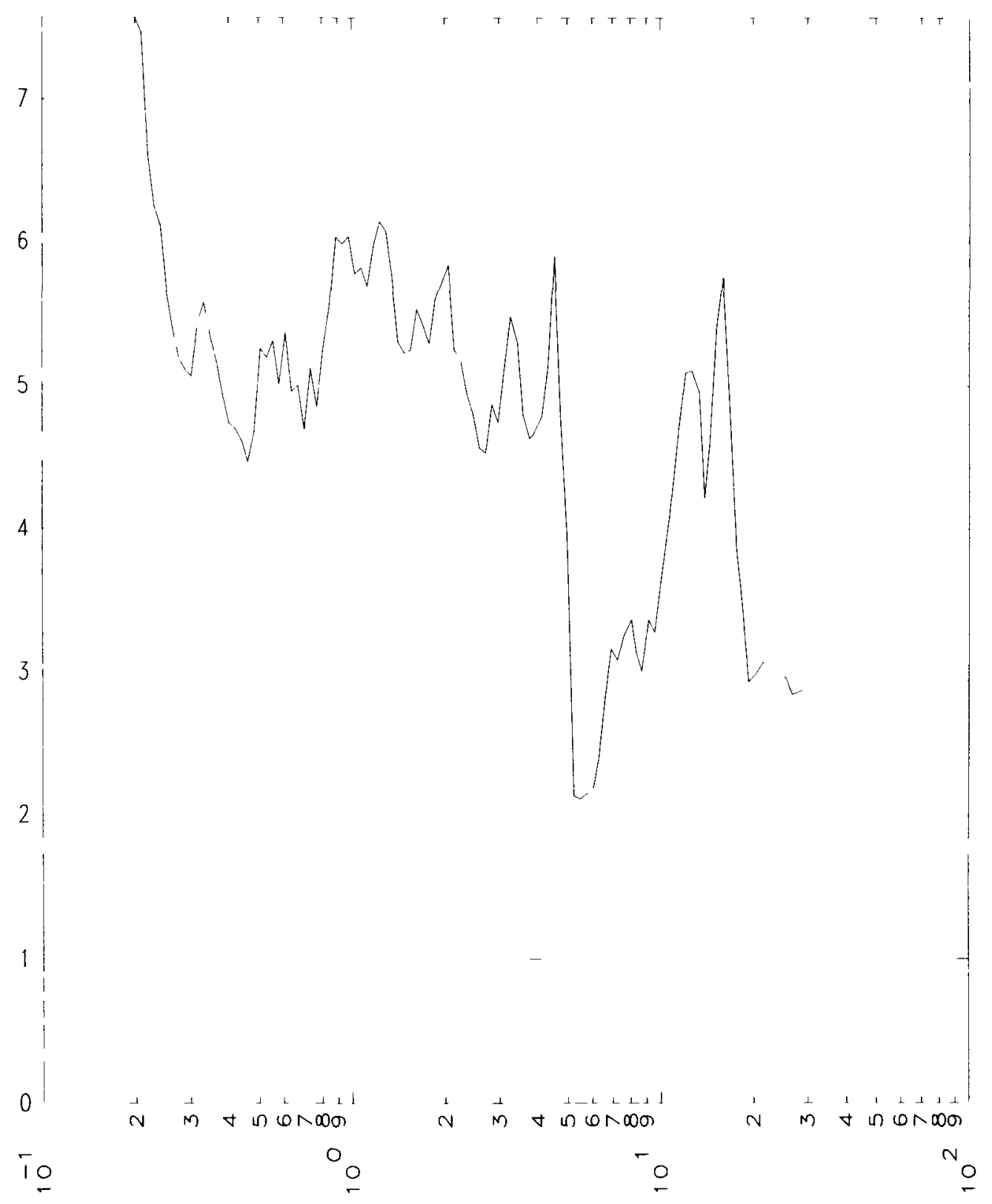

RATIO OF MEAN VALUE OF RG TO MEAN VALUE OF REAL VS FREQ (HZ) $20 \%$ DAMP

FIG. 28. Mathematical model for main steam valve house and quench spray area $($ key $=24$, node $=6$, direction $=2)$. 
MATHEMATICAL MODEL FOR MAIN STEAM VALVE HOUSE \& QUENCH SPRAY AREA NODE $=2$ DIRECTION $=1 \quad$ DT $=00100$ SEC

STRUCTURAL DAMPING IN ALL MODES 5 0\% AVERAGE DVFV BROADENED $15 \%$

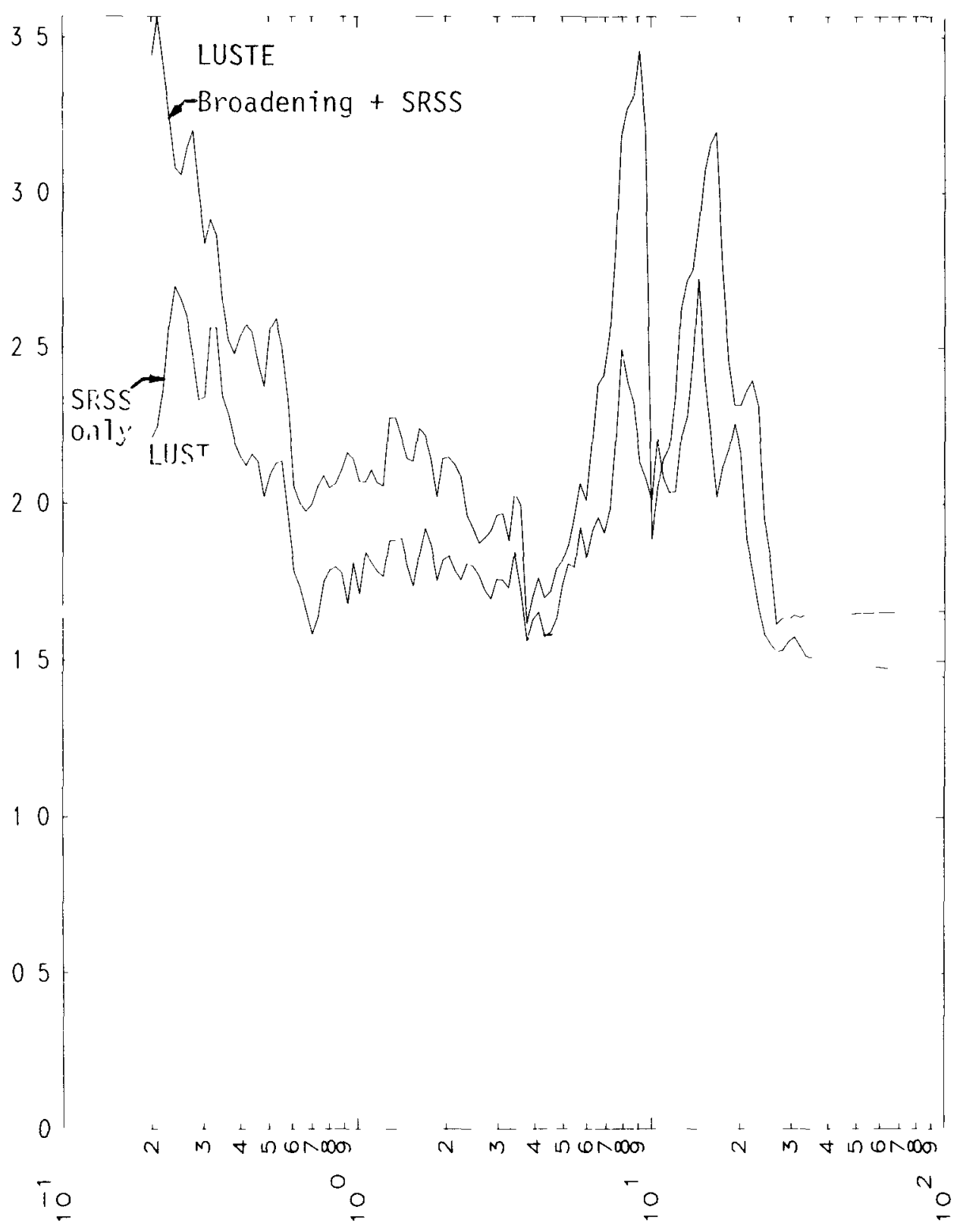

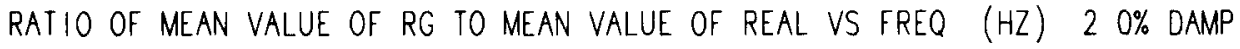

FIG. 29. Mathematical model for main steam valve house and quench spray area (node $=2$, direction $=1$ ). 
MATHEMATICAL MODEL FOR MAIN STEAM VALVE HOUSE \& QUENCH SPRAY AREA NOOE $=2$ DIRECTION $=2$ DT $=0.0100$ SEC

STRUCTURAL DAMPING IN ALL MODES 5.0\% AVERAGE DVFV BROADENED $15 \%$

'.

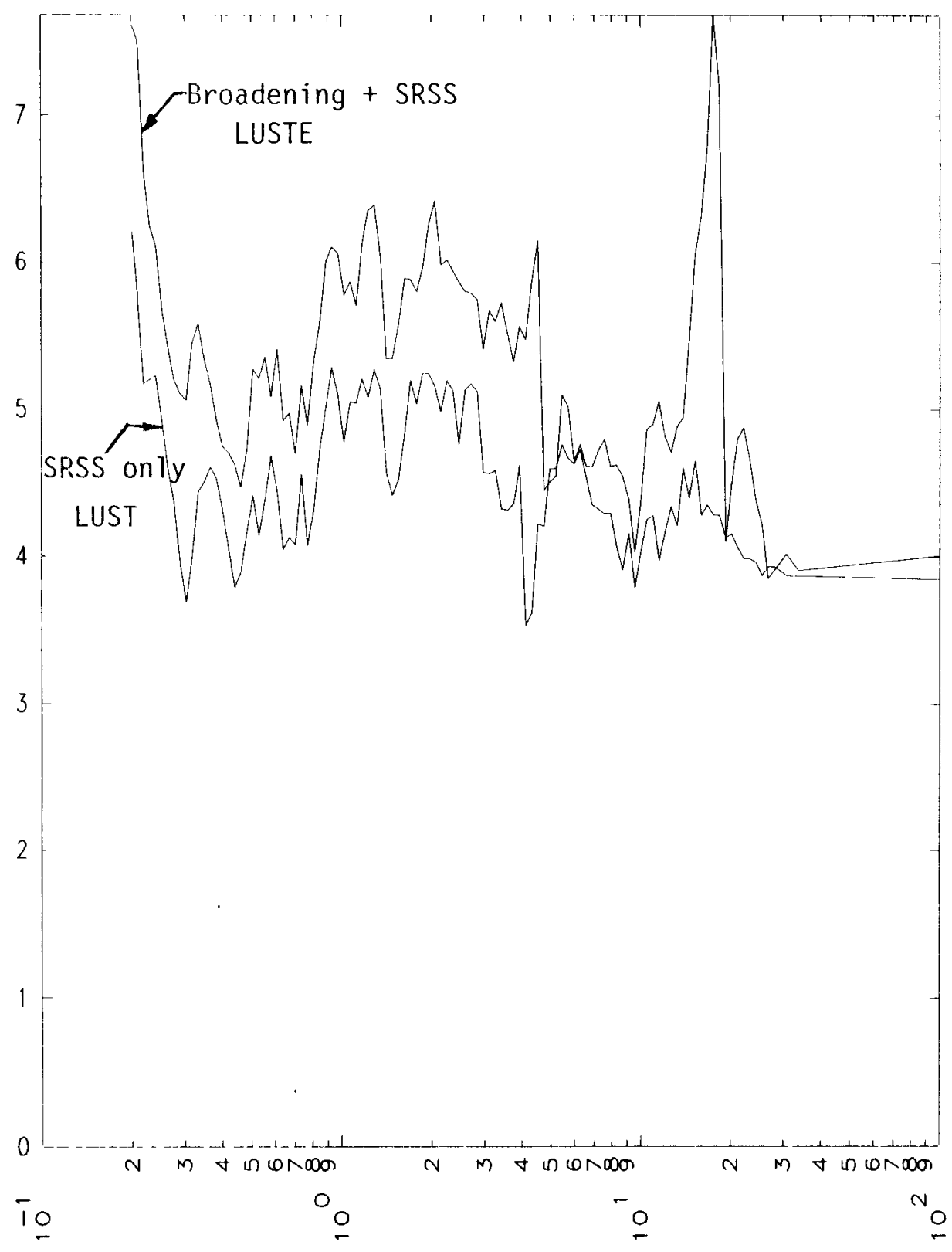

ratio of mean value of RG tO mean Value of Real vS freQ. (hZ) $2.0 \%$ damp

FIG. 30. Mathematical model for main steam valve house and quench spray area (node $=2$, direction $=2$ ). 
MATHEMATICAL MODEL FOR MAIN STEAM VALVE HOUSE \& QUENCH SPRAY AREA

NODE $=6$ DIRECTION $=1 \quad$ DT $=0.0100$ SEC

STRUCTURAL DAMPING IN ALL MODES 5.0\% AVERAGE DVFV BROADENED $15 \%$

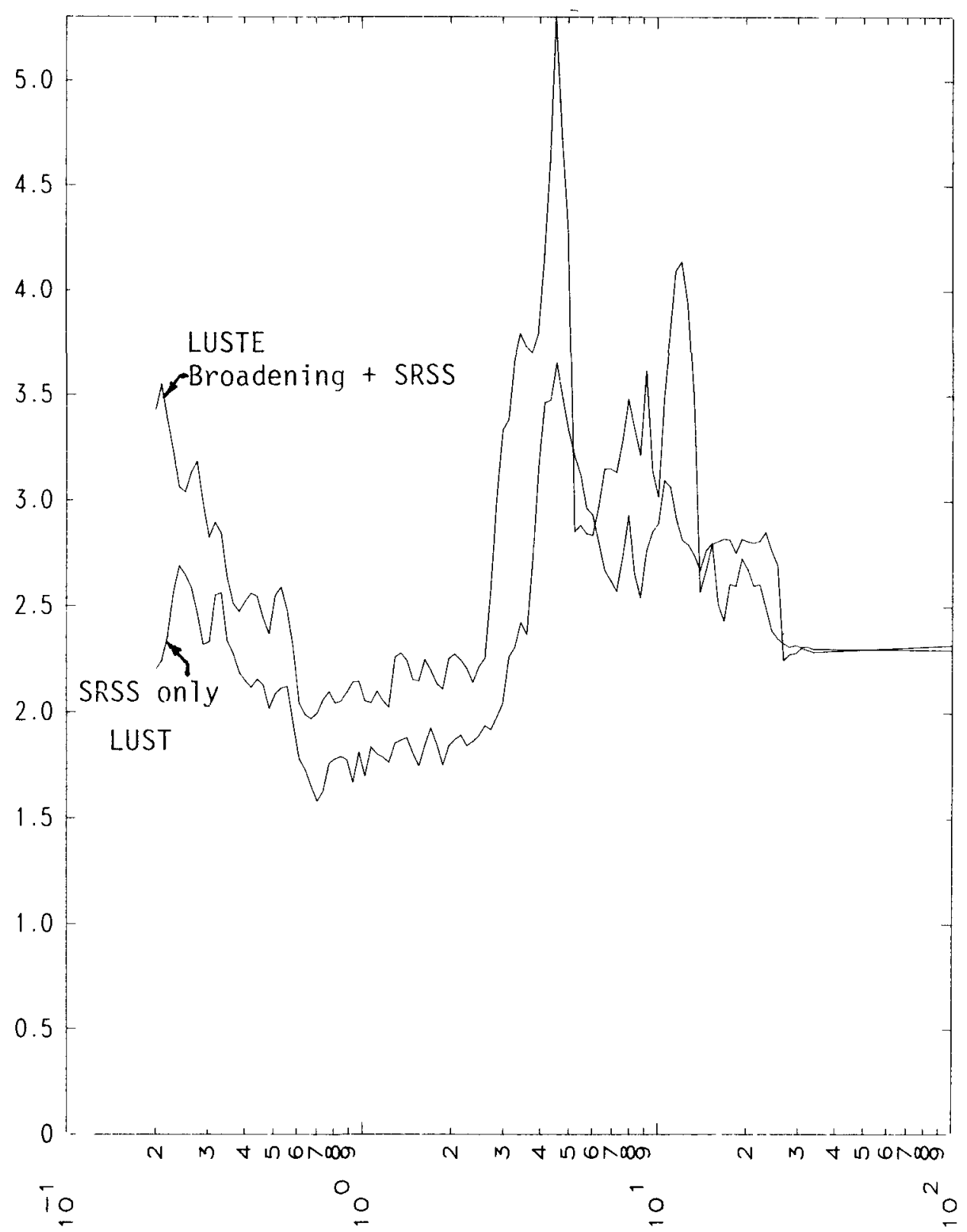

RATIO OF MEAN VALUE OF RG TO MEAN VALUE OF REAL VS FREQ. ( $\mathrm{HZ}) \quad 2.0 \%$ DAMP

FIG. 31. Mathematical model for main steam valve house and quench spray area (node $=6$, direction $=1$ ). 
MATHEMATICAL MODEL FOR MAIN STEAM VALVE HOUSE \& QUENCH SPRAY AREA

NOOE $=6 \quad$ DIRECTION $=2 \quad$ OT $=00100 \mathrm{SEC}$

STRUCTURAL DAMPING IN ALL MODES 5 O\% AVERAGE DVFV BROADENED $15 \%$

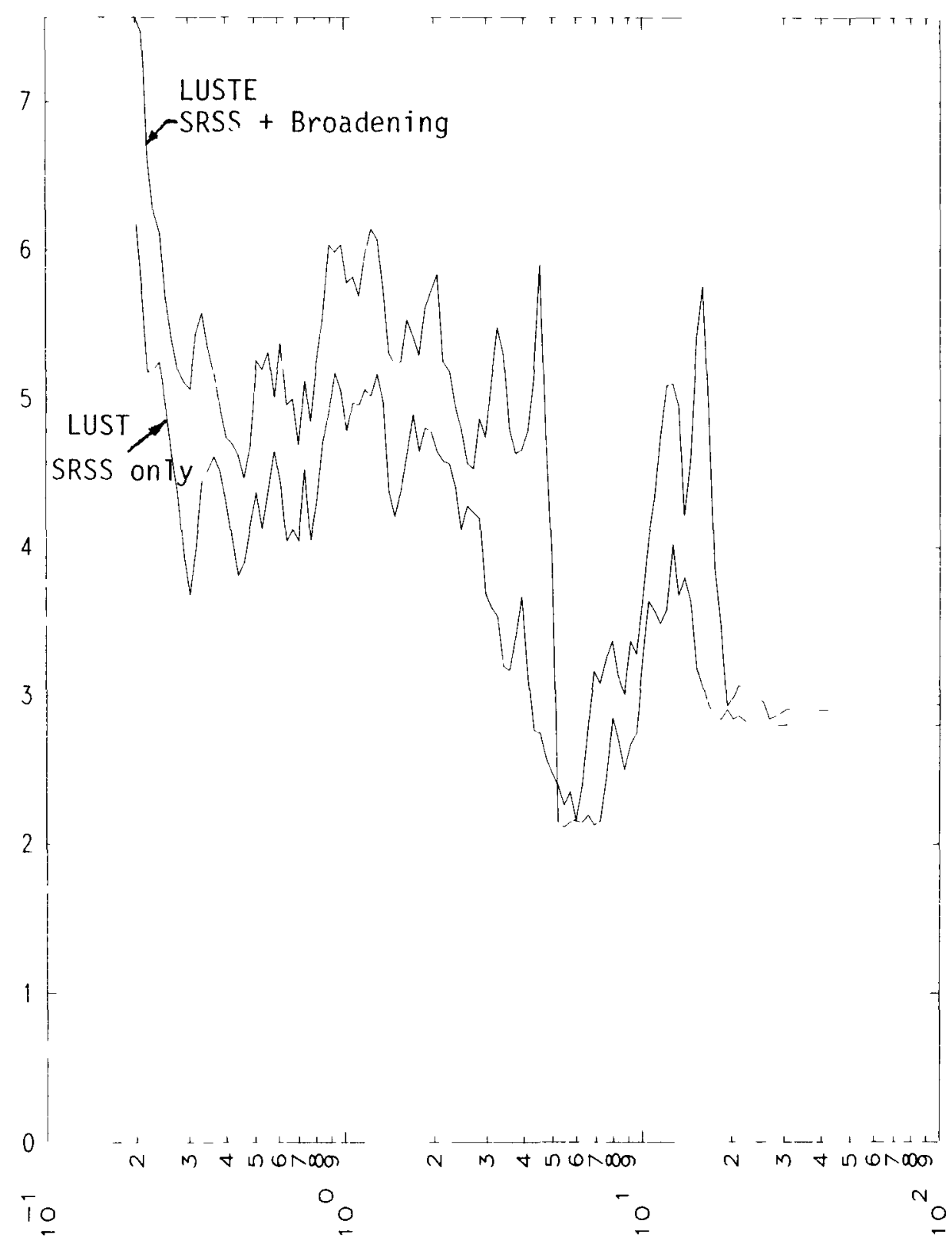

RATIO OF MEAN VALUE OF RG TO MEAN VALUE OF REAL VS FREQ (HZ) $20 \%$ DAMP

FIG. 32. Mathematical model for main steam valve house and quench spray area (node $=6$, direction $=2$ ). 


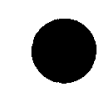

.

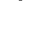




\section{CONCLUSIONS AND RECOMMENDATIONS}

\subsection{CONCLUSIONS}

The concept of Best Estimate-Evaluation Method (BE-EM) has been introduced with respect to the seismic analysis and design of nuclear power plants. The concept has been shown to be extremely useful in the evaluation of two alternative methodologies. The illustrative example coupled two links in the SMC and introduced a possible method of comparison. The significance of the quantitative results is limited due to the methodologies selected. However, the results clearly illustrated the utility of such an approach. Compounding of effects through the SMC was shown.

\subsection{RECOMMENDATIONS FOR FURTHER STUDY}

- Future studies should include as many links of the SMC as appropriate to realistically analyze the phenomenon of interest. For example, structures founded on soil sites should be analyzed including the effects of soil-structure interaction. For subsystem response quantities of interest, the entire SMC should be treated in the analysis.

- The bases of comparison--the Factor of Comparison (FOC) and the Probability of Exceedance (POE)--introduced in this report need to be evaluated for their usefulness and alternatives proposed, if necessary.

- Alternative seismic analysis and design methodologies must be defined for comparison in the future. Each link in the SMC--seismic input, soil-structure interaction, major structural response, and subsystem response--will require the definition of alternative techniques. Initial comparisons should be between Best Estimate (BE) and a design methodology (EM). However, any two alternative approaches may be compared.

- We recommend establishing BE methodologies for each link in the SMC. 


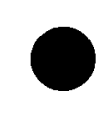

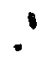

- 


\section{REFERENCES}

1. J. J. Johnson and R. P. Kennedy, "Earthquake Response of Nuclear Power Facilities, Journal of the Power Division, ASCE, Vol. 105, No. EY1, Proc. Paper 14296 (January 1979).

2. P. D. Smith, et al., Seismic Safety Margins Research Program--Program Plan, Revision II, UCID-17824, Rev. II, Lawrence Livermore Laboratory, Livermore, Calif. (August 1978).

3. G. W. Johnsen, et al., A Comparison of "Best Estimate" and "Evaluation Model" LOCA Calculations: The BE/EM Study, PG-R-76-009, Idaho National Engineering Laboratory (December 1976).

4. P. D. Smith, S. E. Bumpus, and O. R. Maslenikov, LLL/DOR Conservatism Program: Investigations of the Conservatism in the Seismic Design of Nuclear Power Plants. Part VI: Response to Three Input Components, Lawrence Livermore Laboratory, Livermore, Calif., UCID-17959 (1979).

5. P. D. Smith, S. E. Bumpus, and O. R. Maslenikov, LLL/DOR Conservatism Program: Investigations of the Conservatism in the Seismic Design of Nuclear Power Plants. Part VII: Broadening of Floor Response Spectra, Lawrence Livermore Laboratory, Livermore, Calif., UCID-18104 (1979).

6. P. D. Smith, LLL/DOR Seismic Conservatism Program: Investigations of the Conservatisms in the Seismic Design of Nuclear Power Plants. Part I: Synthetic Time History Data Base, Lawrence Livermore Laboratory, Livermore, Calif., UCID-17988 (1979).

7. United States Atomic Energy Commission Regulatory Guide 1.60, "Design Response Spectra for Nuclear Power Plants" (1973).

8. W. Gersch, "On the Achievable Accuracy of Structural System Parameter Estimates," Journal of Souna and Vibration, Vol. 34, No. 1 (1974).

9. United States Nuclear Regulatory Commission, "Combining Modal Responses and Spatial Components in Seismic Response Analysis," Regulatory Guide 1.92, Rev. 1 (December 1974).

10. United States Nuclear Regulatory Commission, "Development of Floor Design Response Spectra for Seismic Design of Floor-Supported Equipment or Components," Regulatory Guide 1.122, Rev. 1 (February 1978).

11. California Institute of Technology, Earthquake Engineering Research Laboratory, "Strong Motion Earthquake Accelerograms," Index Volume, Report NO. EERL76-02, Pasadena, Calif. (August 1976). 
14. A. H. Hadjian, et al., "Variability in Engineering Aspects of Structural Modeling," Proceedings Sixth World Conference on Earthquake Engineering, New Delhi, India (1977).

13. C. W. Hamilton and A. H. Hadjian, "Probabilistic Frequency Variations of Structure-Soil Systems," Nuclear Engineering and Design, 38 (1976), 303-322. 


\section{APPENDIX A: LUSTE OUTPUT DESCRIPTIONS}

The computer program LUSTE, which is an acronym for Limited Understanding of the Statistics of Transients with Extension, provides output in the form of 27 different types of computer plots. Each plot is identified by KEY $=01$ to $K E Y=26$ or $\mathrm{KEY}=\mathrm{L}$ in the upper left-hand corner. LUSTE automatically produced these plots. The plots have self-descriptive information displayed at the top. This information includes a description of the structure, the key number, the node analyzed, the direction for which output results were obtained (not input analysis direction), the integration time-step, the version (date) of LUSTE used, the average structural damping, the amount of broadening if (applicable), and other data that vary from plot to plot. At the bottom, the ordinate and the abscissa are described, and the spectral damping is given.

We describe now the different types of plots, key number by key number. $\mathrm{KEY}=01$

These plots show the response spectra at the indicated node and in the indicated direction for the $44(16+16+12)$ synthetic time histories. Each of the 44 curves resulted from a single time history analysis. The 3072 SRSS-broadened combinations are not shown.

$\mathrm{KEY}=\mathrm{L}$

These plots show spectra from plot KEY $=1$ but with every spectra broadened by 158 . The plots are for illustrative purposes only to show typical broadened spectra. All subsequent plots and results were obtained by first doing the SRSS combination and then broadening 158.

$\mathrm{KEY}=02$

These plots show the cumulative distribution function (CDF) and a 958 confidence interval for the 3072 SRSS-broadened spectral values at frequencies nearest to the indicated mode of the structure. At this frequency the 3072 SRSS spectral responses were sorted according to increasing acceleration and normalizea to 1.0 to construct the CDF. The CDF measures the probability of the spectral acceleration being below the value given on the abscissa. Three separate $\mathrm{KEY}=02$ plots show the results for the first three modal frequencies. 
The $95 \%$ confidence intervals were calculated by the Kolmogorov-Smirnov (K-S) method. These $\mathrm{K}-\mathrm{S}$ confidence bands are independent of any assumption of distribution type. Confidence intervals obtained by using an assumption of normality and the K-S method, as well as the point estimates, are printed on these plots.

$\mathrm{KEY}=03$

These plots show the extremes and means of the SRSS-broadened response spectra derived from the 44 spectra in $K E Y=01$. The lowest (dotted) curve is a compilation of the minimum spectral values in the KEY $=01$ plot. The curve above it is a compilation of the minimum spectral values from the 3072 SRSS-broadened spectra. The middle curve, with the $\mathrm{N}$ overprint, is the mean of the 3072 SRSS-broadened spectra. At each spectral frequency, the mean was calculated as the simple arithmetic average of the 3072 spectra values at that frequency. The higher dotted curve is a compilation of the maximum spectral values in the $\mathrm{KEY}=01$ plot. The highest curve is a similar compilation for the 3072 SRSS-broadened spectra.

$\mathrm{KEY}=04$ to $\mathrm{KEY}=07$

These plots basically illustrate a distribution-free statistical test for normal and lognormal distribution assumptions about the 3072 SRSS-broadened spectral curves. These tests were conducted by using a modification of the $\mathrm{K}-\mathrm{S}$ method.

$$
\mathrm{KEY}=08
$$

These plots show the mean of the 3072 sRSS-broadened spectra and the corresponding 958 confidence intervals, assuming a normal distribution. Because of the large number of SRSS-broadened spectra, typical confidence intervals about the estimate of the mean are quite narrow and as a result the three curves on these plots are typically indistinguishable. While the classical statistical meaning and interpretation of such narrow confidence bands is clear, their usefulness for engineering purposes is not.

$\mathrm{KEY}=09$

Each of these plots shows the standard deviation of the 3072 SRSS-broadened spectra and the corresponding 958 confidence intervals assuming a normal distribution. Because of the large number of SRSS-broadened spectra, the three curves are again virtually indistinguishable. 
$\mathrm{KEY}=10$

These plots show the response spectra at the indicated node and in the indicated direction for the 46 real earthquake analyses. Each of these 46 spectra is the result of the simultaneous application of three orthogonal real time histories.

$\mathrm{KEY}=11$

These plots are analogous to $\mathrm{KEY}=02$, but are based on the analyses using real time $\mathrm{h}$ istories.

$\mathrm{KEY}=12$

These plots display the minimum, the MSD (with $N$ overprint), and the maximum of the 46 spectra from the real earthquake analyses.

$\mathrm{KEY}=13$ to $\mathrm{KEY}=16$

These plots are analogous to the plots $\mathrm{KEY}=04$ to $\mathrm{KEY}=07$.

$\mathrm{KEY}=17$

These plots show the mean of 46 spectra from the real earthquake analyses and the corresponding 958 confidence intervals, again assuming a normal distribution. These plots thus show the best estimate of the in-structure response spectra due to three-dimensional real earthquakes.

$\mathrm{KEY}=18$

Each of these plots shows the standard deviation of the 46 spectra from the real earthquake analyses and the corresponding 958 confidence intervals, assuming a normal distribution.

$\mathrm{KEY}=19$

These plots show the MSD of the 46 spectra from the real earthquake analyses (also shown by $K E Y=12$ ) and the corresponding 958 confidence limits. We computed the confidence intervals by assuming a normal distribution and performing 2000 Monte Carlo simulations at each of the 112 spectral frequencies.

$K E Y=20$

These plots display the Factor of Comparison (FOC) for in-structure response spectra and the corresponding 958 confidence intervals. The FOC is the quotient of the mean of the 3072 SRSS-broadened spectra (KEY = 08) and the MSD of the 46 spectra from the real earthquake analyses ( $K E Y=19$ ). The 958 
confidence intervals were calculated by assuming a normal distribution and performing 2000 Monte Carlo simulations at each of the 112 spectral frequencies.

$$
\mathrm{KEY}=21
$$

These plots display the FOC from the KEY $=20$ plot and a measure of the Probability of Exceedance (POE), which has a P overprint. The POE was obtained by comparing each of the 3072 SRSS-broadened spectra with the first of the 46 spectra from the real earthquake analyses and then counting the number of times that the real spectrum exceeded the SRSS spectrum, to give $n_{1}$. We repeated this procedure for the remaining 45 spectra to give $n$, where $n=n_{1}+\ldots+n_{46}$. The POE was calculated as $n /(46 \times 3072)$. The calculation was performed separately for each of the 112 spectral frequencies.

$$
\mathrm{KEY}=22
$$

These plots show on a logarithmic scale the same POE from plot KEY $=21$ with an overprint $P$ label. AnY POE that had been computed to be 0.0 in plot $K E Y=21$ was set to an arbitrary value of $10^{-6}$. Also shown with a dotted line is the POE that can be calculated from the coefficients of variation (COVs) of the real and Regulatory Guide (R.G.) analyses as shown in plot $\mathrm{KEY}=23$, the ratio of the means given in plot $\mathrm{KEY}=24$, and an assumption that the variables are lognormally distributed. This latter computed POE correlates well with the former POE, which results from strict comparison counting.

$$
\mathrm{KEY}=23
$$

These plots show the calculated Covs for the R.G. (dotted line) and real (solid line) analyses. The COV for the R.G. analyses was computed by dividing the standard deviation in plot KEY $=09$ by the mean in plot KEY $=08$. Likewise, the COV for the real analyses was computed by dividing the standard deviation in plot $\mathrm{KEY}=18$ by the mean shown in plot $\mathrm{KEY}=17$.

$\mathrm{KEY}=24$

These plots probably provide the most important results of this study. They display the ratio of the means of the R.G. analyses (from plot $K E Y=08$ ) and the real analyses (from plot KEY $=17$ ). The plots show the relationship between the $\mathrm{BE}$ and the $\mathrm{EM}$ types of structural analysis. 
$\mathrm{KEY}=25$

These tables display information similar to that in the plots, but the results pertain only to peak absolute accelerations which closely approximate the spectral accelerations at $100 \mathrm{~Hz}$. Units are $\mathrm{ft} / \mathrm{s}^{2}$.

$\mathrm{KEY}=26$

These plots show the Cumulative Distribution Functions (CDFs) for the peak absolute accelerations from the 3072 SRSS spectra and from the 46 spectra from real time histories. These CDFs and the corresponding 958 confidence intervals are shown on two separate plots. The first plot shows results for the SRSS spectra, the second plot shows results for the real earthquake spectra. 
APPENDIX B: LUSTE OUTPUT PLOTS 
-

:

.

• 
MATHEMATICAL MODEL FOR MAIN STEAM VALVE HOUSE \& QUENCH SPRAY AREA

KEY $=1$ NODE $=6 \quad$ DIRECTION $=1 \quad$ DT $=0.0100 \mathrm{SEC} \quad$ CODE $=02 / 15 / 80 \mathrm{R}$ STRUCTURAL DAMPING IN ALL MODES 5.0\% AVERAGE DVFV SCALEV $=0.66667$

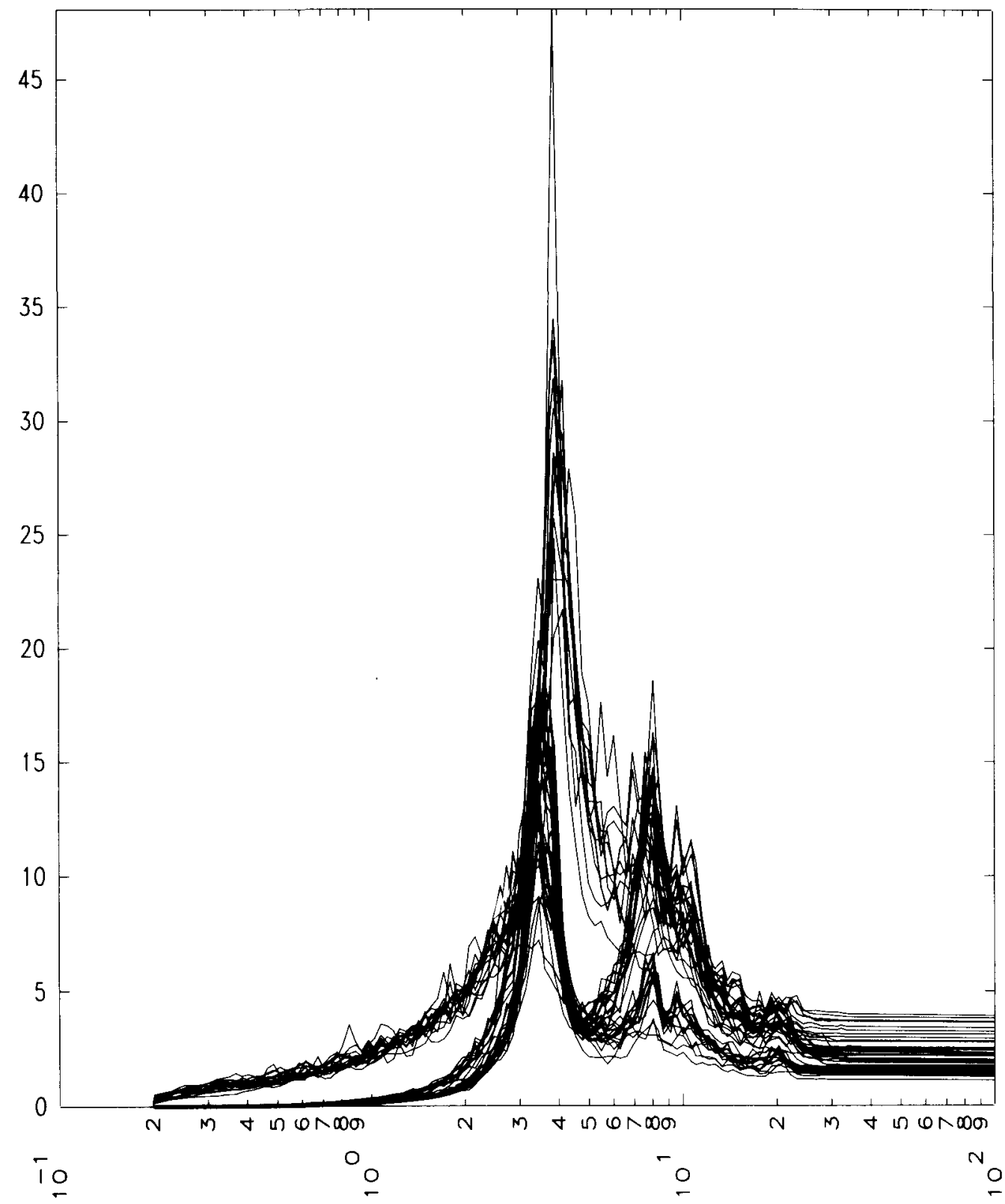

R.G. 1.60 EQ ACCELERATION SPECTRA (GEES) VS FREQUENCY (HZ) $2.0 \%$ DAMPING

FIG. B-1. Mathematical model for main steam valve house and quench spray area $($ key $=1$, node $=6$, direction $=1)$. 
MATHEMATICAL MODEL FOR MAIN STEAM VALVE HOUSE \& QUE' if SPRAY AREA

KEY $=L \quad N O D E=6 \quad$ DIRECTION $=1 \quad$ DT $=0.0100 \mathrm{~S} \quad$ CODE $=02 / 15 / 80 \mathrm{R}$

STRUCTURAL DAMPING IN ALL MODES 5.0\% AVE ;E DVFV BROADENED $15 \%$

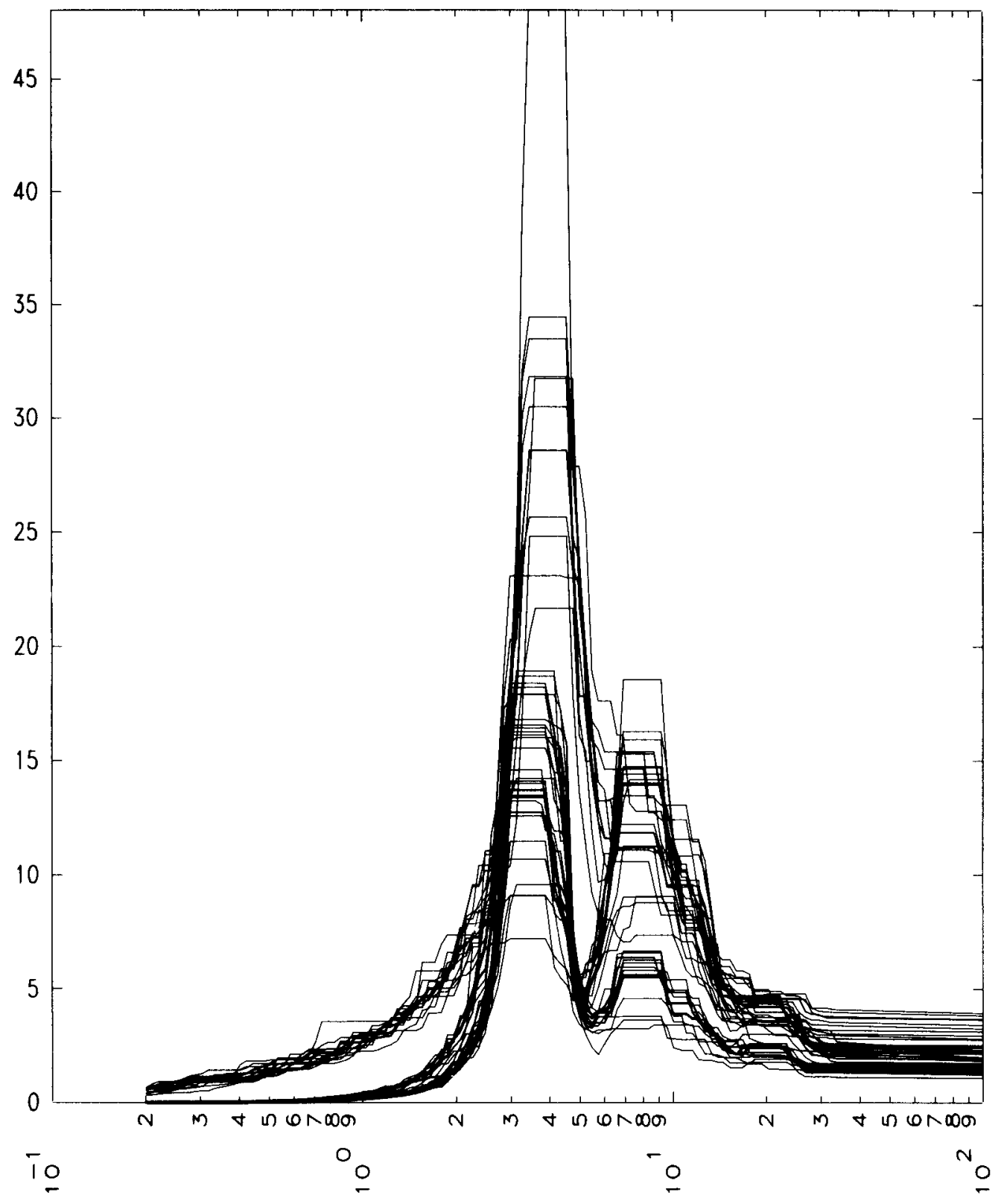

R.G. 1.60 EQ ACCELERATION SPECTRA (GEES) VS FREQUENCY (HZ) 2.0\% DAMPING

FIG. B-2. Mathematical model for main steam valve house and quench spray area $($ key $=\mathrm{L}$, node $=6$, direction $=1)$. 
MATHEMATICAL MODEL FOR MAIN STEAM VALVE HOUSE \& QUENCH SPRAY AREA

KEY $=2$ NODE $=6 \quad$ DIRECTION $=1 \quad$ DT $=0.0100$ SEC $\quad$ CODE $=02 / 15 / 80 R$ STRUCTURAL DAMPING IN ALL MODES 5.0\% AVERAGE DVFV BROADENED $15 \%$

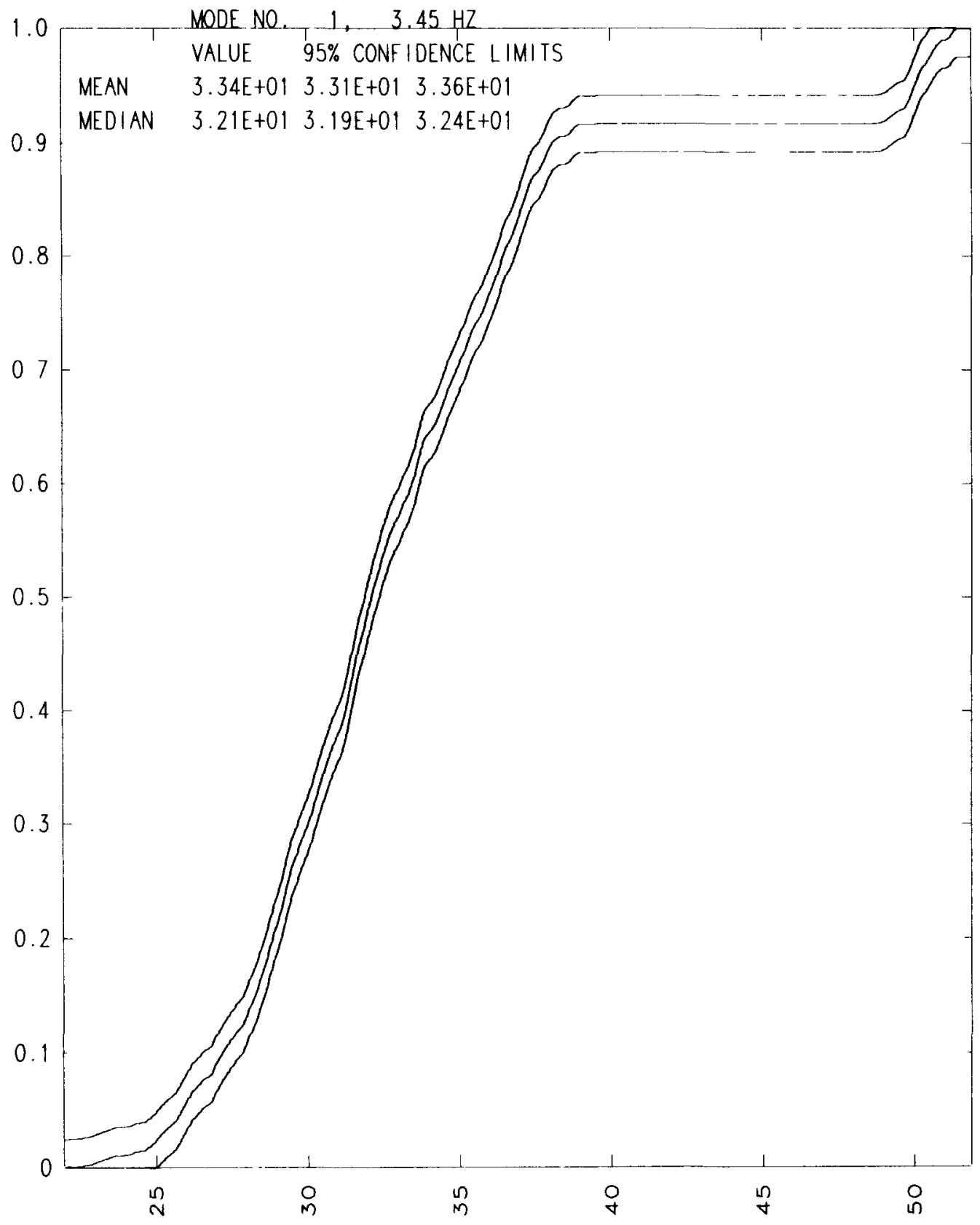

CUMMULATIVE DIST. FCN. (RG EQ,SRSS) VS SPECTRAL ACCN. (GEES) $2.0 \%$ DAMP WITH 95\% CONF IDENCE BAND FROM KOLMOGOROV-SMIRNOV TEST

FIG. B-3. Mathematical model for main steam valve house and quench spray area $($ key $=2$, node $=6$, direction $=1)$. 
MATHEMATICAL MODEL FOR MAIN STEAM VALVE HOUSE \& QUENCH SPRAY AREA

KEY $=2$ NODE $=6 \quad$ DIRECTION $=1 \quad$ DT $=00100 \mathrm{SEC} \quad$ CODE $=02 / 15 / 80 \mathrm{R}$ STRUCTURAL DAMPING IN ALL MODES 5 O\% AVERAGE DVFV BROADENED $15 \%$

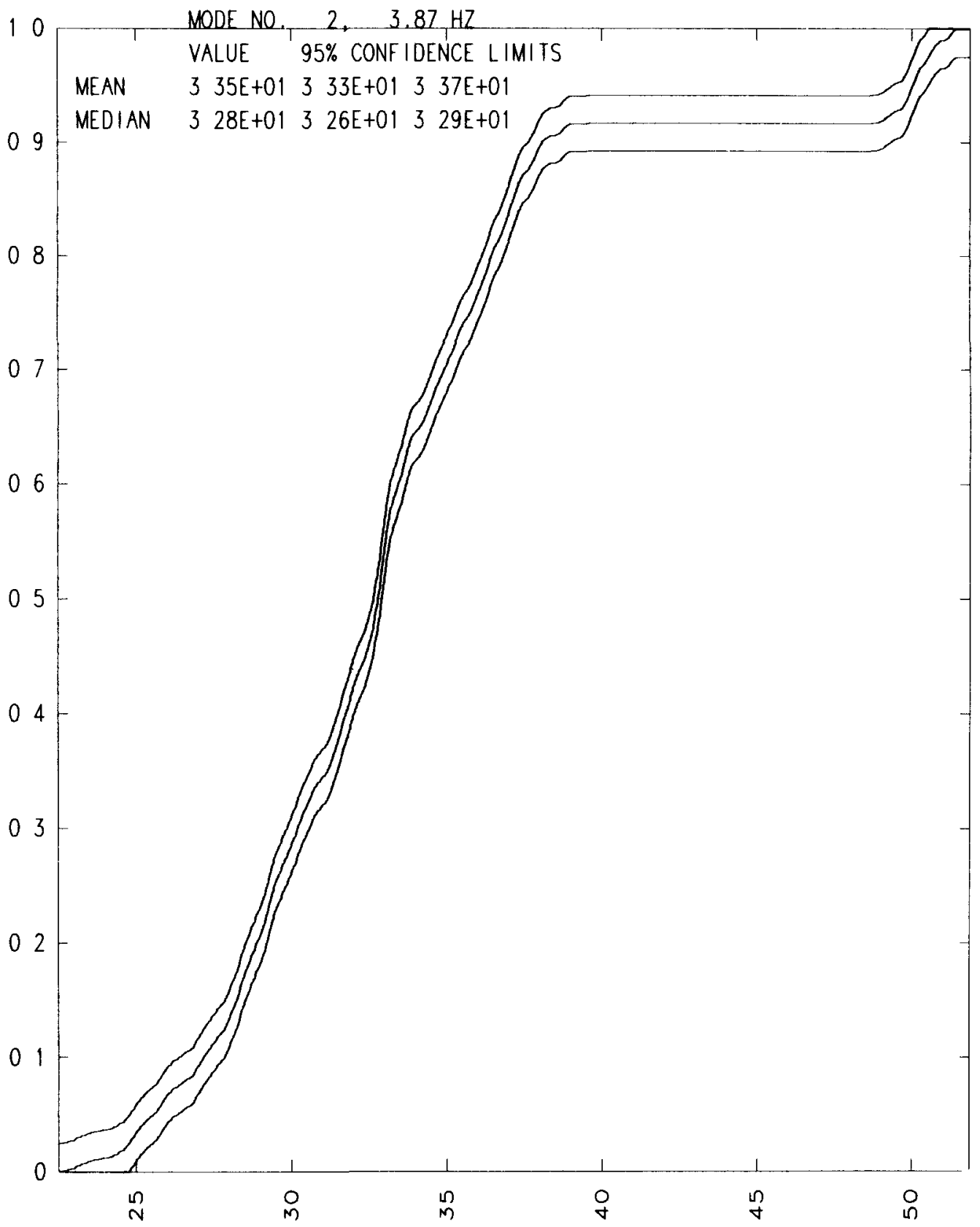

CUMMULATIVE DIST FCN (RG EQ,SRSS) VS SPECTRAL ACCN (GEES) $20 \%$ DAMP WITH 95\% CONFIDENCE BAND FROM KOLMOGOROV-SMIRNOV TEST

FIG. B-4. Mathematical model for main steam valve house and quench spray area $($ key $=2$, node $=6$, direction $=1$ ). 
MATHEMATICAL MODEL FOR MAIN STEAM VALVE HOUSE \& QUENCH SPRAY AREA

KEY $=2$ NODE $=6 \quad$ DIRECTION $=1 \quad$ DT $=00100 \mathrm{SEC} \quad$ CODE $=02 / 15 / 80 \mathrm{R}$ STRUCTURAL DAMPING IN ALL MODES $50 \%$ AVERAGE DVFV BROADENED $15 \%$

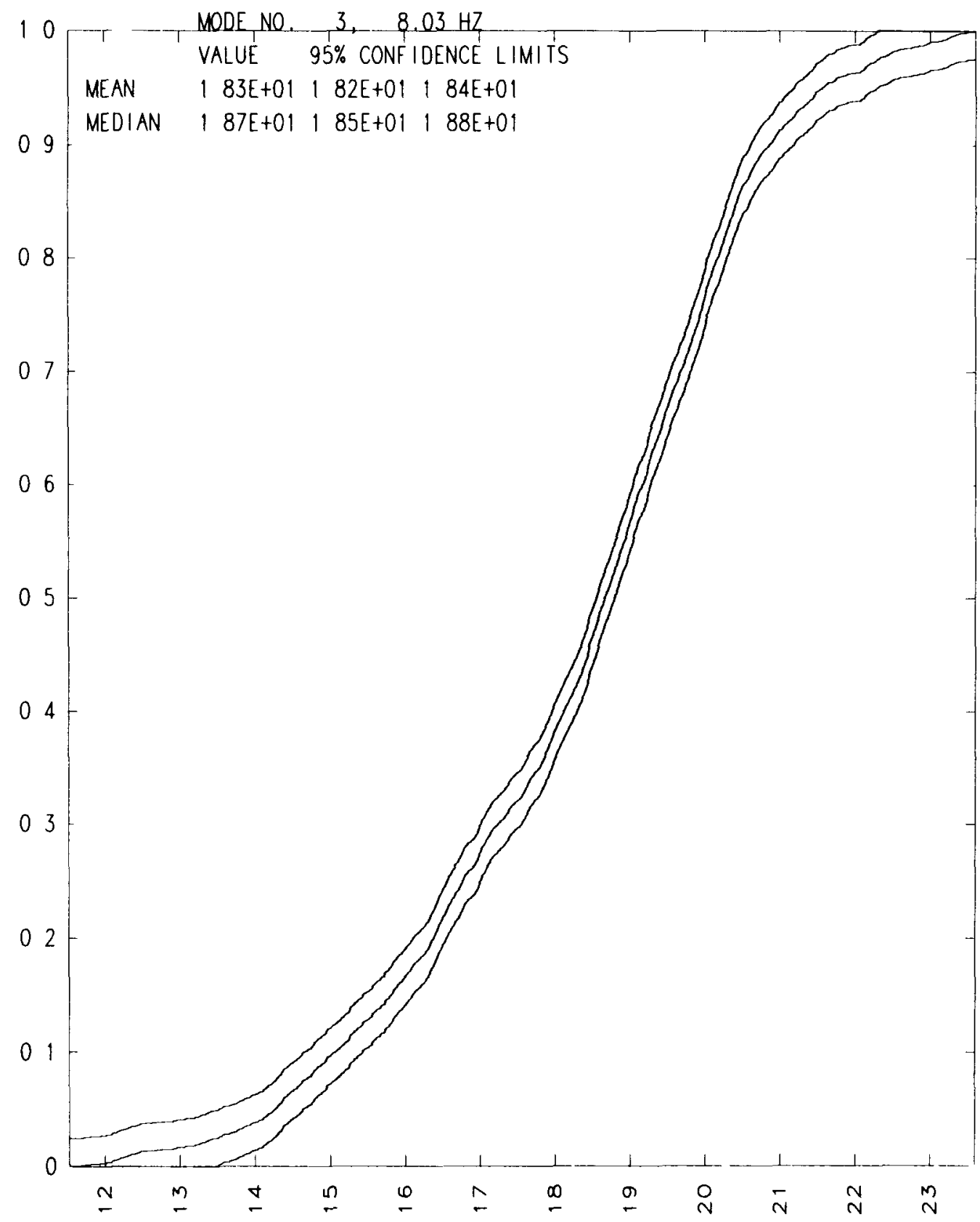

CUMMULATIVE DIST FCN (RG EQ,SRSS) VS SPECTRAL ACCN (GEES) $20 \%$ DAMP WI TH 95\% CONFIDENCE BAND FROM KOLMOGOROV-SMIRNOV TEST

FIG. B-5. Mathematical model for main steam valve house and quench spray area $($ key $=2$, node $=6$, direction $=1$ ). 
MATHEMATICAL MODEL FOR MAIN STEAM VALVE HOUSE \& QUENCH SPRAY AREA

KEY $=3 \quad$ NODE $=6 \quad$ DIRECTION $=1 \quad$ DT $=0.0100 \mathrm{SEC} \quad$ CODE $=02 / 15 / 80 \mathrm{R}$ STRUCTURAL DAMPING IN ALL MODES 5.0\% AVERAGE DVFV BROADENED $15 \%$

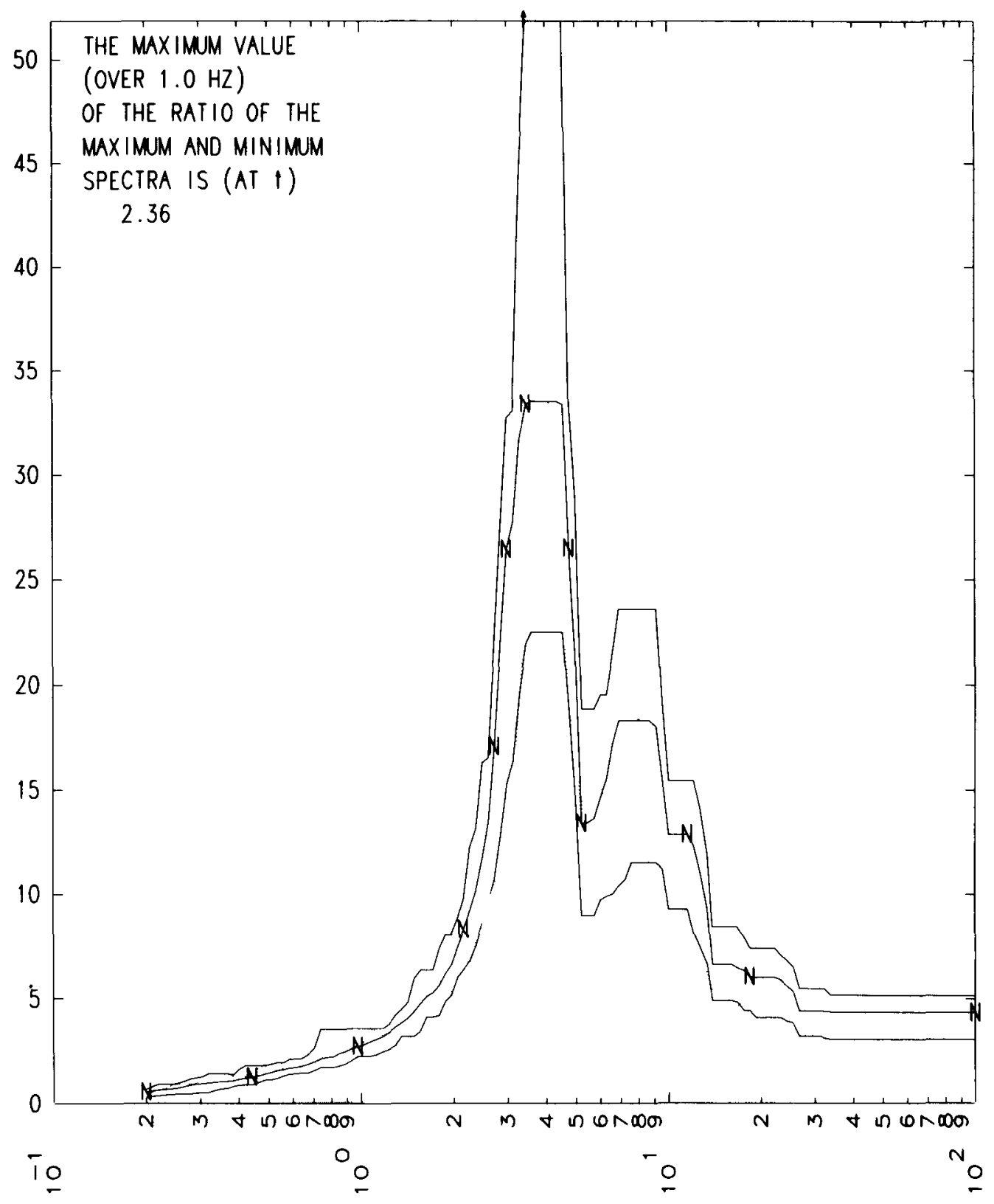

MAX. MEAN + MIN. ACC. SPECTRA (RG EQ,GEES) VS FREQUENCY (HZ) 2.0\% DAMP

FIG. B-6. Mathematical model for main steam valve house and quench spray area (key $=3$, node $=6$, direction $=1$ ). 
MATHEMATICAL MODEL FOR MAIN STEAM VALVE HOUSE \& QUENCH SPRAY AREA

KEY $=4$ NODE $=6 \quad$ DIRECTION $=1 \quad$ DT $=0.0100 \mathrm{SEC} \quad$ CODE $=02 / 15 / 80 \mathrm{R}$ STRUCTURAL DAMPING IN ALL MODES 5.0\% AVERAGE DVFV BROADENED $15 \%$

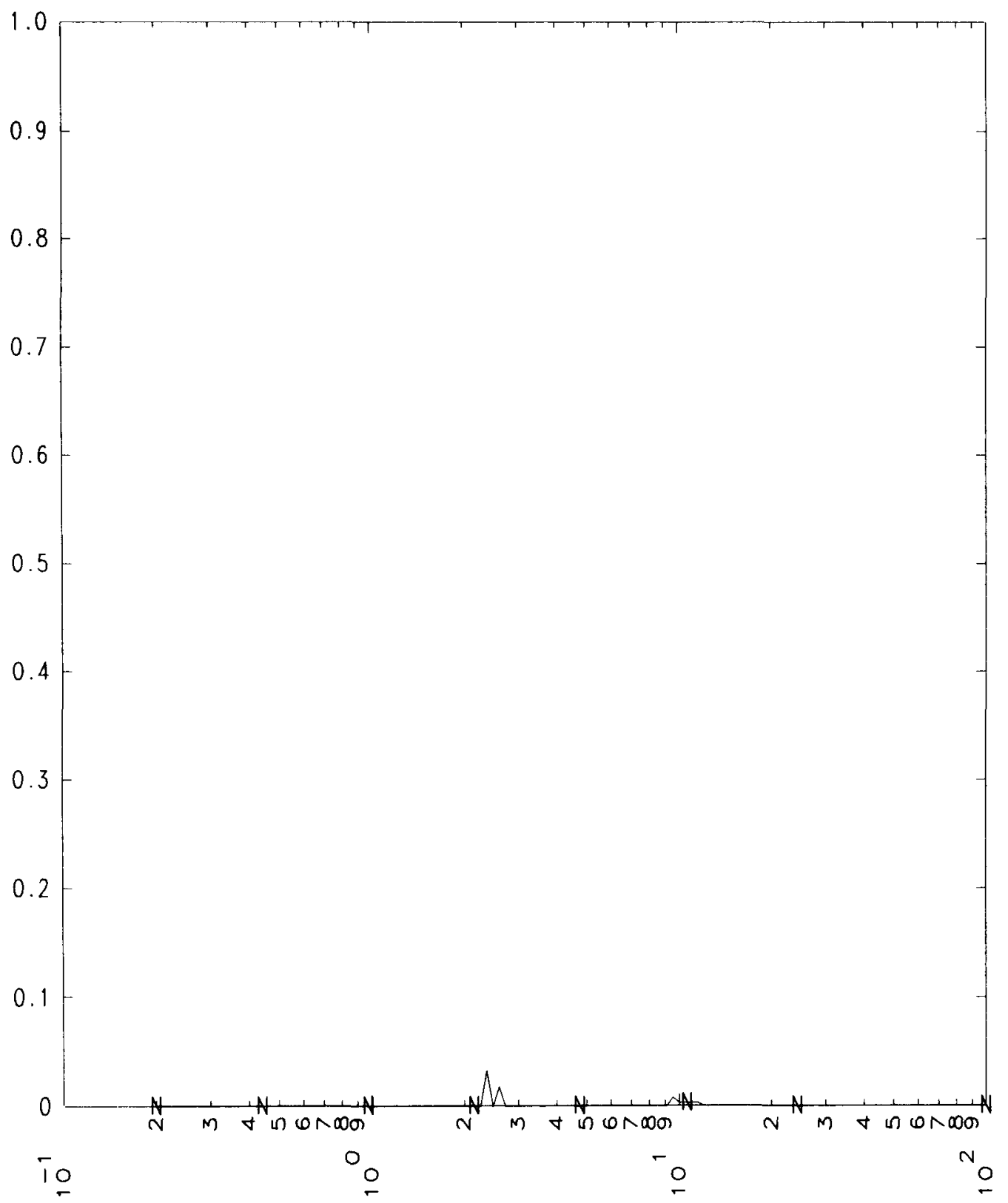

(RG EQ) KOLMOGOROV-SMIRNOV TEST OF NORMAL DISTRIBUTION HYPOTHESIS GOODNESS OF FIT VS FREQUENCY (HZ) $2.0 \%$ DAMP

FIG. B-7. Mathematical model for main steam valve house and quench spray area $($ key $=4$, node $=6$, direction $=1)$. 
MATHEMATICAL MODEL FOR MAIN STEAM VALVE HOUSE \& QUENCH SPRAY AREA

KEY $=5 \quad$ NODE $=6 \quad$ DIRECTION $=1 \quad$ DT $=0.0100 \mathrm{SEC} \quad$ CODE $=02 / 15 / 80 \mathrm{R}$ STRUCTURAL DAMPING IN ALL MODES 5.0\% AVERAGE DVFV BROADENED $15 \%$

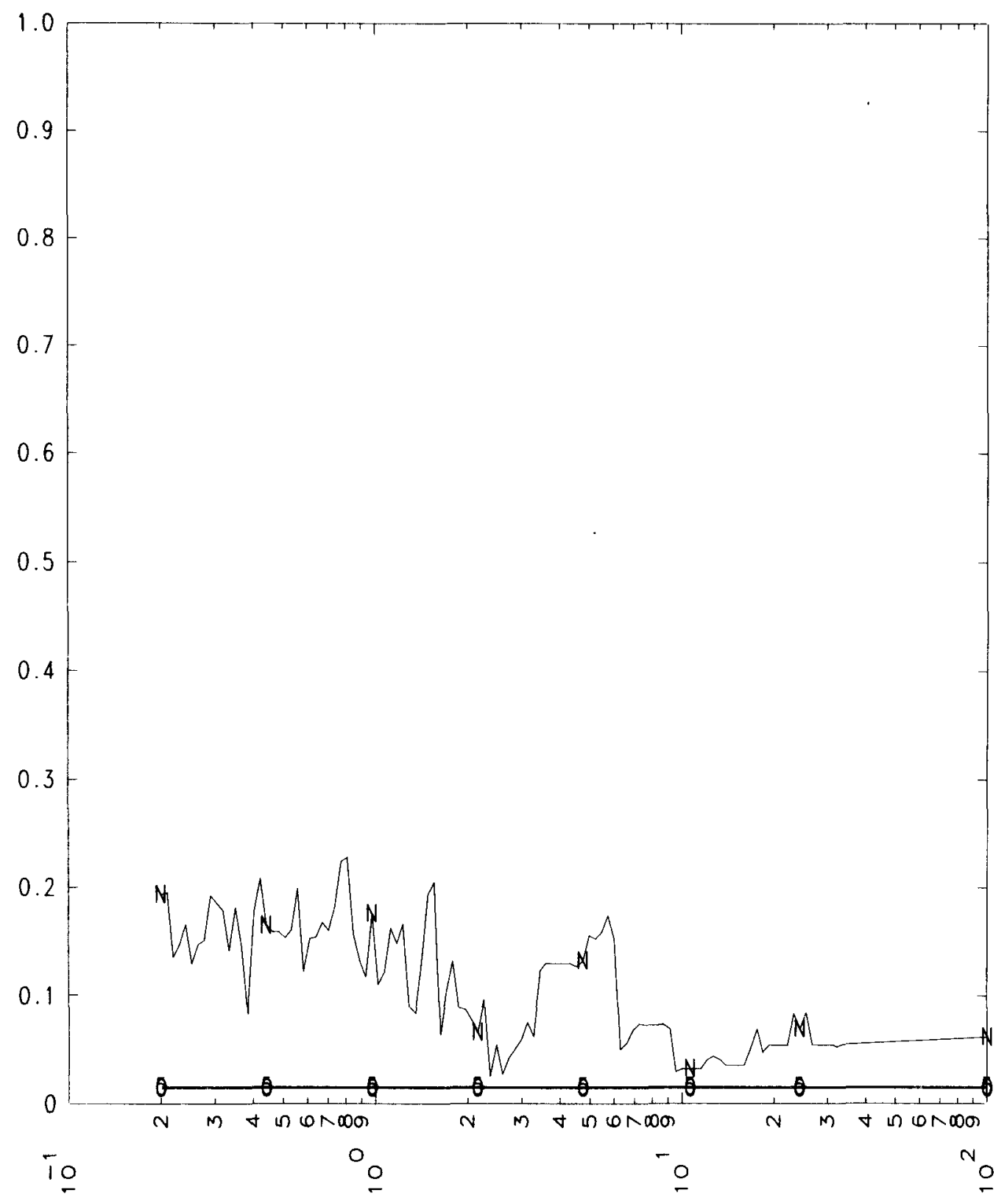

(RG EQ) KOLMOGOROV-SMIRNOV TEST OF NORMAL DISTRIBUTION HYPOTHESIS GOODNESS OF FIT VS FREQUENCY (HZ) $2.0 \%$ DAMP

FIG. B-8. Mathematical model for main steam valve house and quench spray area $($ key $=5$, node $=6$, direction $=1)$. 
MATHEMATICAL MOOEL FOR MAIN STEAM VALVE HOUSE \& QUENCH SPRAY AREA

KEY $=6 \quad$ NODE $=6 \quad$ DIRECTION $=1 \quad$ DT $=0.0100 \mathrm{SEC} \quad$ CODE $=02 / 15 / 80 R$ STRUCTURAL DAMPING IN ALL MODES $5.0 \%$ AVERAGE DVFV BROADENED $15 \%$

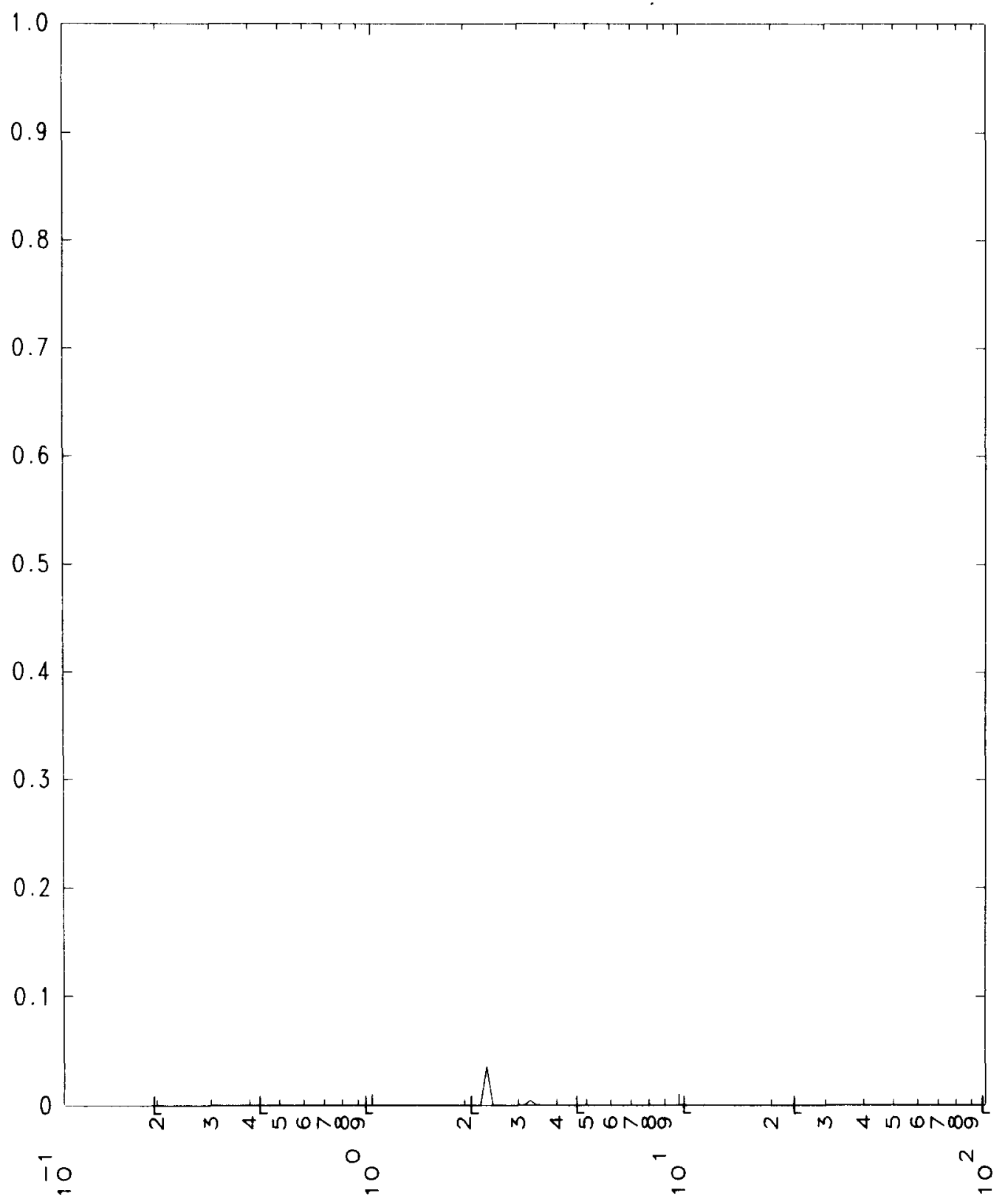

(RG EQ) KOLMOGOROV-SMIRNOV TEST OF LOG NORMAL DISTRIBUTION HYPOTHESIS GOODNESS OF FIT VS FREQUENCY (HZ) $2.0 \%$ DAMP

FIG. B-9. Mathematical model for main steam valve house and quench.spray area (key $=6$, node $=6$, direction $=1$ ). 
MATHEMATICAL MODEL FOR MAIN STEAM VALVE HOUSE \& QUENCH SPRAY AREA

KEY $=7$ NODE $=6 \quad$ DIRECTION $=1 \quad$ DT $=0.0100 \mathrm{SEC} \quad$ CODE $=02 / 15 / 80 \mathrm{R}$ STRUCTURAL DAMPING IN ALL MODES 5.0\% AVERAGE DVFV BROADENED $15 \%$

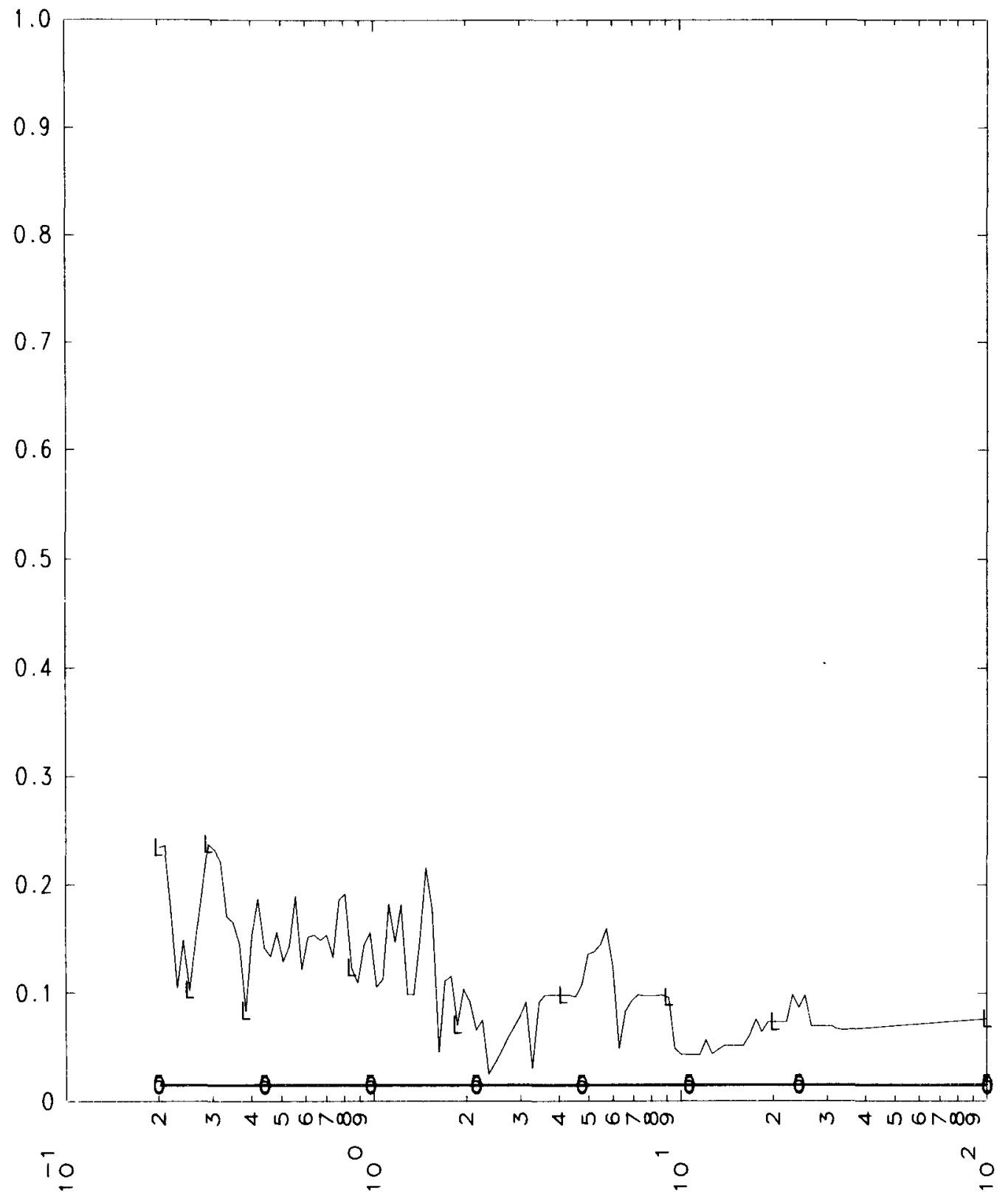

(RG EQ) KOLMOGOROV-SMIRNOV TEST OF LOG NORMAL DISTRIBUTION HYPOTHESIS GOODNESS OF FIT VS FREQUENCY (HZ) $2.0 \%$ DAMP

FIG. B-10. Mathematical model for main steam valve house and quench spray area $($ key $=7$, node $=6$, direction $=1)$. 
MATHEMATICAL MODEL FOR MAIN STEAM VALVE HOUSE \& QUENCH SPRAY AREA

KEY $=8 \quad$ NODE $=6 \quad$ DIRECTION $=1 \quad$ DT $=0.0100 \mathrm{SEC} \quad$ CODE $=02 / 15 / 80 \mathrm{R}$ STRUCTURAL DAMPING IN ALL MODES 5.0\% AVERAGE DVFV BROADENED $15 \%$

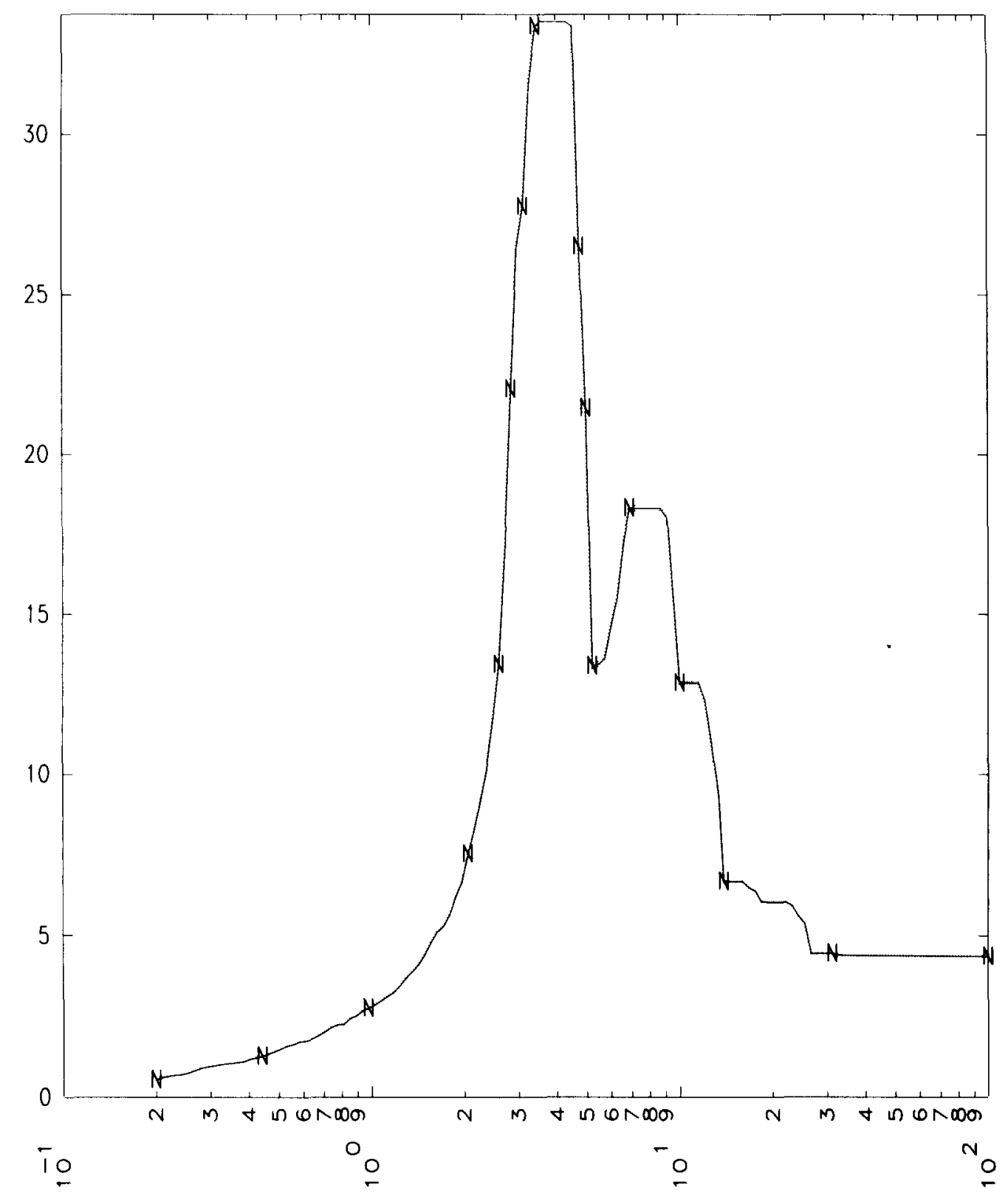

MEAN AND 95\% CONF. LIMIT SPECTRA (RG EQ,GEES) VS FREQ. (HZ) 2.0\% DAMP

FIG. B-1l. Mathematical model for main steam valve house and quench spray area $($ key $=8$, node $=6$, direction $=1)$. 
MATHEMATICAL MODEL FOR MAIN STEAM VALVE HOUSE \& QUENCH SPRAY AREA

KEY $=9 \quad$ NODE $=6 \quad$ DIRECTION $=1 \quad$ DT $=0.0100 \mathrm{SEC} \quad$ CODE $=02 / 15 / 80 \mathrm{R}$ STRUCTURAL DAMPING IN ALL MODES 5.0\% AVERAGE DVFV BROADENED $15 \%$

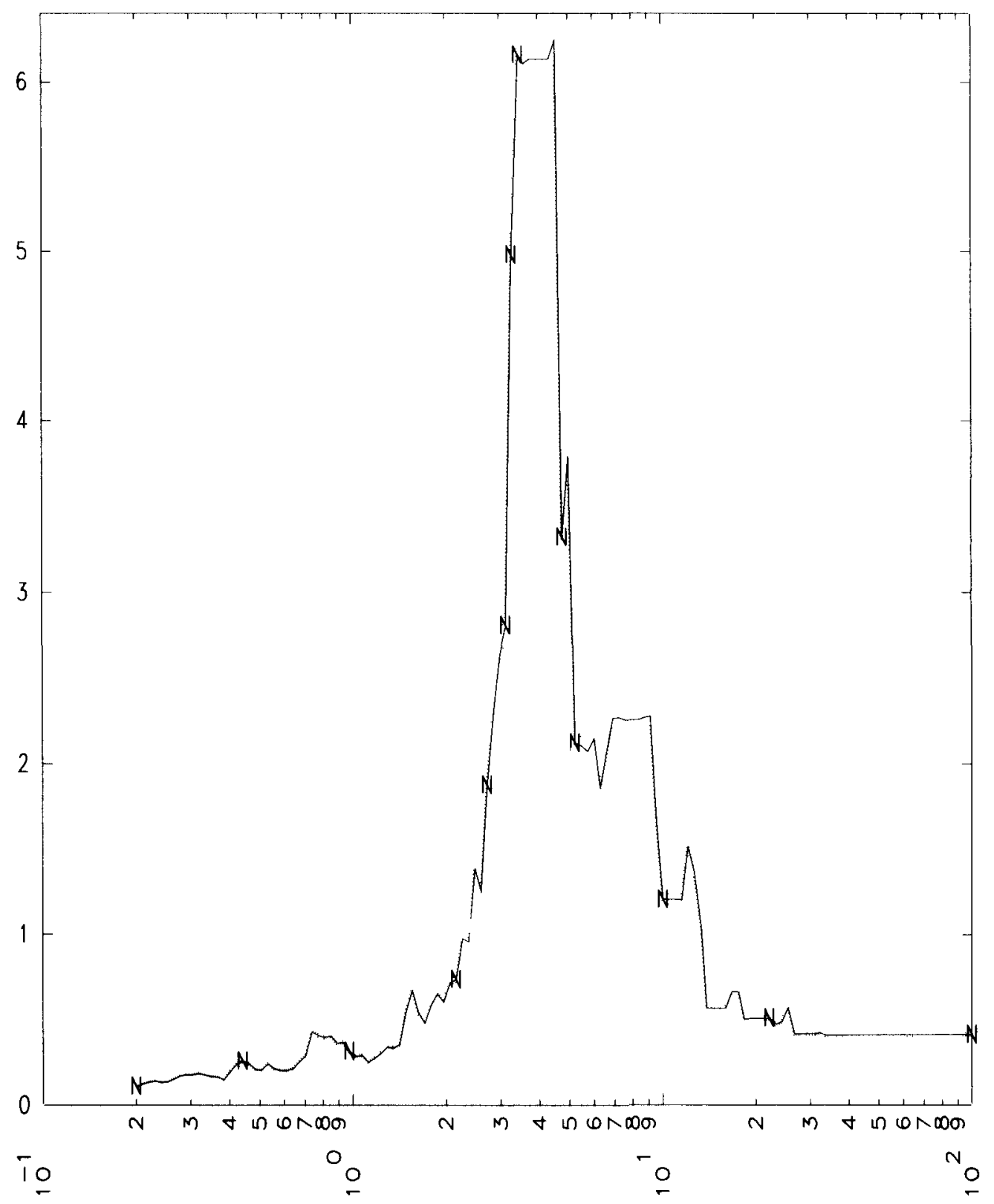

STD. DEV. (WITH 95\% CONF. LIMITS) (RG EQ,GEES) VS FREQ. (HZ) $2.0 \%$ DAMP

FIG. B-12. Mathematical model for main steam valve house and quench spray area (key $=9$, node $=6$, direction $=1$ ). 
MATHEMATICAL MODEL FOR MAIN STEAM VALVE HOUSE \& QUENCH SPRAY AREA

KEY $=10 \quad$ NODE $=6 \quad$ DIRECTION $=1 \quad$ DT $=0.0100 \mathrm{SEC} \quad$ CODE $=02 / 15 / 80 \mathrm{R}$ STRUCTURAL DAMPING IN ALL MODES 5.0\% AVERAGE DVFV

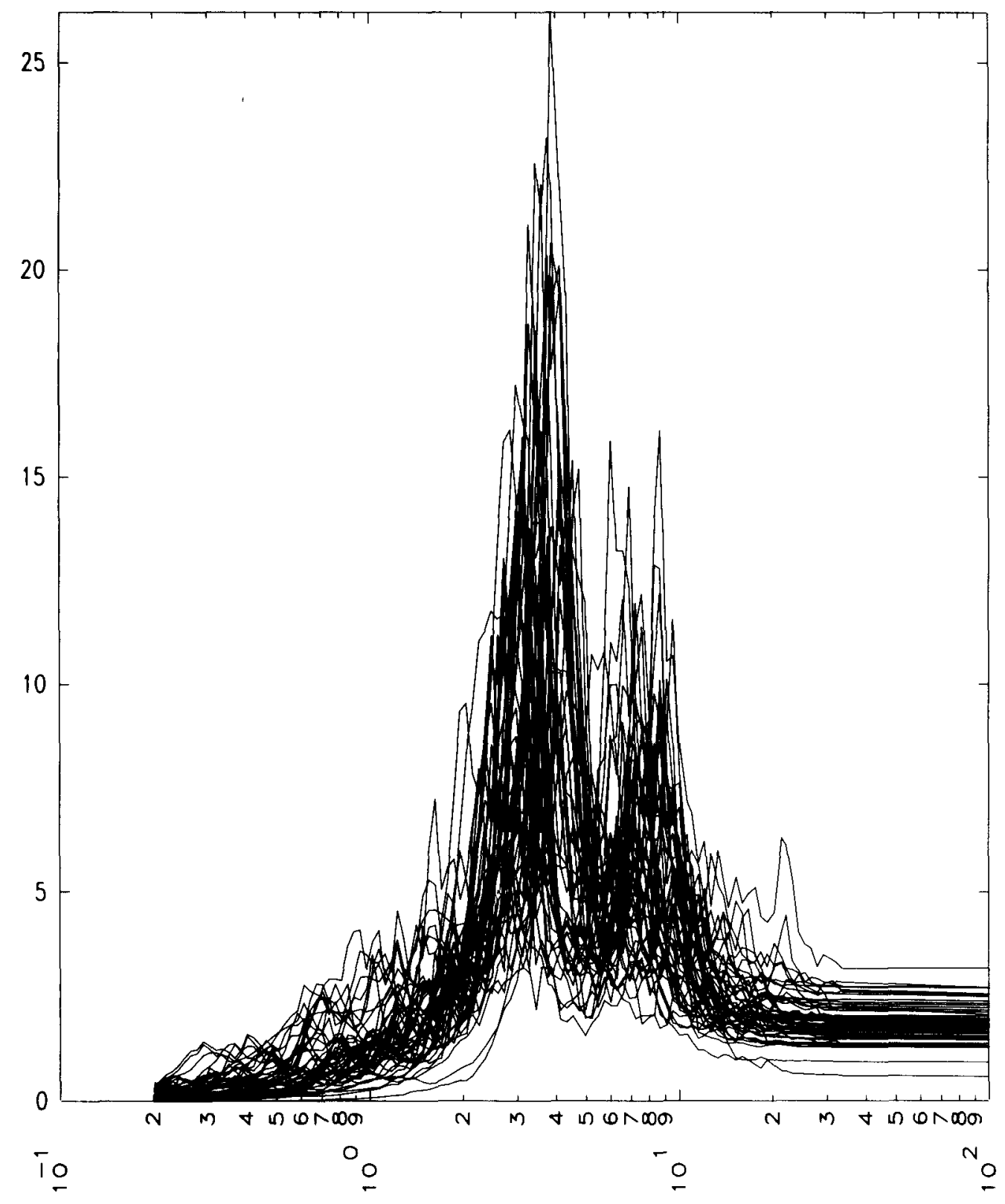

REAL EQ ACCELERATION SPECTRA (GEES) VS FREQUENCY (HZ) $2.0 \%$ DAMPING

FIG. B-13. Mathematical model for main steam valve house and quench spray area $($ key $=10$, node $=6$, direction $=1)$. 
MATHEMATICAL MODEL FOR MAIN STEAM VALVE HOUSE \& QUENCH SPRAY AREA

KEY $=11 \quad$ NODE $=6 \quad$ DIRECTION $=1 \quad$ DT $=0.0100 \mathrm{SEC} \quad$ CODE $=02 / 15 / 80 R$ STRUCTURAL DAMPING IN ALL MODES 5.0\% AVERAGE DVFV

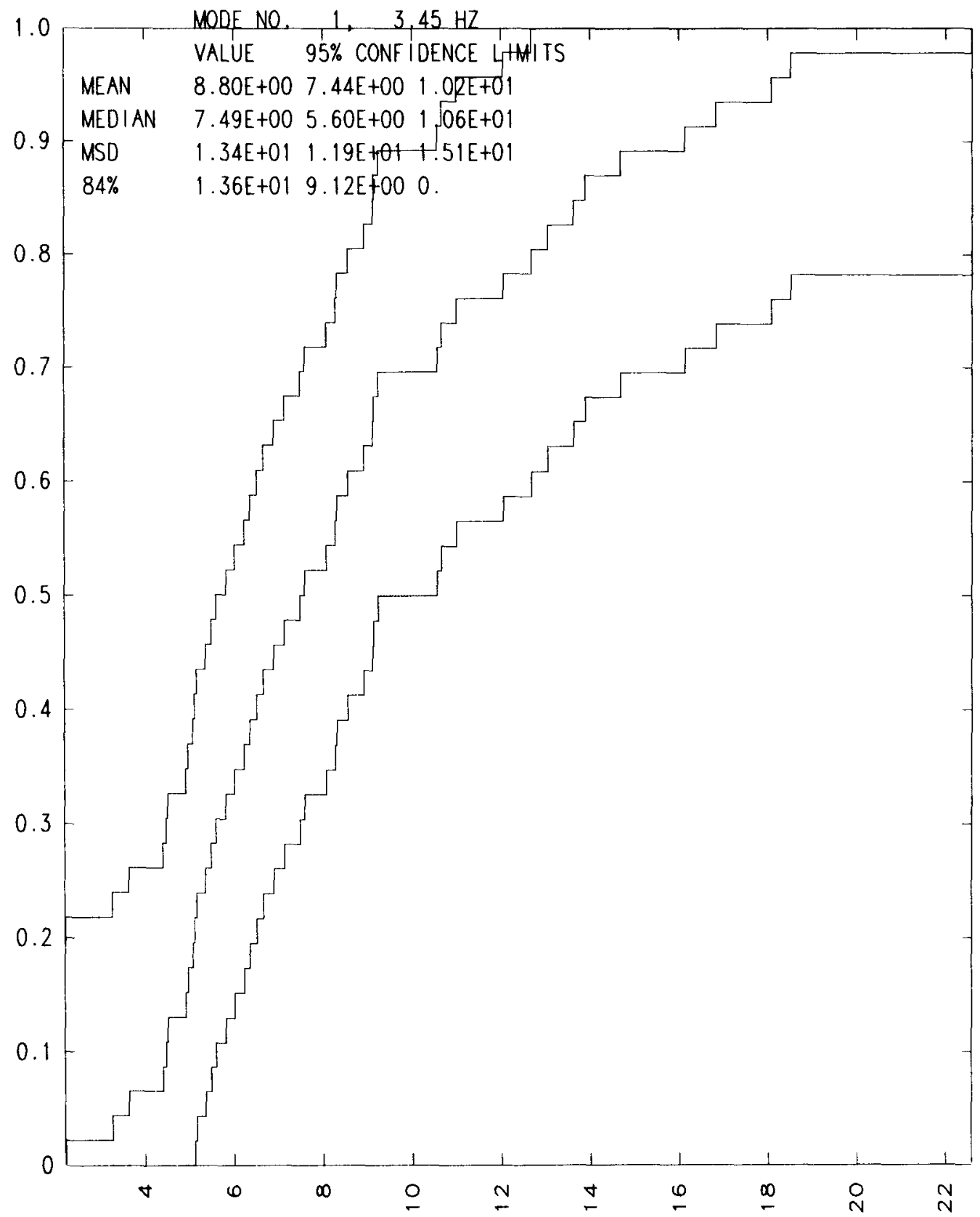

CUMMULATIVE DIST. FCN. (REAL EQ) VS SPECTRAL ACCN. (GEES) $2.0 \%$ DAMP WITH 95\% CONFIDENCE BAND FROM KOLMOGOROV-SMIRNOV TEST

FIG. B-14. Mathematical model for main steam valve house and quench spray area $($ key $=11$, node $=6$, direction $=1)$. 
MATHEMATICAL MODEL FOR MAIN STEAM VALVE HOUSE \& QUENCH SPRAY AREA

KEY $=11 \quad$ NODE $=6 \quad$ DIRECTION $=1 \quad$ DT $=00100 \mathrm{SEC} \quad$ CODE $=02 / 15 / 80 R$ STRUCTURAL DAMPING IN ALL MODES $50 \%$ AVERAGE DVFV

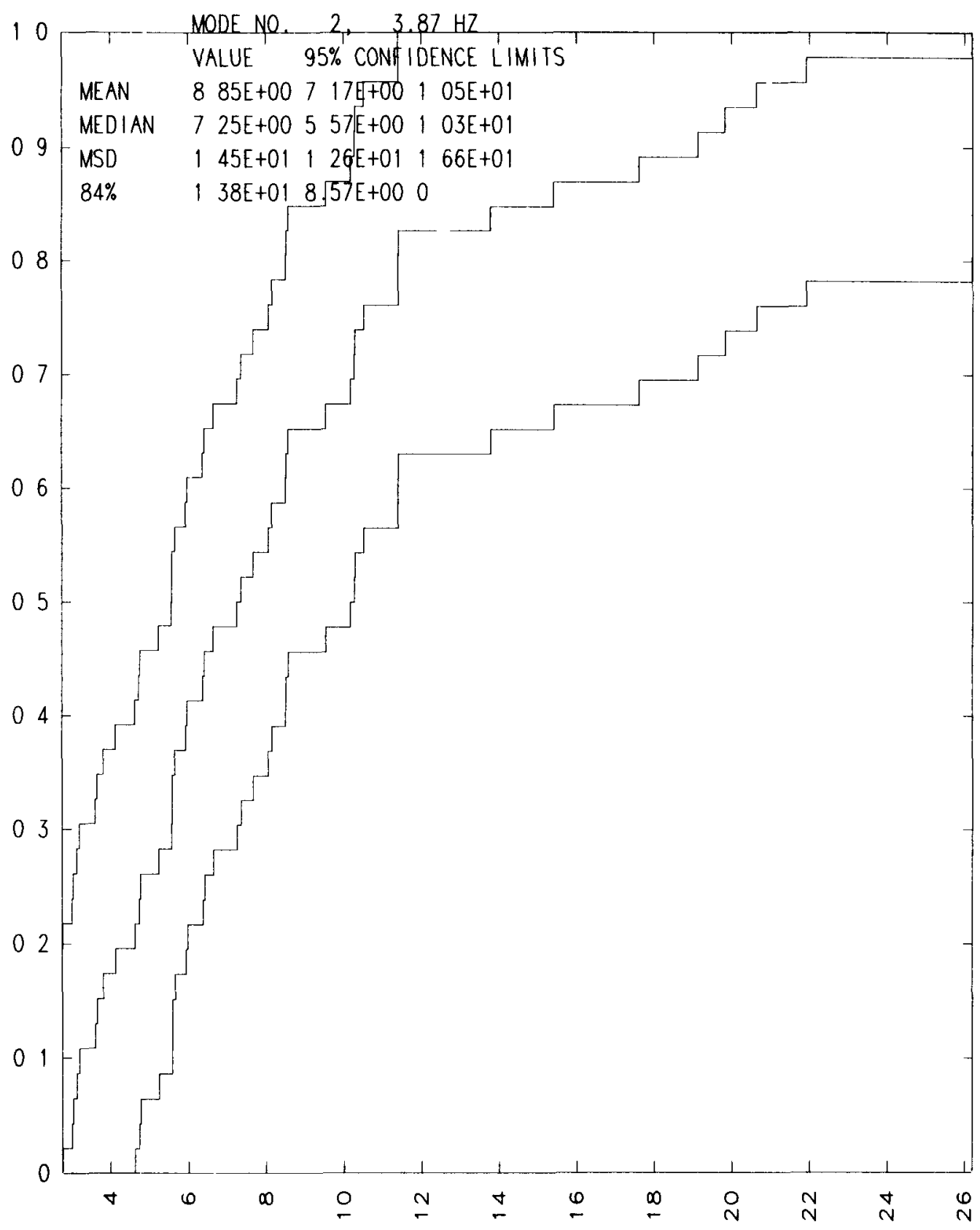

CUMMULATIVE DIST FCN (REAL EQ) VS SPECTRAL ACCN (GEES) $20 \%$ DAMP WITH 95\% CONFIDENCE BAND FROM KOLMOGOROV-SMIRNOV TEST

FIG. B-15. Mathematical model for main steam valve house and quench spray area $($ key $=11$, node $=6$, direction $=1)$. 
MATHEMATICAL MODEL FOR MAIN STEAM VALVE HOUSE \& QUENCH SPRAY AREA

KEY $=11$ NODE $=6 \quad$ DIRECTION $=1 \quad$ DT $=0.0100 \mathrm{SEC} \quad$ CODE $=02 / 15 / 80 \mathrm{R}$ STRUCTURAL DAMPING IN ALL MODES 5.0\% AVERAGE DVFV

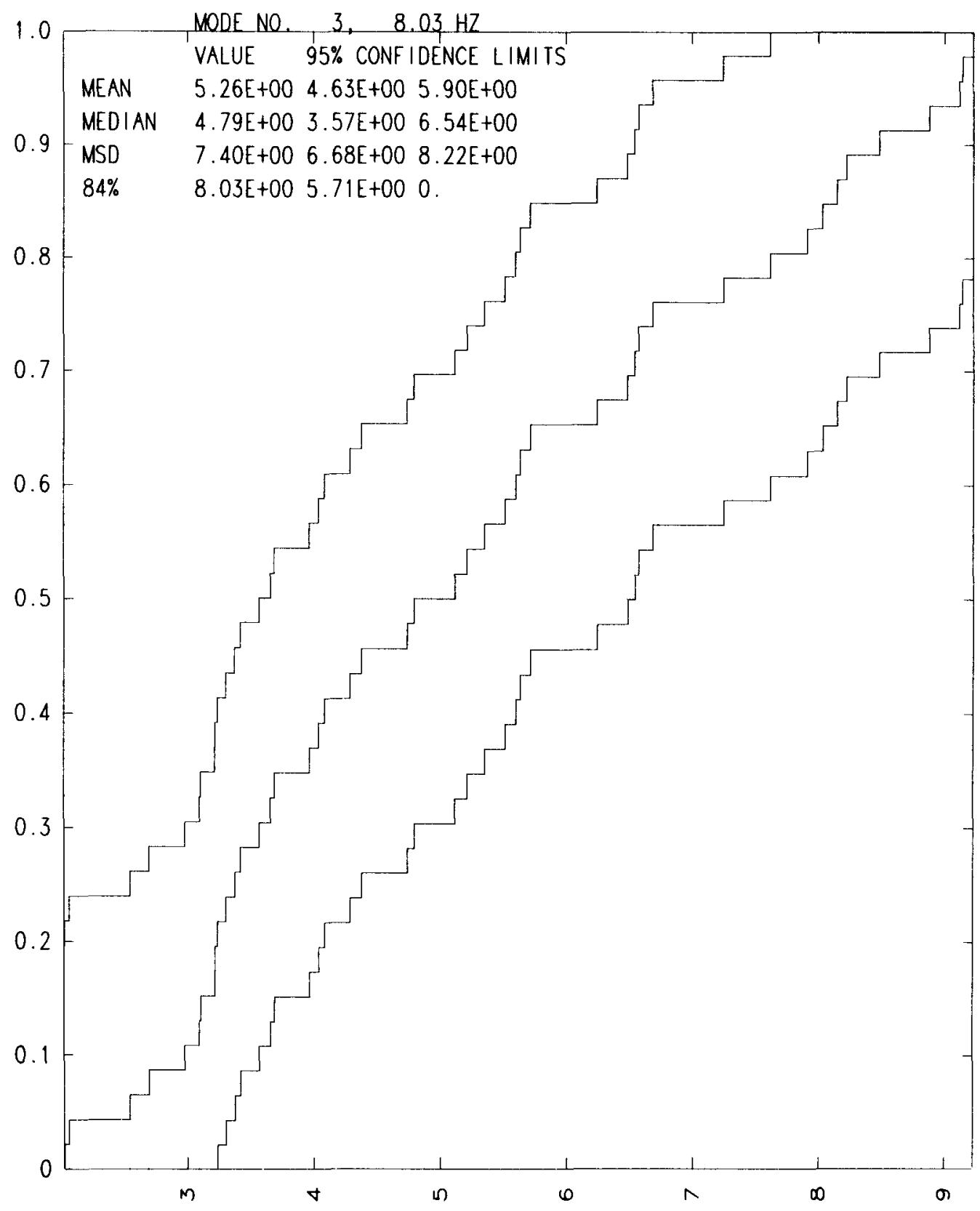

CUMMULATIVE DIST. FCN. (REAL EQ) VS SPECTRAL ACCN. (GEES) 2.0\% DAMP WITH 95\% CONFIDENCE BAND FROM KOLMOGOROV-SMIRNOV TEST

FIG. B-16. Mathematical model for main steam valve house and quench spray area $($ key $=11$, node $=6$, direction $=1)$. 
MATHEMATICAL MODEL FOR MAIN STEAM VALVE HOUSE \& QUENCH SPRAY AREA

KEY $=12 \quad$ NODE $=6 \quad$ DIRECTION $=1 \quad$ DT $=0.0100$ SEC $\quad$ CODE $=02 / 15 / 80 R$ STRUCTURAL DAMPING IN ALL MODES 5.0\% AVERAGE DVFV
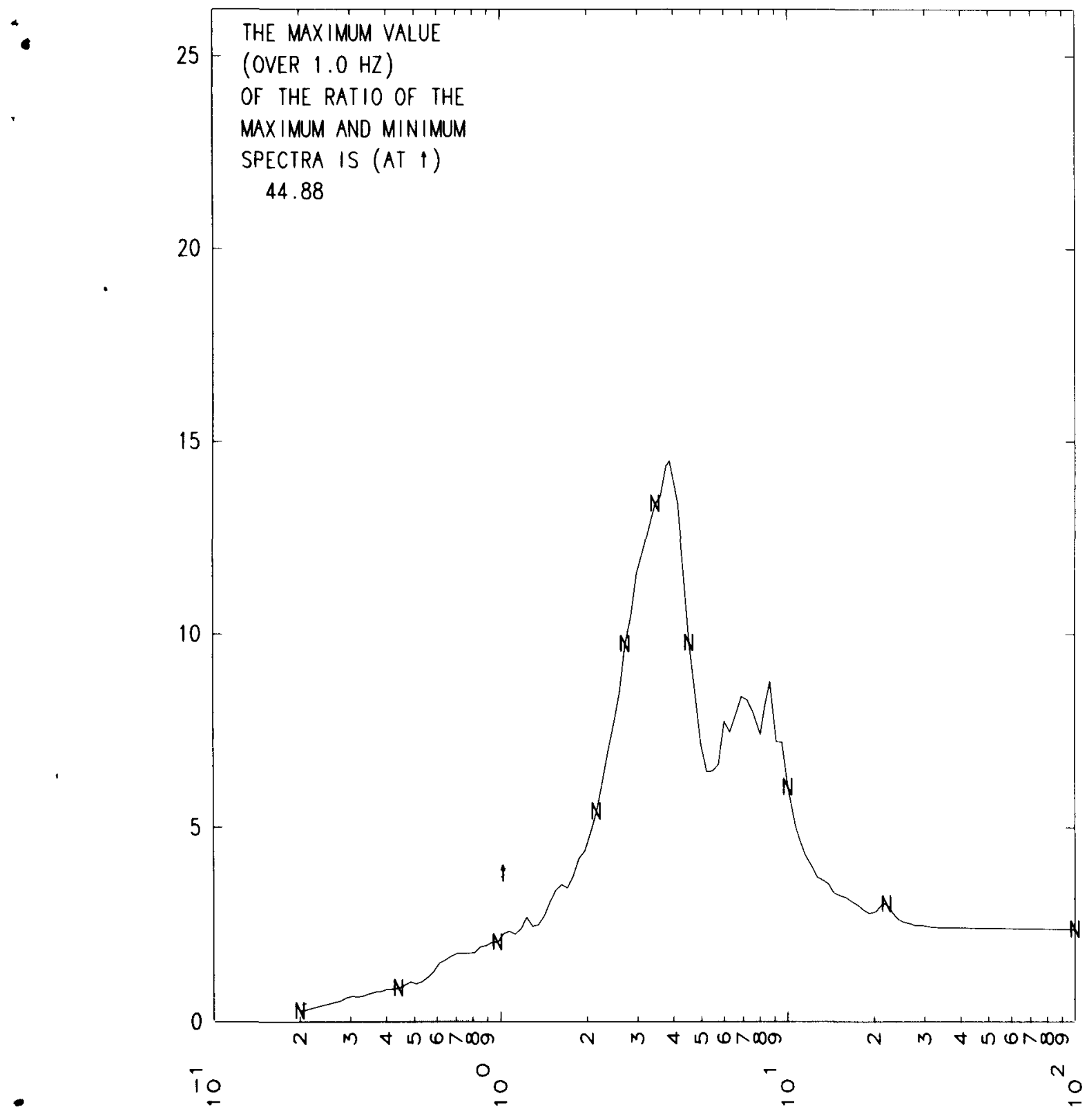

MAX. MSD + MIN ACC. SPECTRA (REAL EQ,GEES) VS FREQUENCY (HZ) $2.0 \%$ DAMP

FIG. B-17. Mathematical model for main steam valve house and quench spray area $($ key $=12$, node $=6$, direction $=1)$. 
MATHEMATICAL MODEL FOR MAIN STEAM VALVE HOUSE \& QUENCH SPRAY AREA

KEY $=13$ NODE $=6 \quad$ DIRECTION $=1 \quad$ DT $=0.0100 \mathrm{SEC} \quad$ CODE $=02 / 15 / 80 \mathrm{R}$

STRUCTURAL DAMPING IN ALL MODES 5.0\% AVERAGE DVFV

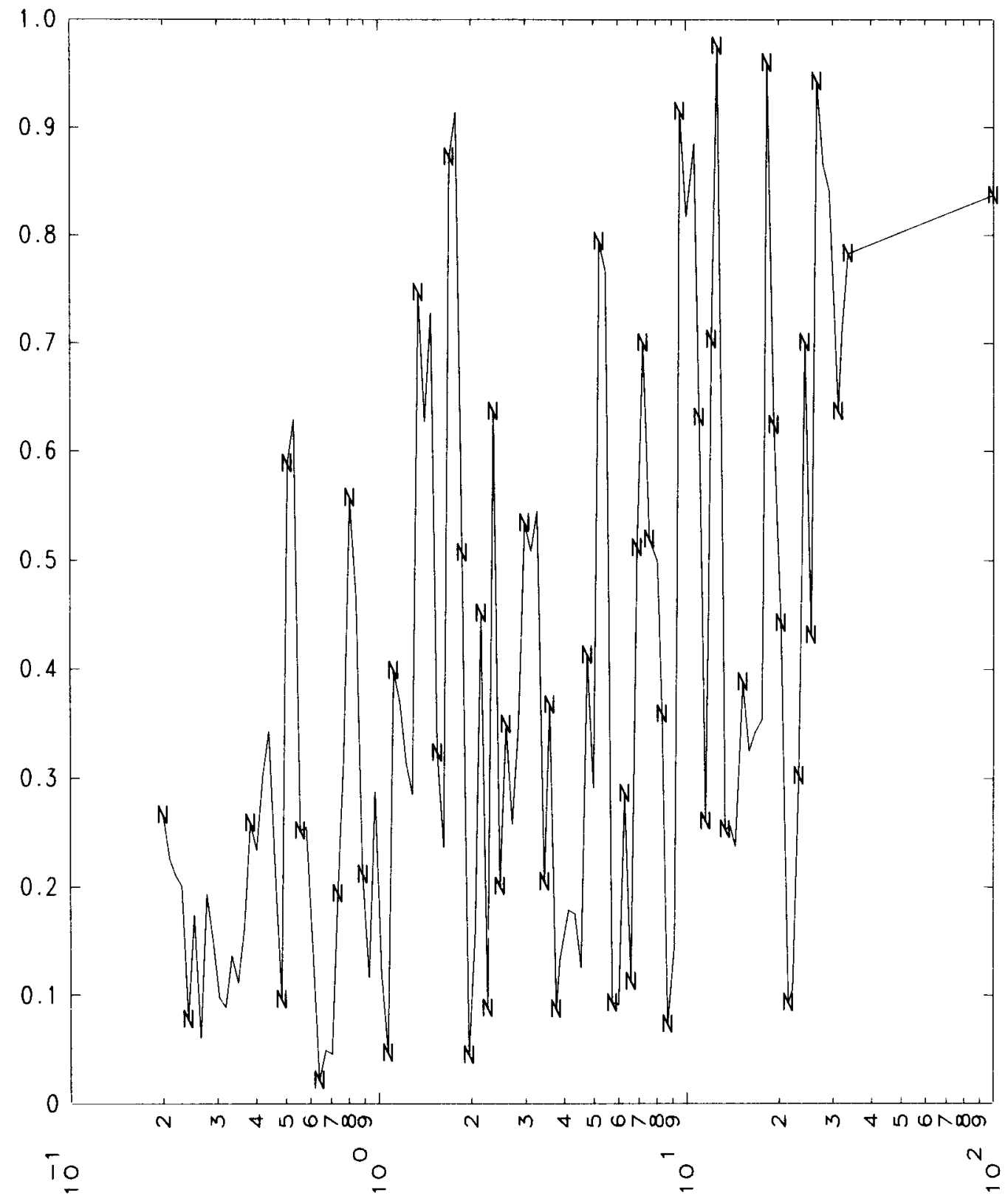

(REAL EQ) KOLMOGOROV-SMIRNOV TEST OF NORMAL DISTRIBUTION HYPOTHESIS GOODNESS OF FIT VS FREQUENCY ( $\mathrm{HZ}$ ) $2.0 \%$ DAMP

FIG. B-18. Mathematical model for main steam valve house and quench spray area $($ key $=13$, node $=6$, direction $=1)$. 
MATHEMATICAL MODEL FOR MAIN STEAM VALVE HOUSE \& QUENCH SPRAY AREA

KEY $=14 \quad$ NODE $=6 \quad$ DIRECTION $=1 \quad$ DT $=0.0100$ SEC $\quad$ CODE $=02 / 15 / 80 R$ STRUCTURAL DAMPING IN ALL MODES 5.0\% AVERAGE DVFV

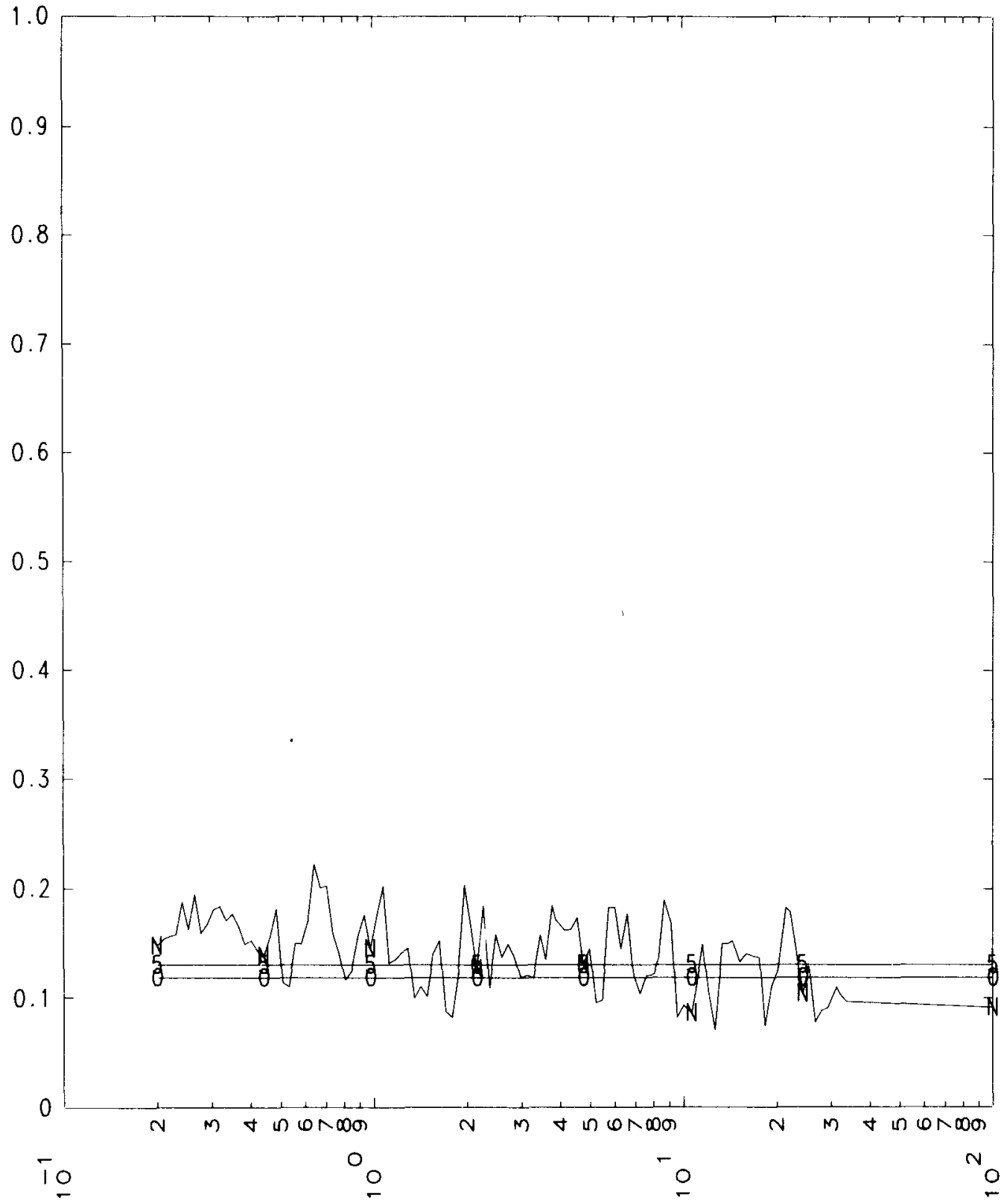

(REAL EQ) KOLMOGOROV-SMIRNOV TEST OF NORMAL DISTRIBUTION HYPOTHESIS GOODNESS OF FIT VS FREQUENCY (HZ) $2.0 \%$ DAMP

FIG. B-19. Mathematical model for main steam valve house and quench spray area $($ key $=14$, node $=6$, direction $=1)$. 
MATHEMATICAL MODEL FOR MAIN STEAM VALVE HOUSE \& QUENCH SPRAY AREA

KEY $=15 \quad$ NODE $=6 \quad$ DIRECTION $=1 \quad$ DT $=0.0100 \mathrm{SEC} \quad$ CODE $=02 / 15 / 80 R$ STRUCTURAL DAMPING IN ALL MODES 5.0\% AVERAGE DVFV

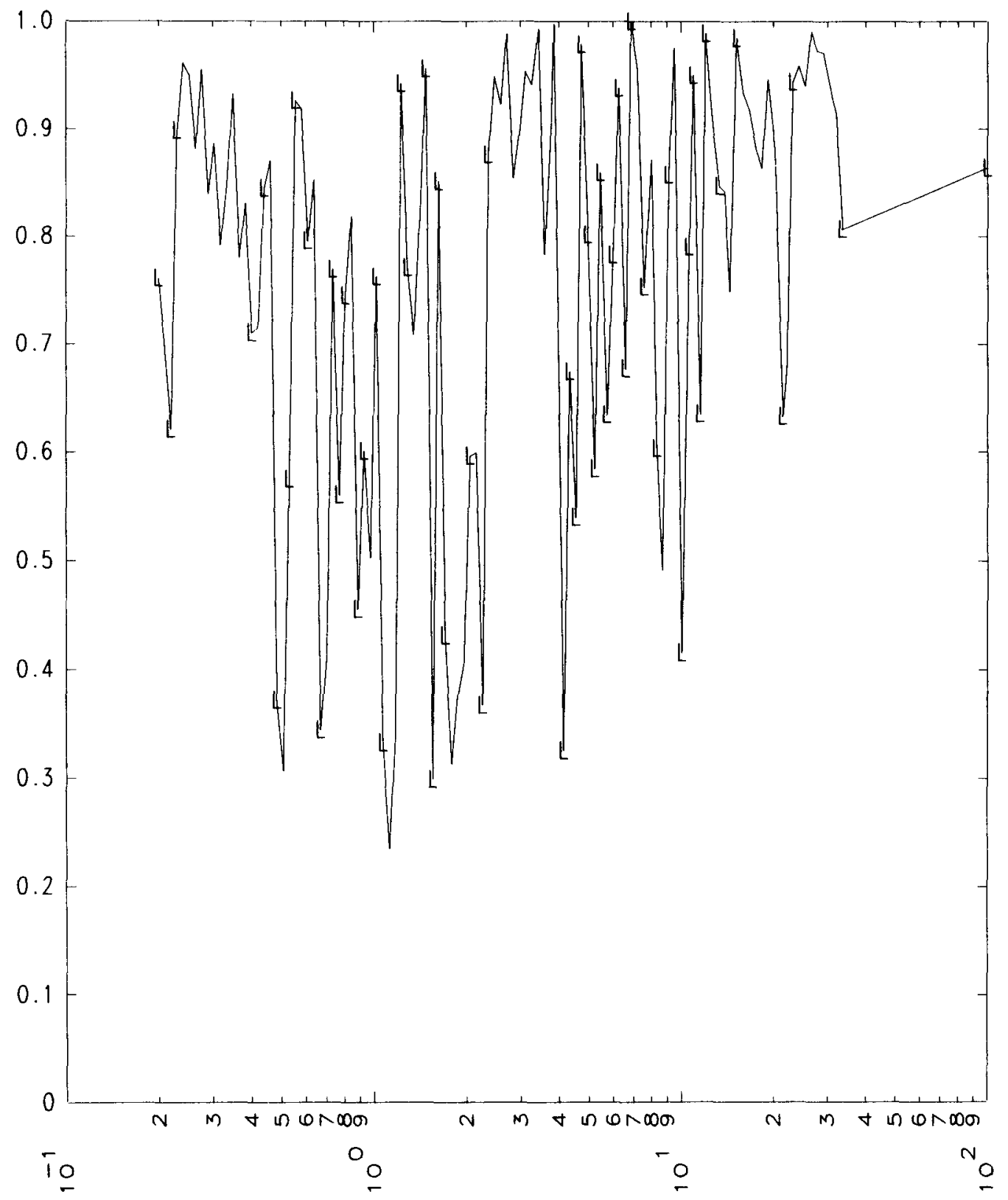

(REAL EQ) KOLMOGOROV-SMIRNOV TEST OF LOG NORMAL DISTRIBUTION HYPOTHESIS GOODNESS OF FIT VS FREQUENCY (HZ) $2.0 \%$ DAMP

FIG. B-20. Mathematical model for main steam valve house and quench spray area $($ key $=15$, node $=6$, direction $=1)$. 
MATHEMATICAL MODEL FOR MAIN STEAM VALVE HOUSE \& QUENCH SPRAY AREA

KEY $=16 \quad$ NODE $=6 \quad$ DIRECTION $=1 \quad$ DT $=0.0100 \mathrm{SEC} \quad$ CODE $=02 / 15 / 80 R$ STRUCTURAL DAMPING IN ALL MODES 5.0\% AVERAGE DVFV

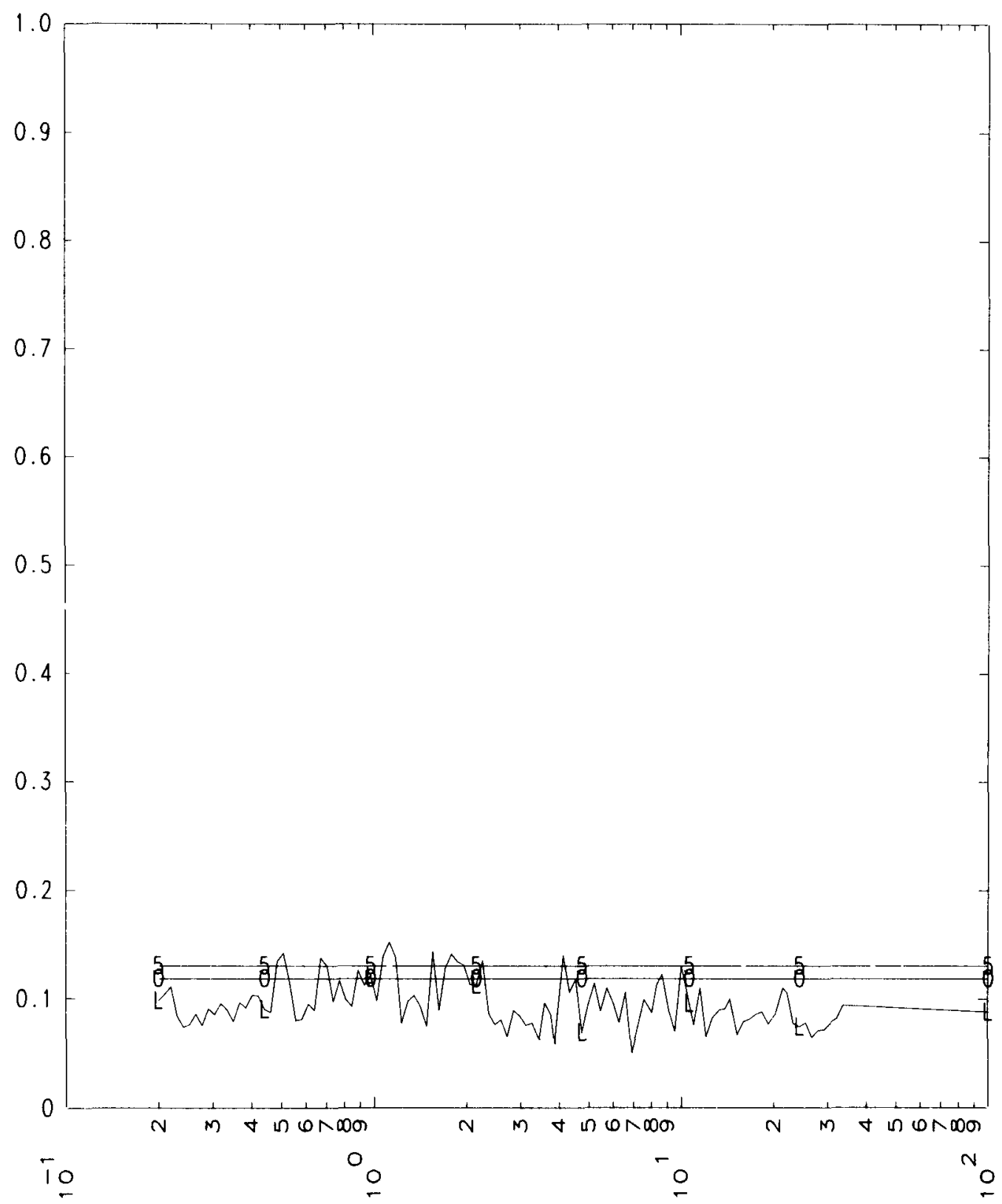

(REAL EQ) KOLMOGOROV-SMIRNOV TEST OF LOG NORMAL DISTRIBUTION HYPOTHESIS GOODNESS OF FIT VS FREQUENCY (HZ) $2.0 \%$ DAMP

FIG. B-21. Mathematical model for main steam valve house and quench spray area $($ key $=16$, node $=6$, direction $=1)$. 
MATHEMATICAL MODEL FOR MAIN STEAM VALVE HOUSE \& QUENCH SPRAY AREA

KEY $=17$ NODE $=6 \quad$ DIRECTION $=1 \quad$ OT $=0.0100 \mathrm{SEC} \quad$ CODE $=02 / 15 / 80 \mathrm{R}$ STRUCTURAL DAMPING IN ALL MODES 5.0\% AVERAGE DVFV

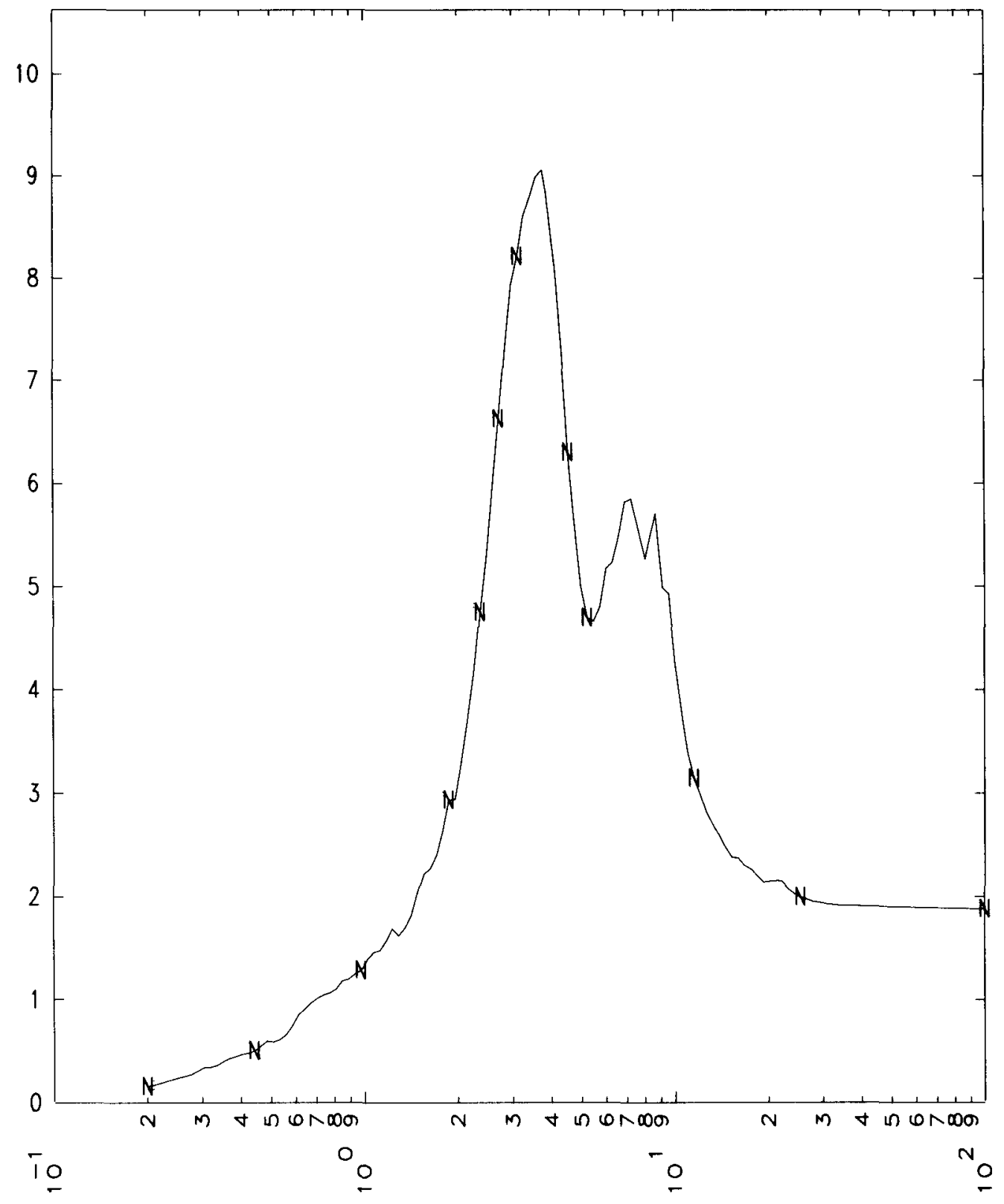

MEAN AND 95\% CONF. LIMIT SPECTRA (REAL EQ,GEES) VS FREQ. (HZ) $2.0 \%$ DAMP

FIG. B-22. Mathematical model for main steam valve house and quench spray area $($ key $=17$, node $=6$, direction $=1)$. 
MATHEMATICAL MODEL FOR MAIN STEAM VALVE HOUSE \& QUENCH SPRAY AREA

KEY $=18 \quad \mathrm{NODE}=6 \quad$ DIRECTION $=1 \quad$ DT $=0.0100 \mathrm{SEC} \quad$ CODE $=02 / 15 / 80 \mathrm{R}$ STRUCTURAL DAMPING IN ALL MODES 5.0\% AVERAGE DVFV

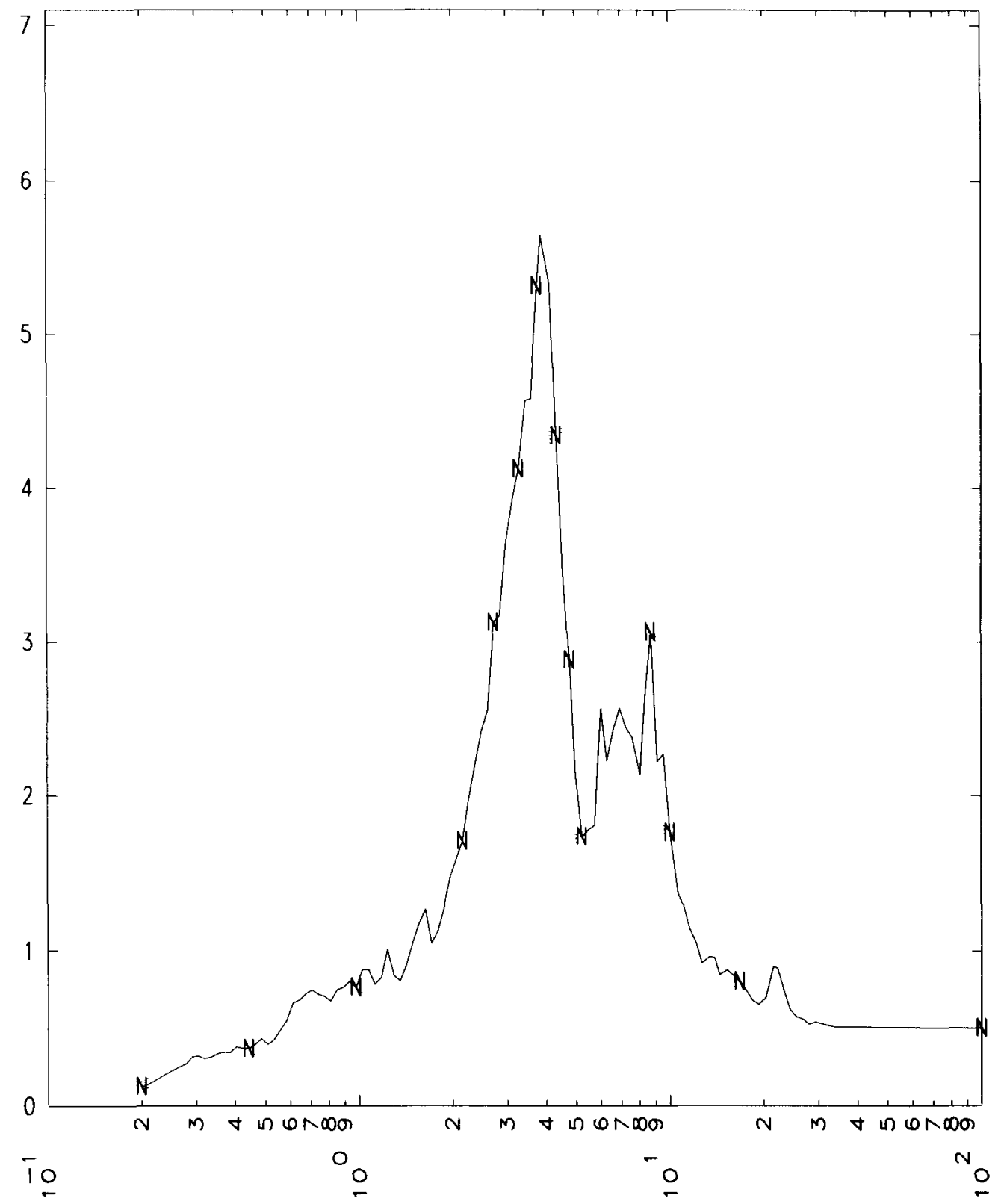

STD. DEV. (W/95\% CONF. LIMITS) (REAL EQ,GEES) VS FREQ. (HZ) 2.0\% DAMP

FIG. B-23. Mathematical model for main steam valve house and quench spray area (key $=18$, node $=6$, direction $=1)$. 
MATHEMATICAL MODEL FOR MAIN STEAM VALVE HOUSE \& QUENCH SPRAY AREA

KEY $=19 \quad$ NODE $=6 \quad$ DIRECTION $=1 \quad$ DT $=0.0100 \mathrm{SEC} \quad$ CODE $=02 / 15 / 80 R$ SIRUCTURAL DAMPING IN ALL MODES 5.0\% AVERAGE DVFV

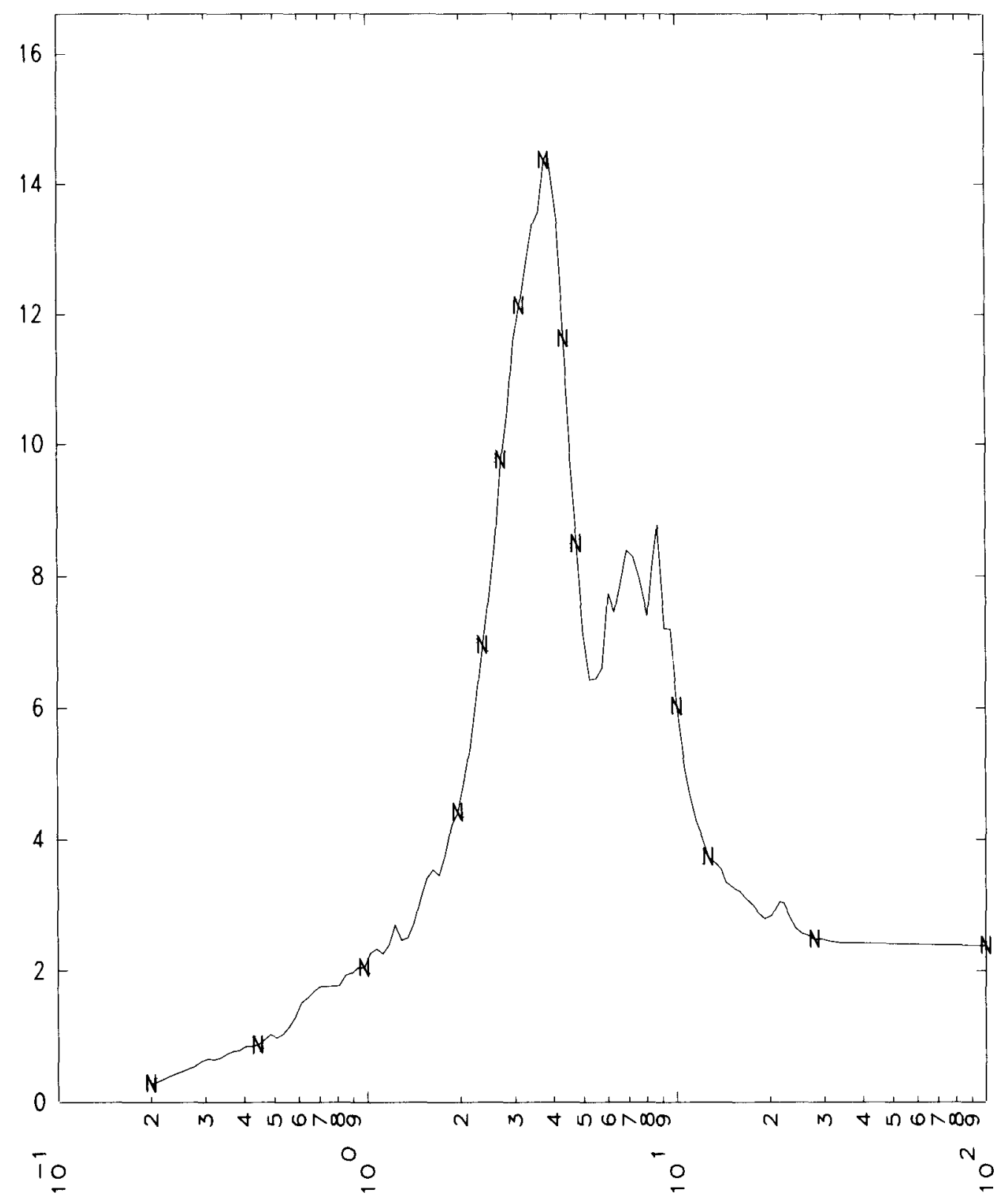

MSD AND 95\% CONF. LIMIT SPECTRA (REAL EQ,GEES) VS FREQ. (HZ) 2.0\% DAMP

FIG. B-24. Mathematical model for main steam valve house and quench spray area $($ key $=19$, node $=6$, direction $=1)$. 
MATHEMATICAL MODEL FOR MAIN STEAM VALVE HOUSE \& QUENCH SPRAY AREA

KEY $=20 \quad$ NODE $=6 \quad$ DIRECTION $=1 \quad$ DT $=0.0100$ SEC $\quad$ CODE $=02 / 15 / 80 R$ STRUCTURAL DAMPING IN ALL MODES 5.0\% AVERAGE DVFV

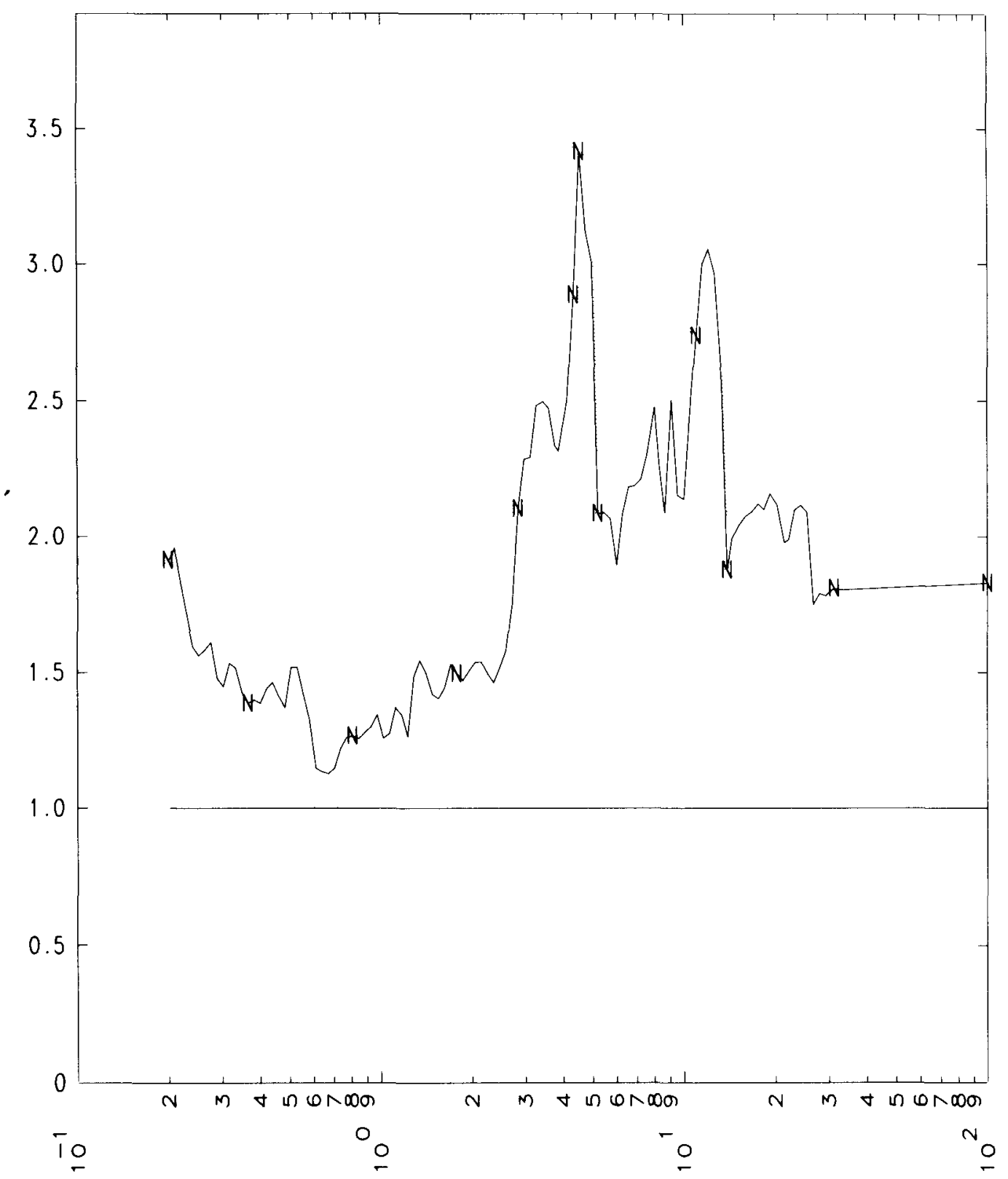

FACTOR OF COMPARISON (WITH 95\% CONF. LIMITS) VS FREQ. (HZ) $2.0 \%$ DAMP

FIG. B-25. Mathematical model for main steam valve house and quench spray area $($ key $=20$, node $=6$, direction $=1)$. 
MATHEMATICAL MODEL FOR MAIN STEAM VALVE HOUSE \& QUENCH SPRAY AREA

KEY $=21 \quad$ NODE $=6 \quad$ DIRECTION $=1 \quad$ DT $=0.0100 \mathrm{SEC} \quad$ CODE $=02 / 15 / 80 R$ STRUCTURAL DAMPING IN ALL MODES 5.0\% AVERAGE DVFV BROADENED $15 \%$

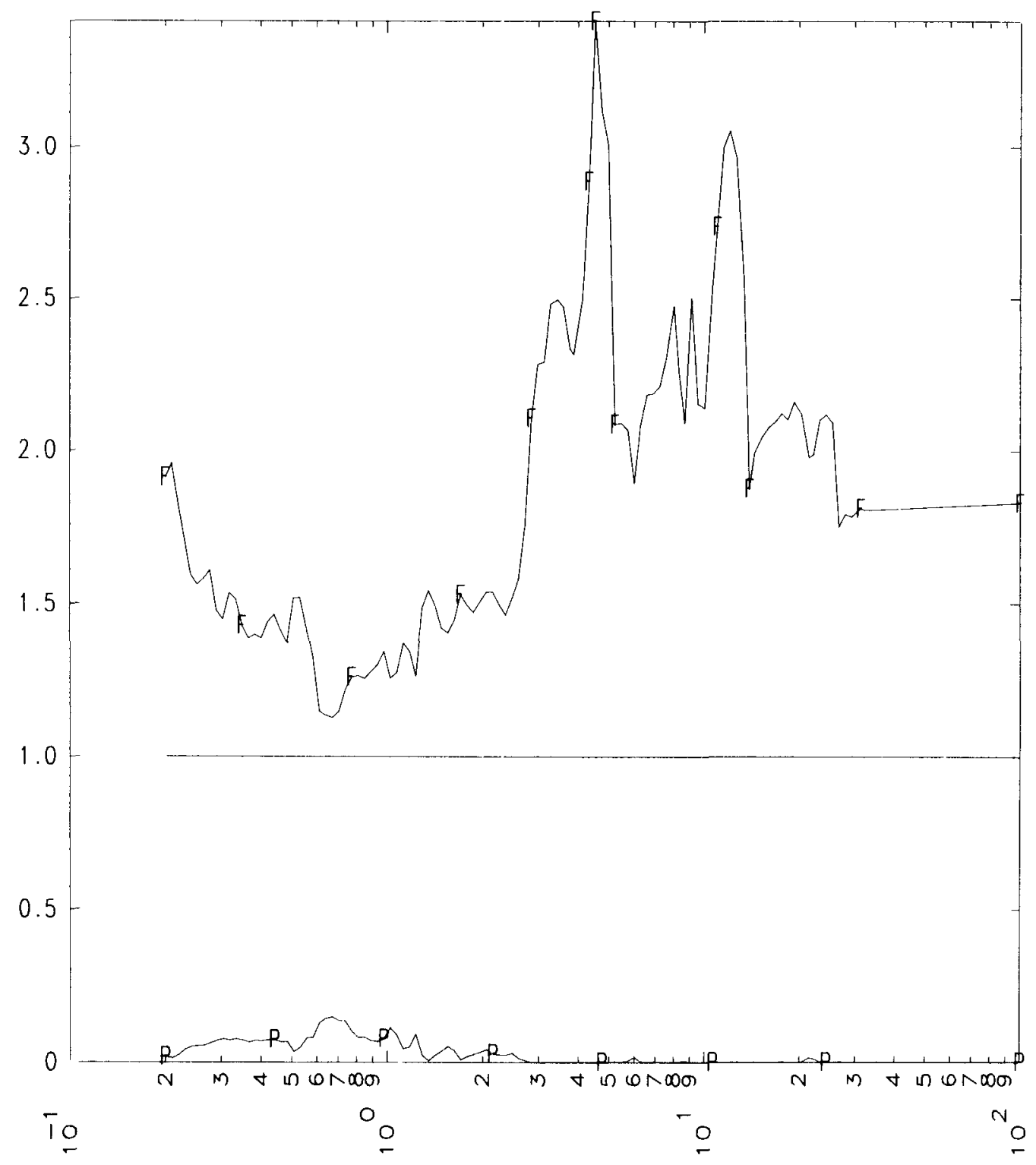

FACTOR OF COMPARISON (F) VS FREQUENCY SUPERIMPOSED ON MEASURE OF PROBABILITY OF EXCEEDING SRSS SPECTRA FROM R.G. 1.60 SYNTHETIC TIME HIST. PROBABILITY VS FREQUENCY (HZ) $2.0 \%$ DAMPING

FIG. B-26. Mathematical model for main steam valve house and quench spray area $($ key $=21$, node $=6$, direction $=1)$. 
MATHEMATICAL MODEL FOR MAIN STEAM VALVE HOUSE \& QUENCH SPRAY AREA

KEY $=22 \quad$ NODE $=6 \quad$ DIRECTION $=1 \quad$ DT $=0.0100 \mathrm{SEC} \quad$ CODE $=02 / 15 / 80 \mathrm{R}$ STRUCTURAL DAMPING IN ALL MODES 5.0\% AVERAGE DVFV BROADENED $15 \%$

:

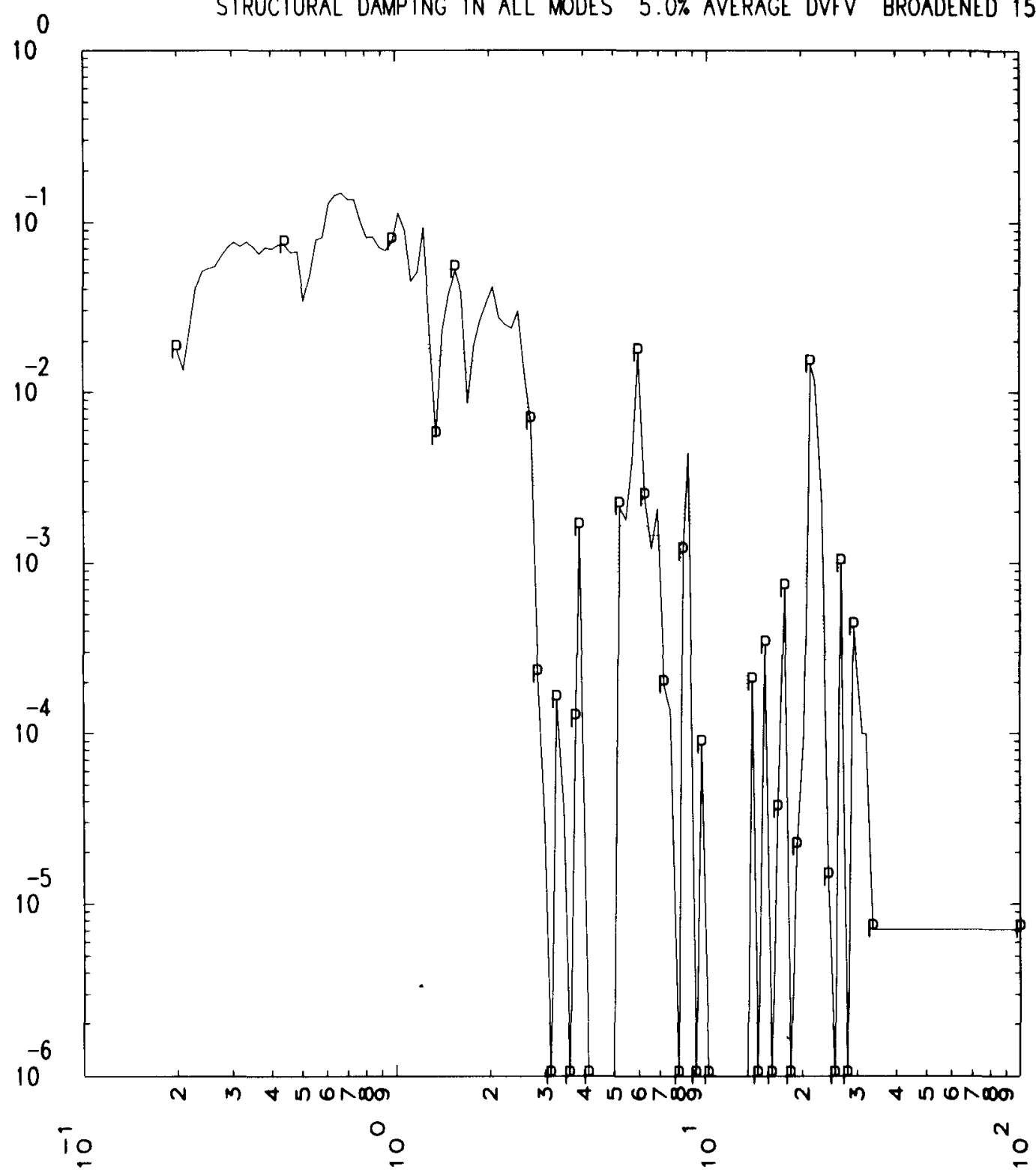

PROBABILITY OF EXCEEDING SRSS SPECTRA FROM R.G. 1.60 SYNTHETIC TIME HIST. PROBABILITY VS FREQUENCY (HZ) $2.0 \%$ DAMPING

FIG. B-27. Mathematical model for main steam valve house and quench spray area $($ key $=22$, node $=6$, direction $=1)$. 
MATHEMATICAL MODEL FOR MAIN STEAM VALVE HOUSE \& QUENCH SPRAY AREA

KEY $=23 \quad$ NODE $=6 \quad$ DIRECTION $=1 \quad$ DT $=0.0100 \mathrm{SEC} \quad$ CODE $=02 / 15 / 80 R$ STRUCTURAL DAMPING IN ALL MODES 5.0\% AVERAGE DVFV BROADENED $15 \%$

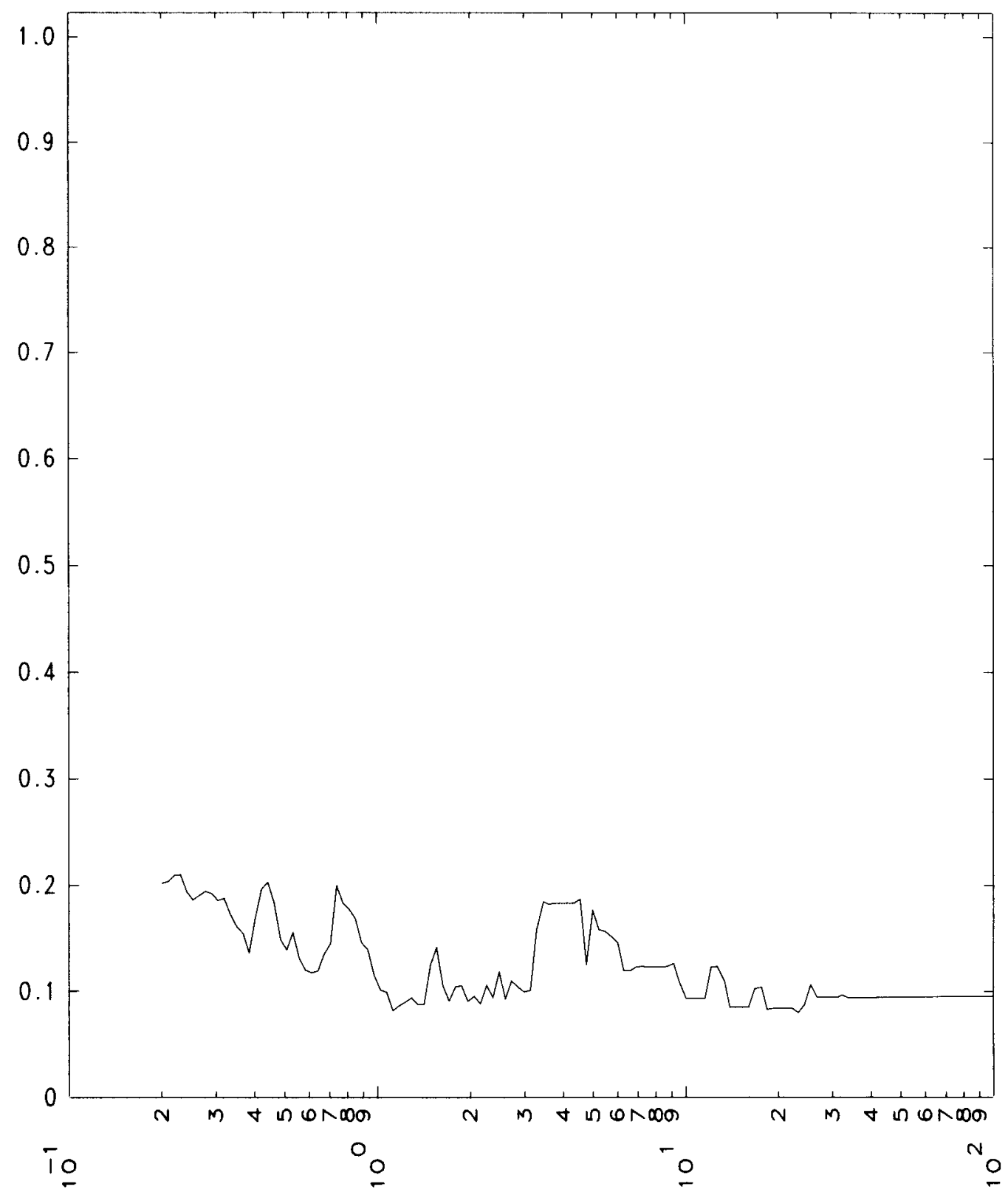

COEFFICIENT OF VARIATION (REALS \& RG) VS FREQ. (HZ) $2.0 \%$ DAMP

FIG. B-28. Mathematical model for main steam valve house and quench spray area (key $=23$, node $=6$, direction $=1)$. 
MATHEMATICAL MODEL FOR MAIN STEAM VALVE HOUSE \& QUENCH SPRAY AREA

KEY $=24 \quad$ NODE $=6 \quad$ DIRECTION $=1 \quad$ DT $=0.0100 \mathrm{SEC} \quad$ CODE $=02 / 15 / 80 \mathrm{R}$ STRUCTURAL DAMPING IN ALL MODES 5.0\% AVERAGE DVFV BROADENED $15 \%$

$\because$

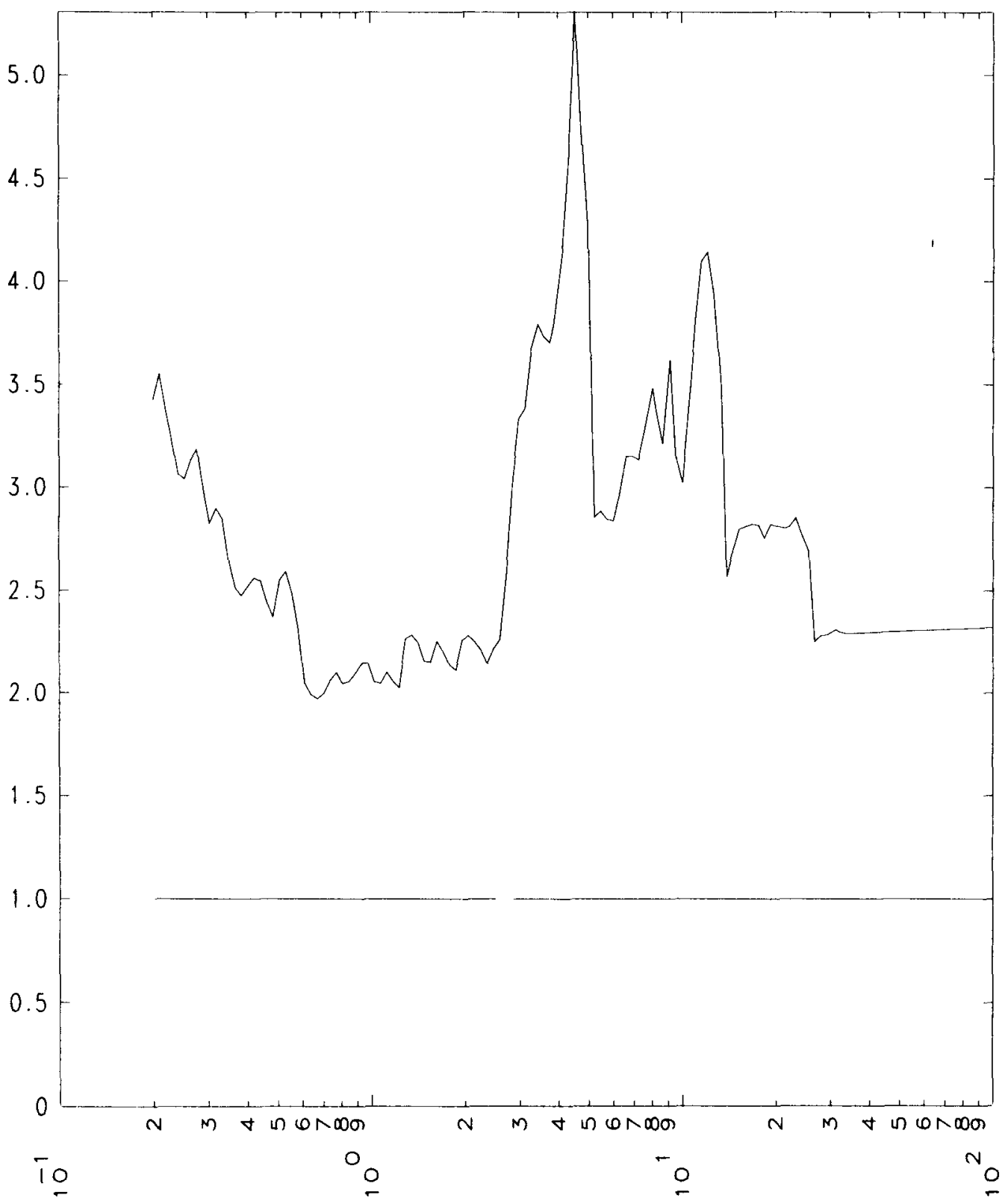

RATIO OF MEAN VALUE OF RG TO MEAN VALUE OF REAL VS FREQ. (HZ) $2.0 \%$ DAMP

FIG. B-29. Mathematical model for main steam valve house and quench spray area $($ key $=24$, node $=6$, direction $=1)$. 
MATHEMATICAL MODEL FOR MAIN STEAM VALVE HOUSE \& QUENCH SPRAY AREA
$K E Y=25$
DT $=00100$ SEC
CODE $=02 / 15 / 80 R$

STRUCTURAL DAMPING IN ALL MODES 5 O $\%$ AVERAGE DVFV BROADENED $15 \%$ NODE $=6 \quad$ DIRECTION $=1$ ABS $\quad A C C N$

$9703297 E+01$ MINIMUM R G 160 EQ VALUE (SRSS)

$1599550 E+02$ MAXIMUM R G 160 EQ VALUE (SRSS)

$1648460 E+00$ RATIO OF MAXIMUM TO MINIMUM

$1350416 E+02$ MEAN OF R G 160 EARTHQUAKES (SRSS)

$1345856 E+02$ LOWER 95\% CONFIDENCE LIMIT

1354977 E +02 UPPER 95\% CONFIDENCE LIMIT

$1289457 E+01$ STD DEV OF R G 160 EARTHQUAKES (SRSS)

$1258003 E+01$ LOWER 95\% CONF IDENCE LIMIT

1322537 E+01 UPPER 95\% CONF IDENCE LIMIT

$1916118 E+01$ MINIMUM REAL EQ VALUE

$1020392 E+02$ MAXIMUM REAL EQ VALUE

$5325308 E+00$ RATIO OF MAXIMUM TO MINIMUM

6 043464E+01 MEAN OF REAL EARTHQUAKES

$5561902 E+01$ LOWER 95\% CONFIDENCE LIMIT

$6525025 E+01$ UPPER 95\% CONFIDENCE LIMIT

$1621619 E+01$ STD DEV OF REAL EARTHQUAKES

$1345001 E+01$ LOWER 95\% CONF IDENCE LIMIT

2042807 + +1 UPPER 95\% CONF IDENCE LIMIT

$7665083 E+01$ MEAN PLUS STD DEV OF REAL EQ

$7129393 E+01$ LOWER 95\% CONFIDENCE LIMIT

8290911 E+01 UPPER 95\% CONFIDENCE LIMIT

1761777 E +00 FACTOR OF COMPARISON

$1628510 E+00$ LOWER 95\% CONFIDENCE LIMIT

$1894022 E+00$ UPPER 95\% CONF IDENCE LIMIT

1203012 E-04 MEASURE OF PROBABILITY OF EXCEEDING

R G 160 EARTHQUAKE SRSS VALUE

FIG. B-30. Mathematical model for main steam valve house and quench spray area (key $=25$, node $=6$, direction $=1$ ). 
MATHEMATICAL MODEL FOR MAIN STEAM VALVE HOUSE \& QUENCH SPRAY AREA
KEY $=26$
DT $=0.0100 \mathrm{SEC} \quad$ CODE $=02 / 15 / 80 \mathrm{R}$

STRUCTURAL DAMPING IN ALL MODES 5.0\% AVERAGE DVFV BROADENED $15 \%$

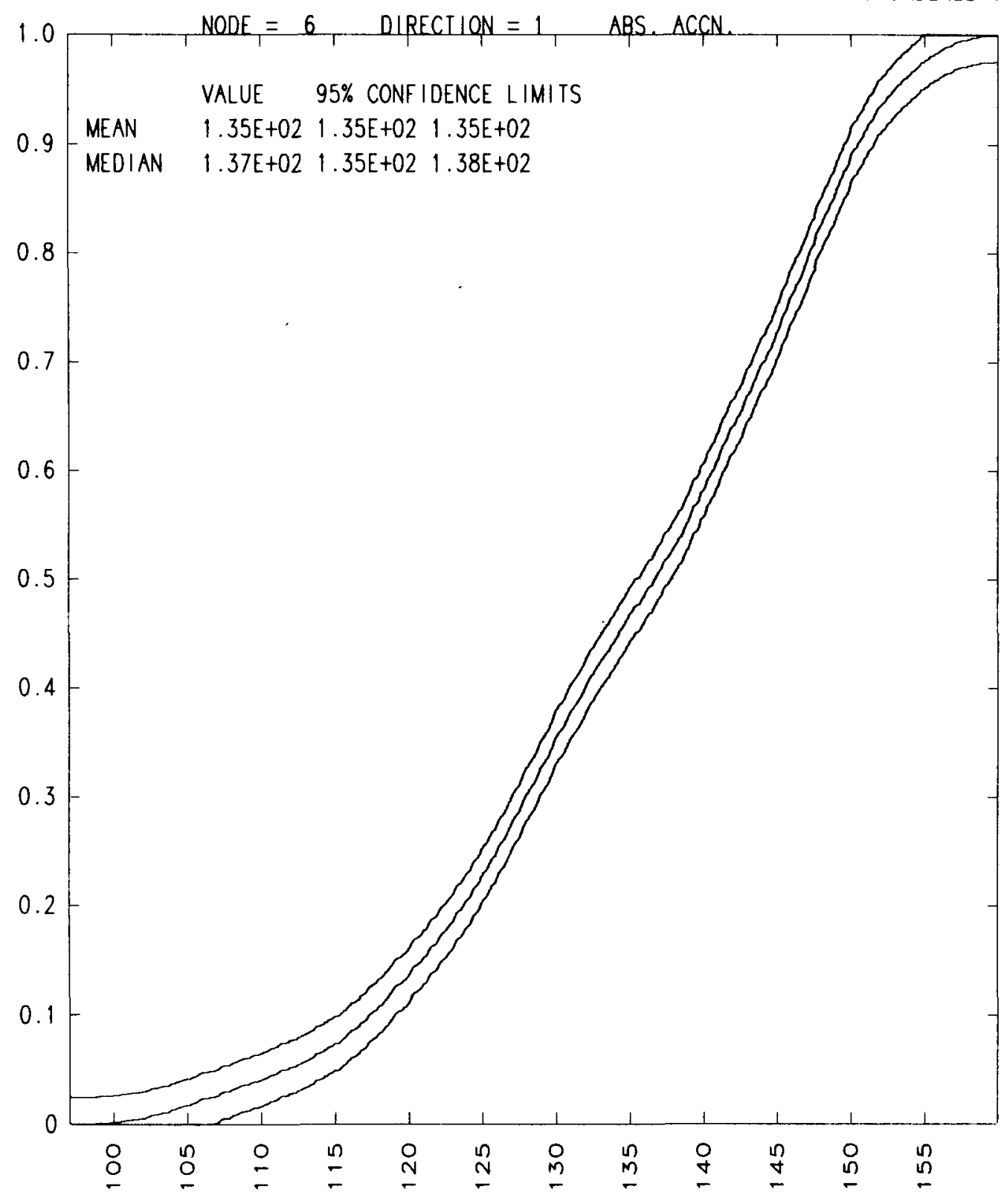

CUMMULATIVE DISTRIBUTION FUNCTION FOR MAXIMA OF SRSS (R.G. 1.60 EQ) WITH 95\% CONFIDENCE BAND FROM KOLMOGOROV-SMIRNOV TEST

FIG. B-31. Mathematical model for main steam valve house and quench spray area $($ key $=26$, node $=6$, direction $=1)$. 
MATHEMATICAL MODEL FOR MAIN STEAM VALVE HOUSE \& QUENCH SPRAY AREA

KEY $=26 \quad$ DT $=0.0100$ SEC CODE $=02 / 15 / 80 R$ STRUCTURAL DAMPING IN ALL MODES 5.0\% AVERAGE DVFV BROADENED $15 \%$

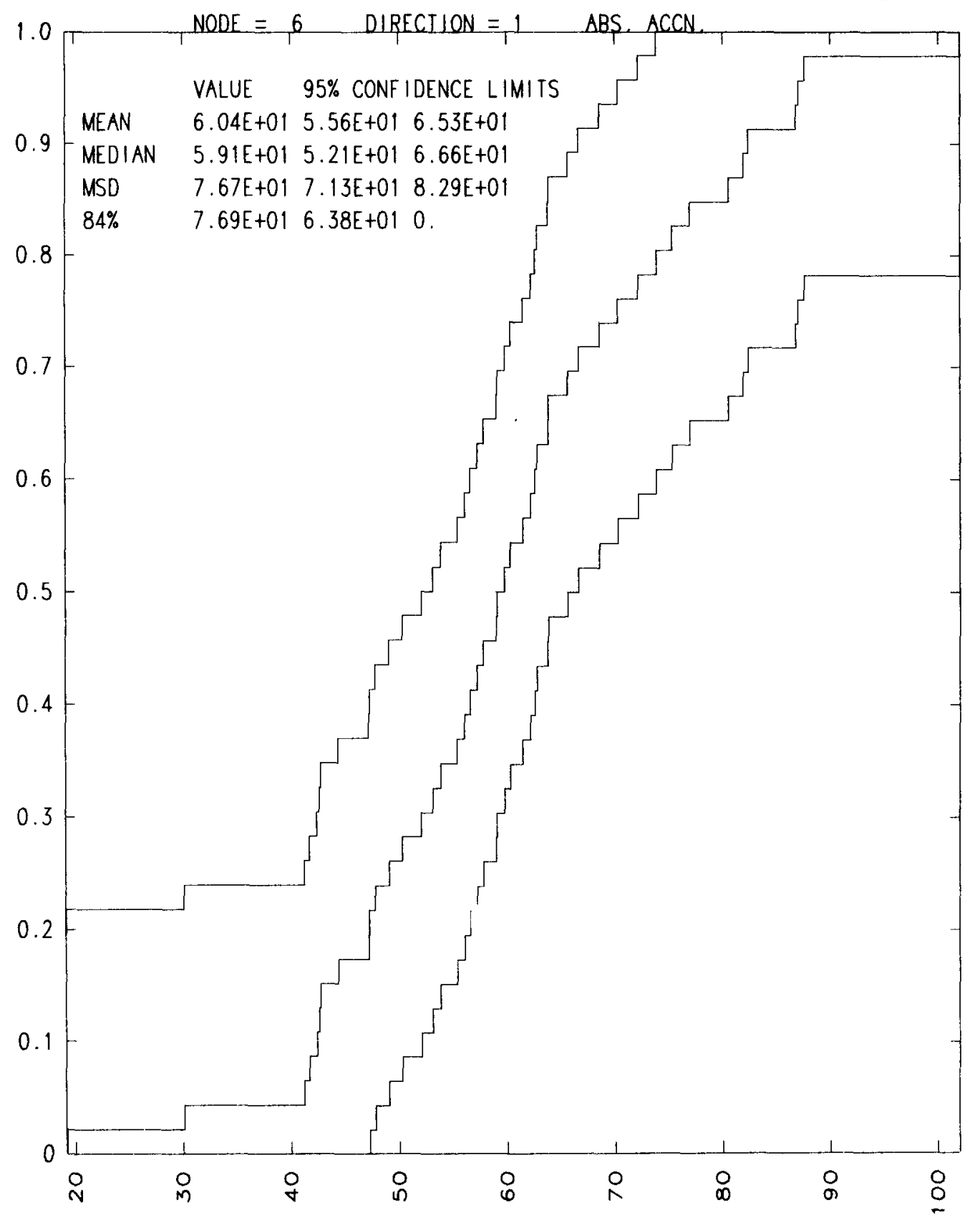

CUMMULATIVE DISTRIBUTION FUNCTION FOR MAXIMA FROM REAL EARTHQUAKES WITH 95\% CONFIDENCE BAND FROM KOLMOGOROV-SMIRNOV TEST

FIG. B-32. Mathematical model for main steam valve house and quench spray area $($ key $=26$, node $=6$, direction $=1)$. 